\title{
Towards personalised management using the assessment of burden of COPD (ABC) tool
}

Citation for published version (APA):

Gidding - Slok, A. H. M. (2016). Towards personalised management using the assessment of burden of COPD $(A B C)$ tool. [Doctoral Thesis, Maastricht University]. Maastricht University. https://doi.org/10.26481/dis.20161109ag

Document status and date:

Published: 01/01/2016

DOI:

10.26481/dis.20161109ag

Document Version:

Publisher's PDF, also known as Version of record

\section{Please check the document version of this publication:}

- A submitted manuscript is the version of the article upon submission and before peer-review. There can be important differences between the submitted version and the official published version of record.

People interested in the research are advised to contact the author for the final version of the publication, or visit the DOI to the publisher's website.

- The final author version and the galley proof are versions of the publication after peer review.

- The final published version features the final layout of the paper including the volume, issue and page numbers.

Link to publication

\footnotetext{
General rights rights.

- You may freely distribute the URL identifying the publication in the public portal. please follow below link for the End User Agreement:

www.umlib.nl/taverne-license

Take down policy

If you believe that this document breaches copyright please contact us at:

repository@maastrichtuniversity.nl

providing details and we will investigate your claim.
}

Copyright and moral rights for the publications made accessible in the public portal are retained by the authors and/or other copyright owners and it is a condition of accessing publications that users recognise and abide by the legal requirements associated with these

- Users may download and print one copy of any publication from the public portal for the purpose of private study or research.

- You may not further distribute the material or use it for any profit-making activity or commercial gain

If the publication is distributed under the terms of Article $25 \mathrm{fa}$ of the Dutch Copyright Act, indicated by the "Taverne" license above, 
Towards personalised management using the Assessment of Burden of COPD (ABC) tool 


\section{Colophon}

Cover design: Mascha Twellaar

Lay-out: Annerika Slok

Printed by: Gildeprint

ISBN: 978-94-6233-395-6

(C) Annerika H.M. Slok, Maastricht 2016

The research presented in this dissertation was conducted at the School for Public Health and Primary Care (CAPHRI), Department of Family Medicine, Maastricht University. CAPHRI participates in the Netherlands School of Primary Care Research (CaRe), acknowledged by the Royal Dutch Academy of Science (KNAW). CAPHRI was classified as 'excellent' by the external evaluation committee of leading international experts that reviewed CAPHRI in December 2010.

This research described in this dissertation presents was funded by the Lung Alliance Netherlands (in Dutch: Long Alliantie Nederland; www.longalliantie.nl).

All rights are reserved. No part of this book may be reproduced or transmitted in any form or by any means, without the written permission from the author or, where appropriate, the publisher of the article. 


\title{
Towards personalised management using the Assessment of Burden of COPD (ABC) tool
}

\author{
PROEFSCHRIFT \\ Ter verkrijging van de graad van doctor \\ aan de Universiteit Maastricht, \\ op gezag van de Rector Magnificus, Prof. Dr. Rianne M. Letschert, \\ volgens het besluit van het College van Decanen, \\ in het openbaar te verdedigen op \\ woensdag 09 november 2016 om 16.00u \\ door \\ Anne Hendrika Marie Slok \\ Geboren op 13 oktober 1986 te Rhenen
}




\section{Promotores}

Prof. Dr. C.P. van Schayck

Prof. Dr. D. Kotz, Heinrich-Heine-University of Düsseldorf

Prof. Dr. N.H. Chavannes, Leids Universitair Medisch Centrum

\section{Co-promotor}

Dr. J.C.C.M. in 't Veen, Franciscus Gasthuis Rotterdam

\section{Beoordelingscommissie}

Prof. Dr. J.F.M. Metsemakers (voorzitter)

Prof. Dr. J.W.M. Muris

Dr. J.B. Snoeck-Stroband (LUMC)

Prof. Dr. G.J. Wesseling 


\section{Contents}

CHAPTER 1 General Introduction 7

CHAPTER 2 Development of the Assessment of Burden of COPD (ABC) tool: 19 an integrated tool to measure the burden of COPD.

npj Primary Care Respiratory Medicine. 2014;24

CHAPTER 3 Effectiveness of the Assessment of Burden of Chronic

Obstructive Pulmonary Disease $(A B C)$ tool: study protocol of a cluster randomised trial in primary and secondary care.

BMC Pulmonary Medicine. 2014;14:131.

CHAPTER 4 The Assessment of Burden of COPD (ABC) scale: a reliable and 55 valid questionnaire.

COPD: Journal Of Chronic Obstructive Pulmonary Disease. 2016;14:431-438.

CHAPTER 5 Effectiveness of the Assessment of Burden of COPD (ABC) tool 73 on health-related quality of life in patients with COPD: a cluster randomised controlled trial in primary and hospital care

BMJ Open. 2016;6:e011519.

CHAPTER 6 'To use or not to use': A qualitative study to evaluate experiences of healthcare providers and patients with the Assessment of Burden of COPD (ABC) tool.

Accepted for publication in npj Primary Care Respiratory Medicine

CHAPTER 7 General Discussion

Summary

Samenvatting

Valorisatie

Appendices

Dankwoord

Curriculum Vitae 



\section{1}

General Introduction 



\section{GENERAL INTRODUCTION}

\section{Definition of health}

In 1948 the World Health Organisation (WHO) defined health as 'a state of complete physical, mental and social well-being and not merely the absence of disease or infirmity'. ${ }^{1}$ This definition is no longer aligned with developments in Western populations. With an aging population ${ }^{2}$ the number of people with multiple chronic conditions is expected to increase. ${ }^{3}$ People with chronic diseases have a higher use of healthcare services and also visit more different professionals than people without chronic diseases. ${ }^{4}$ Keeping the definition of WHO would leave most of us unhealthy most of the time..$^{5}$ Therefore, in 2011 a new definition of health was proposed by Huber and colleagues: 'the ability to adapt and to self-manage' ${ }^{6}$

When evaluating health, attention should be paid to the three domains of health: physiological, mental and social health. ${ }^{6}$ This model goes back to the early 70 s of the $20^{\text {th }}$ century when a new vision on medicine was presented by Engel, which he called the biopsychosocial model. ${ }^{7}$ This new model was also underlined by Weiss in 1980 for the delivery of primary care. ${ }^{8}$ The model originated from the need to better understand the human being as a whole, and next to biological also take psychological and social factors into account when experiencing sickness and health. ${ }^{9}$ To evaluate these different aspects of health, patient-reported outcomes are more and more used in the evaluation of the disease and the possible treatment options. ${ }^{10-13}$ Patientsreported outcome measures include standardised measures of amongst others measures of health status and health-related quality of life. ${ }^{14}$

\section{Chronic Obstructive Pulmonary Disease}

In the management of Chronic Obstructive Pulmonary Disease (COPD) there is also a shift; away from merely focussing on biomedical factors and doctor-driven care, towards evaluating psychosocial and behavioural factors and patient selfmanagement. $^{15}$

COPD is a chronic condition that affects millions of people worldwide, ${ }^{16}$ and more specific approximately 360,000 people in the Netherlands. ${ }^{17}$ It is a major cause of morbidity, the fourth leading cause of death in the world and the seventh leading cause of disability adjusted life years in $2030 .{ }^{18-20}$ COPD is defined by the American Thoracic Society (ATS) and the European Respiratory Society (ERS) as a preventable 
and treatable disease that is characterised by airflow limitation and is not fully reversible, usually progressive and associated with an enhanced chronic inflammatory response in the airways and the lung to noxious particles or gases. Despite the fact that COPD concerns the lungs, it also produces significant systemic consequences. ${ }^{16,21}$ Examples of systemic consequences are systemic inflammation, nutritional abnormalities and weight loss, and skeletal muscle dysfunctions such as exercise limitation. $^{22}$

\section{Risk factors}

In developed countries, the major risk factor for COPD is tobacco smoking, ${ }^{23}$ but there are also other environmental factors and genetic factors ${ }^{21}$ that can cause COPD. Factors that are associated with progression and disease development are age, genes, lung growth and development, exposure to particles, socioeconomic status, asthma/bronchial hyper-reactivity, and infections. ${ }^{16}$

\section{Symptoms}

Not all patients have symptoms, but possible symptoms of COPD are dyspnoea, cough, sputum production, wheezing and chest tightness. In severe cases patients can also have symptoms like fatigue, weight loss and anorexia. ${ }^{16}$ Sometimes, patients have an exacerbation, which is an acute event characterised by a worsening of the patients' respiratory symptoms that is beyond normal day to day variations, and leads to a change in medication. ${ }^{24}$ Exacerbations negatively affect patients' quality of life, have an effect on symptoms and lung function, are associated with mortality and have high socioeconomic costs. ${ }^{24-26}$

\section{Assessment}

COPD is diagnosed using spirometry measuring lung function parameters. ${ }^{16}$ Previously the assessment of COPD was mainly based on these parameters, but the current Global Initiative for Chronic Obstructive Lung Diseases (GOLD) guideline describes a combined assessment of COPD, by determining the disease severity, its impact on patient's health status, and the risks of future events (e.g., exacerbations and hospitalisations). ${ }^{16}$ Disease severity can be assessed with spirometry, with a categorisation of patients into stages one to four: GOLD 1, mild; GOLD 2, moderate; GOLD 3, severe; and GOLD 4, very severe. ${ }^{16,24}$ For assessing the impact on patient's health status the GOLD guideline recommends the use of the Modified British Medical 
Research Council (mMRC) questionnaire on breathlessness ${ }^{27}$ or the COPD Assessment Test $(C A T)^{28}$ or the Clinical COPD Questionnaire $(C C Q)^{29}$ to measure symptoms. Risk of future events can be assessed with three methods: (1) spirometry to determine the GOLD grade, GOLD 1 and 2 is low risk, GOLD 3 and 4 is high risk; (2) the number of exacerbation the patient had in the previous year, 0 or 1 is low risk, 2 or more is high risk; or (3) determine whether the patient was hospitalised due to an exacerbation in the previous year.

Combining these different components results in the so-called ' $A B C D$ ' classificationmodel: group A, low risk, less symptoms; group B, low risk, more symptoms; group $C$, high risk less symptoms; and group $D$, high risk, more symptoms. ${ }^{16}$

In the Netherlands, the Dutch Healthcare standard COPD (in Dutch: Zorgstandaard COPD) can be used as a guideline in the assessment and treatment of COPD. This guideline is in accordance with the ATS/ERS and GOLD guidelines and states that disease severity should be based on experienced burden of COPD, and not merely on lung function parameters. ${ }^{30}$

As stated earlier, in the assessment of health, patient-reported outcomes can be used. This is also recommended for assessing the impact of COPD, since previous research found a poor correlation between airflow limitation and symptoms and health status. $^{31,32}$ This stresses the importance of this more integrated approach in the assessment and treatment of COPD. Furthermore, health status has shown to be associated with increased severity of dyspnoea, ${ }^{33}$ a longer duration of the disease, ${ }^{33}$ the prognosis of frequent exacerbations, ${ }^{34}$ hospital readmissions ${ }^{35}$ and mortality. ${ }^{36,37}$

\section{Management of COPD}

\section{Chronic care model}

Healthcare systems used to be designed for treating acute events, and consequently patients were not taught to adequately take care for their own illnesses. ${ }^{38,39}$ Therefore, the chronic care model (CCM) was developed to be used for developing effective chronic care for patients with chronic illnesses. ${ }^{40}$ It is developed as a concrete guide in improving healthcare. ${ }^{38,40}$ The model consists of six components health system, delivery system design, decision support, clinical information systems, community and self-management support. These components are interrelated, and the model predicts that when these components are improved it will shift the focus 
from an acute healthcare system to a more chronic care system. The model emphasises the importance of a different role for patients and healthcare providers. Patients should be an active partner in the process, and healthcare providers should provide professional guidance in which they help the patient develop skills in health practices. $^{39}$ Therefore, patients should be activated. Patient activation is defined as 'understanding one's own role in the care process and having the knowledge, skills, and confidence to take on that role'. ${ }^{41}$ Some studies showed that being an active patient is associated with increased adherence, better knowledge about the disease and an improvement of health, ${ }^{42}$ whereas lower activation is associated with higher healthcare costs. ${ }^{43}$ Findings of previous research suggest that increased activation is associated with increased self-management behaviours. ${ }^{44}$

\section{Holistic approach}

Treatment of COPD is focussed on slowing down the progression of the disease, limitation of symptoms, increasing the overall health and the prevention of exacerbations. The treatment should be multidimensional, including both pharmacological treatment as well as non-pharmacological treatment. ${ }^{45}$ Pharmacological treatment aims at relieving symptoms (bronchodilation drugs) or preventing symptoms (inhaled corticosteroid drugs). Non-pharmacological interventions mostly includes lifestyle and behavioural changes, of which smoking cessation is the most important and most effective. ${ }^{45}$

In the management of COPD a holistic approach is desirable, where next to the evaluation of biomedical outcomes of the disease, there is also room for psychosocial aspects. ${ }^{46,47}$ Patient-reported outcomes, such as experienced burden of COPD, can be used in this approach as outcomes parameters. ${ }^{48-51}$

The currently available patient-reported outcome measures are mainly used as tools to evaluate and monitor the disease, but not yet as a tool to guide treatment. However, in a holistic approach, disease severity as reported by patients, should be the basis of making a personalised treatment plan. Therefore, it is important to have a tool that not only measures the burden a patient experiences in daily life due to COPD, but which also leads to tailored treatment, by providing patients with insight in their own disease and providing treatment options, facilitating self-management. 


\section{Self-management}

An important component of the CCM is self-management support. ${ }^{38}$ Since in chronic diseases patients have to become active participants in healthcare ${ }^{39}$ it is important that they receive self-management support. Self-management support is defined as "the systematic provision of education and supportive interventions to increase patients' skills and confidence in managing their health problems, including regular assessment of progress and problems, goal setting, and problem-solving support" ${ }^{52}$ There are not many trials published on the effect of self-management on health status in COPD patients, but there is some evidence now that self-management can have an effect. $^{53-56}$ Self-management programs can increase patients' knowledge ${ }^{57,58}$ and skills, $^{21,22}$ it can reduce hospitalisations, ${ }^{54,59}$ and improve health status. ${ }^{54}$ Selfmanagement should therefore have an important role in the process of COPD care. ${ }^{60}$

\section{Goal setting and shared decision making}

In providing self-management support, strategies can be used such as motivational interviewing to improve goal setting, and shared decision making. ${ }^{61}$ Motivational interviewing is a method of interacting with patients to increase behavioural change. ${ }^{62}$ Goal setting is often associated with increased confidence in self-management skills, however, the efficacy of methods of goal setting have not yet been clearly determined. ${ }^{63}$ Shared decision making is a concept that focuses on more involvement of patients regarding decisions in, for example, making a treatment plan. To accomplish shared decision making in clinical practice, a three-way model is proposed by Elwyn and colleagues (2012). First, a choice has to be introduced (choice talk). The second step is describing options (option talk) and the third step is helping patients explore their preferences and make decisions (decision talk). ${ }^{64}$

\section{This dissertation}

COPD is a chronic disease with a high prevalence, and it is expected to increase in the future. ${ }^{33}$ Many instruments have already been developed measuring symptoms, dyspnoea, activity limitation, exacerbations and health status. However, not all of these instruments are easy to use and can directly guide treatment. The different concepts of COPD need to be operationalised in a tool that not only assesses integrated health status, but also provides a visual overview of the outcomes, to give patients insight in all aspects of their disease, and provides treatment options. Furthermore, the tool needs to facilitate in shared decision making and goal setting; 
healthcare providers should be able to use the tool in daily practice to help patients to get involved in making their own individualised care plan. In the Dutch Healthcare standard COPD the concept of experienced burden of COPD is positioned as a central theme and starting point in the assessment and management of COPD. ${ }^{30}$ Despite the fact that this concept is classified and accepted as extremely relevant, it has not yet been fully operationalised. Therefore, in 2010 the Lung Alliance Netherlands (in Dutch: Long Alliantie Nederland) assembled a nationwide expert group, to develop a tool that assesses integrated health status, with patients' experienced disease burden as core focus, to be used in daily care. The expert group consisted of researchers from different institutes and different disciplines, including amongst others pulmonologists, general practitioners, health technology assessment specialists and representatives of the Dutch Lung Foundation. The result of this multidisciplinary working alliance, a tool aimed at measuring and visualising the experienced burden of COPD, could be a solution to fill the gap between the theories of shared decision making and selfmanagement support in COPD patients, and practice.

\section{Aim and research objective}

The general aim of this research was to develop and evaluate the effectiveness of a tool measuring and treating the experienced burden of COPD. This dissertation focusses on the following research objectives:

1. To develop an instrument that measures burden of COPD.

a. Define burden of COPD.

b. Formulate requirements that a burden of COPD instrument should meet.

c. Perform a literature search for instruments that measure all relevant aspects of the burden of COPD.

d. Develop a questionnaire that measures experienced burden of COPD, and a tool that visualises the outcomes and includes a treatment algorithm.

2. To determine the validity and reliability of the questionnaire that measures burden of COPD.

3. To evaluate the effectiveness of the newly developed tool on disease-specific quality of life, compared to usual COPD care, in COPD patients.

4. To evaluate the experiences of COPD patients and healthcare professionals with the newly developed tool. 


\section{Outline of the dissertation}

Chapter 2 describes the process of developing the Assessment of Burden of COPD $(A B C)$ tool. This process consists of five steps, starting with defining the concept of 'burden of COPD', checking whether the definition is compatible with the experiences of patients and healthcare providers, defining conditions a burden of disease instrument should meet, conducting a systematic review and finally step five; Developing a scale to assess the burden of COPD and a tool to measure patients' integrated health status. A summary of the original report has been published in an international peer-reviewed journal as a brief communication. Chapter 3 describes the protocol of a cluster randomised controlled trial (RCT) to test the effectiveness of the $A B C$ tool in patients with COPD. It includes a description of the background, the study design, the intervention, outcome measures, the sample size calculation and planned analyses. In Chapter 4 the evaluation of psychometric properties of the $A B C$ scale are described. The $A B C$ scale is the questionnaire that measures experienced burden of COPD. Analyses were performed with baseline data of patients who participated in the RCT to evaluate the reliability and validity of the scale. The results of the cluster RCT are described in Chapter 5. Data from 357 patients, from 56 healthcare providers, were analysed to evaluate the effectiveness of the $A B C$ tool in COPD patients. Furthermore, a qualitative study was performed to evaluate the experiences of patients and healthcare providers with the $A B C$ tool. This study and the results of the interviews are described in Chapter 6. The general discussion is written in Chapter 7, where the major findings are summarised, and their implications for practice and further research are discussed. 


\section{REFERENCES}

1. World Health Organisation. Constitution of the World Health Organization. 2006. www.who.int/governance/eb/who_constitution_en.pdf

2. CBS Statistics Netherlands. Population forecasts. Accessed 2016-02-02. http://statline.cbs.nl/Statweb/publication/?VW=T\&DM=SLEN\&PA=03766eng\&D1=a\&D2=0\&D3= $0,3,8,13,18,23,28,33,38,43, I \& H D=160202-1537 \& L A=E N \& H D R=G 2 \& S T B=T$.

3. World Health Organisation. Noncommunicable Diseases Progress Monitor 2015. September 2015. http://apps.who.int/iris/bitstream/10665/184688/1/9789241509459_eng.pdf?ua=1

4. Hoffman C, Rice D \& Sung H. Persons with chronic conditions. Their prevalence and costs. JAMA 1996;276:1473-1479.

5. Smith R. The end of disease and the beginning of health. BMJ Group Blogs 2008. http://blogs.bmj.com/bmj/2008/07/08/richard-smith-the-end-of-disease-and-the-beginning-ofhealth/.

6. Huber M, Knottnerus JA, Green L, van der Horst H, Jadad AR, Kromhout D, Leonard B, Lorig K, Loureiro MI, van der Meer JW, Schnabel P, Smith R, van Weel C \& Smid H. How should we define health? BMJ 2011;343:d4163.

7. Engel GL. The need for a new medical model: a challenge for biomedicine. Science 1977;196:129136.

8. Weiss RJ. The biopsychosocial model and primary care. Psychosom Med 1980;42:123-130.

9. Molina JA. Understanding the biopsychosocial model. Int J Psychiatry Med 1983;13:29-36.

10. Westwood M, Bourbeau J, Jones PW, Cerulli A, Capkun-Niggli G \& Worthy G. Relationship between FEV1 change and patient-reported outcomes in randomised trials of inhaled bronchodilators for stable COPD: a systematic review. Respir Res 2011;12:40.

11. Jones PW, Quirk FH, Baveystock CM \& Littlejohns P. A self-complete measure of health status for chronic airflow limitation. The St. George's Respiratory Questionnaire. Am Rev Respir Dis 1992;145:1321-1327.

12. Oga T, Nishimura K, Tsukino M, Sato S, Hajiro T \& Mishima M. Longitudinal deteriorations in patient reported outcomes in patients with COPD. Respir Med 2007;101:146-153.

13. Revicki DA. Consistent patient-reported outcomes. Value Health 2002;5:295-296.

14. Bowling A. Measuring disease: A review of disease specific quality of life measurements scales. Buckingham, Philadelphia:Open University Press; 1995.

15. Papaioannou Al, Loukides S, Gourgoulianis KI \& Kostikas K. Global assessment of the COPD patient: time to look beyond FEV1? Respir med 2009;103:650-660.

16. From the Global Strategy for the Diagnosis, Management and Prevention of COPD, Global Initiative for Chronic Obstructive Lung Disease (GOLD). Updated 2016. http://www.goldcopd.org/uploads/users/files/WatermarkedGlobal\%20Strategy\%202016(1).pdf.

17. Boezen HM (UMCG), Postma DS (UMCG), Poos MJJC (RIVM). Hoe vaak komt COPD voor en hoeveel mensen sterven eraan? In: Volksgezondheid Toekomst Verkenning, Nationaal Kompas Volksgezondheid. Bilthoven: RIVM. Updated 2013-09-21. http://www.nationaalkompas.nl.

18. World Health Report. Geneva: World Health Organization, 2000. Available from URL: http://www.who.int/whr/2000/en/statistics.htm.

19. Lopez AD, Mathers CD, Ezzati M, Jamison DT \& Murray CJ. Global and regional burden of disease and risk factors, 2001: systematic analysis of population health data. Lancet 2006;367:17471757.

20. Mathers CD \& Loncar D. Projections of global mortality and burden of disease from 2002 to 2030. PLoS Med 2006;3:e442.

21. Celli BR \& MacNee W. Standards for the diagnosis and treatment of patients with COPD: a summary of the ATS/ERS position paper. Eur Respir J 2004;23:932-946.

22. Agusti AG, Noguera A, Sauleda J, Sala E, Pons J \& Busquets X. Systemic effects of chronic obstructive pulmonary disease. Eur Respir J 2003;21:347-360.

23. Forey BA, Thornton AJ \& Lee PN. Systematic review with meta-analysis of the epidemiological evidence relating smoking to COPD, chronic bronchitis and emphysema. BMC Pulm Med 2011;11:36 
24. Vestbo J, Hurd SS, Agusti AG, Jones PW, Vogelmeier C, Anzueto A, Barnes PJ, Fabbri LM, Martinez FJ, Nishimura M, Stockley RA, Sin DD \& Rodriguez-Roisin R. Global strategy for the diagnosis, management, and prevention of chronic obstructive pulmonary disease: GOLD executive summary. Am J Respir Crit Care Med 2013;187:347-365.

25. Kessler R, Stahl E, Vogelmeier C, Haughney J, Trudeau E, Lofdahl CG \& Partridge MR. Patient understanding, detection, and experience of COPD exacerbations: an observational, interviewbased study. Chest 2006;130:133-142.

26. Spencer S, Calverley PM, Burge PS \& Jones PW. Impact of preventing exacerbations on deterioration of health status in COPD. Eur Respir J 2004;23:698-702.

27. Bestall JC, Paul EA, Garrod R, Garnham R, Jones PW \& Wedzicha JA. Usefulness of the Medical Research Council (MRC) dyspnoea scale as a measure of disability in patients with chronic obstructive pulmonary disease. Thorax 1999;54:581-586.

28. Jones PW, Harding G, Berry P, Wiklund I, Chen WH \& Kline Leidy N. Development and first validation of the COPD Assessment Test. Eur Respir J 2009;34:648-654.

29. Van der Molen T, Willemse B, Schokker S, Ten Hacken N, Postma D \& Juniper E. Development, validity and responsiveness of the Clinical COPD Questionnaire. Health Qual Life Outcomes 2003;1:13.

30. Long Alliantie Nederland. Zorgstandaard COPD. Amersfoort:Long Alliantie Nederland; 2013.

31. Tsiligianni I, Kocks J, Tzanakis N, Siafakas N \& van der Molen T. Factors that influence diseasespecific quality of life or health status in patients with COPD: a review and meta-analysis of Pearson correlations. Prim Care Respir J 2011;20:257-268.

32. Curtis JR, Deyo RA \& Hudson LD. Pulmonary rehabilitation in chronic respiratory insufficiency. 7. Health-related quality of life among patients with chronic obstructive pulmonary disease. Thorax 1994;49:162-170.

33. Miravitlles M, Molina J, Naberan K, Cots JM, Ros F \& Llor C. Factors determining the quality of life of patients with COPD in primary care. Ther Adv Respir Dis 2007;1:85-92.

34. Miravitlles M, Ferrer M, Pont A, Zalacain R, Alvarez-Sala JL, Masa F, Verea H, Murio C, Ros F, Vidal R \& Group IS. Effect of exacerbations on quality of life in patients with chronic obstructive pulmonary disease: a 2 year follow up study. Thorax 2004;59:387-395.

35. Osman IM, Godden DJ, Friend JA, Legge JS \& Douglas JG. Quality of life and hospital re-admission in patients with chronic obstructive pulmonary disease. Thorax 1997;52:67-71.

36. Domingo-Salvany A, Lamarca R, Ferrer M, Garcia-Aymerich J, Alonso J, Felez M, Khalaf A, Marrades RM, Monso E, Serra-Batlles J \& Anto JM. Health-related quality of life and mortality in male patients with chronic obstructive pulmonary disease. Am J Respir Crit Care Med 2002;166:680-685.

37. Antonelli-Incalzi R, Pedone C, Scarlata S, Battaglia S, Scichilone N, Forestiere F \& Bellia V. Correlates of mortality in elderly COPD patients: focus on health-related quality of life. Respirology 2009;14:98-104.

38. Bodenheimer T, Wagner EH \& Grumbach K. Improving primary care for patients with chronic illness. JAMA 2002;288:1775-1779.

39. Holman H \& Lorig K. Patient self-management: a key to effectiveness and efficiency in care of chronic disease. Public Health Rep 2004;119:239-243.

40. Wagner EH, Austin BT, Davis C, Hindmarsh M, Schaefer J \& Bonomi A. Improving chronic illness care: translating evidence into action. Health Aff (Millwood) 2001;20:64-78.

41. Hibbard JH, Stockard J, Mahoney ER \& Tusler M. Development of the Patient Activation Measure (PAM): conceptualizing and measuring activation in patients and consumers. Health Serv Res 2004;39:1005-1026.

42. Coulter A \& Ellins J. Effectiveness of strategies for informing, educating, and involving patients. BMJ 2007;335:24-27.

43. Hibbard JH, Greene J \& Overton V. Patients with lower activation associated with higher costs; delivery systems should know their patients' 'scores'. Health Aff (Millwood) 2013;32:216-222.

44. Hibbard JH, Mahoney ER, Stock R \& Tusler M. Do increases in patient activation result in improved self-management behaviors? Health Serv Res 2007;42:1443-1463.

45. Morgan MD \& Britton JR. Chronic obstructive pulmonary disease 8: non-pharmacological management of COPD. Thorax 2003;58:453-457. 
46. Henbest RJ \& Stewart MA. Patient-centredness in the consultation. 1: A method for measurement. Fam Pract 1989;6:249-253.

47. Lewin SA, Skea ZC, Entwistle V, Zwarenstein M \& Dick J. Interventions for providers to promote a patient-centred approach in clinical consultations. Cochrane Database Syst Rev 2001:CD003267.

48. Cazzola M, MacNee W, Martinez FJ, Rabe KF, Franciosi LG, Barnes PJ, Brusasco V, Burge PS, Calverley PM, Celli BR, Jones PW, Mahler DA, Make B, Miravitlles M, Page CP, Palange P, Parr D, Pistolesi M, Rennard SI, Rutten-van Mölken MP, Stockley R, Sullivan SD, Wedzicha JA, Wouters EF, American Thoracic S \& European Respiratory Society Task Force on outcomes of COPD. Outcomes for COPD pharmacological trials: from lung function to biomarkers. Eur Respir $J$ 2008;31:416-469.

49. van der Molen T \& Cazzola M. Beyond lung function in COPD management: effectiveness of LABA/LAMA combination therapy on patient-centred outcomes. Prim Care Respir J 2012;21:101108.

50. Cazzola M, Hanania NA, MacNee W, Rudell K, Hackford C \& Tamimi N. A review of the most common patient-reported outcomes in COPD--revisiting current knowledge and estimating future challenges. Int J Chron Obstruct Pulmon Dis 2015;10:725-738.

51. Haughney J \& Gruffydd-Jones K. Patient-centred outcomes in primary care management of COPD - what do recent clinical trial data tell us? Prim Care Respir J 2004;13:185-197.

52. Institute of Medicine (IOM). Priority areas for national action: transforming health care quality. Washington, DC: National Academy Press, 2003. Available from: http://www.nap.edu/read/10593/chapter/1

53. Blake RL, Jr., Vandiver TA, Braun S, Bertuso DD \& Straub V. A randomized controlled evaluation of a psychosocial intervention in adults with chronic lung disease. Fam Med 1990;22:365-370.

54. Bourbeau J, Julien M, Maltais F, Rouleau M, Beaupre A, Begin R, Renzi P, Nault D, Borycki E, Schwartzman K, Singh R, Collet JP \& Chronic Obstructive Pulmonary Disease axis of the Respiratory Network Fonds de la Recherche en Sante du Q. Reduction of hospital utilization in patients with chronic obstructive pulmonary disease: a disease-specific self-management intervention. Arch Intern Med 2003;163:585-591.

55. Howland J, Nelson EC, Barlow PB, McHugo G, Meier FA, Brent P, Laser-Wolston N \& Parker HW. Chronic obstructive airway disease. Impact of health education. Chest 1986;90:233-238.

56. Renders CM, Valk GD, Griffin S, Wagner EH, Eijk JT \& Assendelft WJ. Interventions to improve the management of diabetes mellitus in primary care, outpatient and community settings. Cochrane Database Syst Rev 2001;1:CD001481.

57. Gourley GA, Portner TS, Gourley DR, Rigolosi EL, Holt JM, Solomon DK, Bass GE, Wicke WR \& Braden RL. Humanistic outcomes in the hypertension and COPD arms of a multicenter outcomes study. J Am Pharm Assoc 1998;38:586-597.

58. Cockcroft A, Bagnall P, Heslop A, Andersson N, Heaton R, Batstone J, Allen J, Spencer P \& Guz A. Controlled trial of respiratory health worker visiting patients with chronic respiratory disability. BMJ 1987;294:225-228.

59. Gadoury MA, Schwartzman K, Rouleau M, Maltais F, Julien M, Beaupre A, Renzi P, Begin R, Nault D, Bourbeau J \& Chronic Obstructive Pulmonary Disease axis of the Respiratory Health Network Fonds de la recherche en sante du Quebec. Self-management reduces both short- and long-term hospitalisation in COPD. Eur Respir J 2005;26:853-857.

60. Bourbeau J, Nault D \& Dang-Tan T. Self-management and behaviour modification in COPD. Patient Educ Couns 2004;52:271-277.

61. Dwinger S, Dirmaier J, Herbarth L, Konig HH, Eckardt M, Kriston L, Bermejo I \& Harter M. Telephone-based health coaching for chronically ill patients: study protocol for a randomized controlled trial. Trials 2013;14:337.

62. Rollnick S \& Miller WR. What is Motivational Interviewing? Behav Cogn Psychother 1995;23:325334.

63. Garrod R, Marshall J \& Jones F. Self efficacy measurement and goal attainment after pulmonary rehabilitation. Int J Chron Obstruct Pulmon Dis 2008;3:791-796.

64. Elwyn G, Frosch D, Thomson R, Joseph-Williams N, Lloyd A, Kinnersley P, Cording E, Tomson D, Dodd C, Rollnick S, Edwards A \& Barry M. Shared decision making: a model for clinical practice. J Gen Intern Med 2012;27:1361-1367. 


\section{CHAPTER 2}

\section{Development of the Assessment of Burden of COPD $(A B C)$ tool: an integrated tool to measure the burden of COPD.}

A brief communication of this article has been published as:

Slok AHM, in 't Veen JCCM, Chavannes NH, van der Molen T, Rutten-van Mölken MPMH, Kerstjens HAM, Salomé PL, Holverda S, Dekhuijzen PNR, Schuiten D, Asijee GM, van Schayck OCP. Development of the Assessment of Burden of COPD tool: an integrated tool to measure the burden of COPD. npj Primary Care Respiratory Medicine. 2014;24 (Published online 10 July 2014). 


\section{ABSTRACT}

\section{Background}

Burden of Chronic Obstructive Pulmonary Disease (COPD), as experienced by patients, is an important element in the treatment of COPD. It is important for daily practice to develop a tool that can both assess the burden of COPD and facilitate communication with patients in clinical practice.

\section{Aims}

This paper describes the development of an integrated tool to assess the burden of COPD in daily practice.

\section{Methods}

Five consecutive steps were taken to develop this tool. 1) Defining the burden of COPD, 2) Checking whether the definition is compatible with the experiences of patients and healthcare providers, 3) Formulating requirements an instrument should meet, 4) Conducting a systematic review, 5) Developing an integrated tool.

\section{Results}

A definition of the burden of COPD was formulated by a Dutch expert team. Interviews showed that patients and healthcare providers agreed on this definition. We found no existing instruments that fully measured burden of disease according to this definition. However, the Clinical COPD Questionnaire (CCQ) meets most requirements, and was therefore used and adapted. The adapted questionnaire is called the Assessment of Burden of COPD (ABC) scale. In addition, the ABC-tool was developed, a computer program with an algorithm that visualises the outcomes and provides treatment advice.

\section{Conclusions}

The $A B C$-scale and tool were developed to assess and visualise the burden of COPD. The next step is to test the validity and effectiveness of both the ABC-scale and tool in daily practice. 


\section{INTRODUCTION}

Chronic Obstructive Pulmonary Disease (COPD) is an increasing health problem worldwide and it is predicted that by 2030 it will have become the third leading cause of death worldwide. ${ }^{1}$ COPD imposes a great burden on patients and is a major cause of morbidity. ${ }^{2}$ COPD is defined as a common preventable and treatable disease characterised by airflow limitation that is not fully reversible. ${ }^{2,3}$ Airway obstruction used to play an important role in assessing disease severity and in treating COPD. Currently however, the assessment of COPD is shifting from merely focusing on airway obstruction towards including Patient Reported Outcomes (PROs), and thus addressing complaints, limitations in daily and social life, the progression of disease, and quality of life from the patients' perspective. ${ }^{4}$ Other factors, such as co-morbidity, phenotype and psychological factors should also be taken into account. ${ }^{5-8}$ The American Thoracic Society (ATS) and European Respiratory Society (ERS) ${ }^{3}$ have formulated guidelines to facilitate diagnosis, disease management and prevention of COPD, and the idea that COPD is more than just airway obstruction is in line with the 2011 Global Initiative for Chronic Obstructive Lung Disease (GOLD) guidelines. ${ }^{2}$ The Dutch Healthcare Standard COPD ${ }^{9}$ is consistent with this new focus and they adopted the concept of 'burden of disease' in their 2010 version. This together with items such as a patient's smoking status and body mass index (BMI) represents the health status of a patient. ${ }^{9}$

As the burden of COPD plays a crucial role in the assessment and individualised treatment of COPD, it is essential to be able to measure it. However, there is no existing definition for the burden of COPD. Moreover, there is no existing description of the requirements that a burden of COPD instrument should meet. This paper aims to contribute to the assessment of the burden of COPD by addressing the following research questions:

1. How should the burden of COPD be defined?

2. What requirements should a burden of COPD instrument meet?

3. Does the literature provide an instrument that measures all relevant aspects of the burden of COPD?

A burden of disease instrument will be developed based on the answers to these research questions. To help patients and healthcare providers adopt this instrument in routine care, we will also develop a tool to assess and visualise the burden of COPD and an algorithm to support treatment decisions in daily care. 


\section{METHODS}

Five consecutive steps were taken to develop a tool for measuring the burden of COPD. Table 2.1 shows these steps.

Table 2.1 Steps to develop a burden of COPD instrument

\begin{tabular}{ll}
\hline Steps & Actions \\
\hline 1 & $\begin{array}{l}\text { Defining burden of COPD } \\
\text { Checking compatibility of definition with the experiences of patients and } \\
\text { healthcare providers (Content validity) }\end{array}$ \\
3 & $\begin{array}{l}\text { Formulating requirements for a burden of COPD instrument } \\
\text { Conducting a systematic review of disease specific quality of life questionnaires / } \\
\text { severity indicators } \\
\text { Developing a scale to assess the burden of COPD and a tool to measure patients' } \\
\text { integrated health status }\end{array}$ \\
\hline
\end{tabular}

\section{First step - Defining burden of COPD}

The first step was to define the burden of disease. A Dutch expert team was installed by the Dutch Lung Alliance (Long Alliantie Nederland; LAN) to formulate this definition. The Dutch expert team comprised members from relevant disciplines, namely GPs, pulmonologists, a psychologist, a Health Technology Assessment (HTA) expert, an epidemiologist, a methodologist and a delegate from the Netherlands Lung Foundation to represent COPD patients. The definition was based on the opinions and theoretical and practical experiences of the experts in the expert group.

\section{Second step - Content validity}

The content validity of the definition was evaluated by means of interviews with open questions, held with patients and healthcare providers. Three focus group interviews were held with a total of 17 COPD patients. In order to control for regional differences, these group interviews took place in the north, in the west and in the south of the Netherlands. Besides, we conducted interviews with three individual patients with very severe, homebound COPD.

The interviews consisted of three parts. First, the patients were asked to describe the problems they experience as a result of COPD. We wrote the patients' experiences on a whiteboard. Second, we used the whiteboard to categorise these experiences into different domains. Finally, we discussed the definition of the burden of COPD.

Furthermore, 21 healthcare providers were interviewed face-to-face: three GPs, four pulmonologists, three physiotherapists, three primary care nurses, five respiratory 
nurses, one dietician, one psychologist and one lung function technician. The structure of the interviews was similar to the interviews with patients.

\section{Third step - Requirements for measuring burden of COPD}

To measure the burden of COPD we defined requirements that a burden of COPD instrument should meet. These requirements are based on consensus within the Dutch expert group, and focus on both content, such as different concepts of integrated health, and practical issues, such as administration characteristics.

\section{Fourth step - Systematic review of disease specific quality of life questionnaires / severity indicators}

A PubMed search was performed to assess whether an instrument with the above properties existed. Box 2.1 shows the MeSH terms that were used.

We analysed the questionnaires using a matrix.

Box 2.1. MeSH terms used to search the literature

()(((("Outcome Assessment (Health Care)"[Mesh] OR "Treatment Outcome"[Mesh]) OR "Outcome and Process Assessment (Health Care)"[Mesh]) OR "Health Services

Research"[Mesh]) OR "Disease Management"[Mesh]) OR "Controlled Clinical Trials as Topic"[Mesh]) OR "Prognosis"[Mesh] AND ("pulmonary disease, chronic obstructive"[MeSH Terms] OR ("pulmonary"[All Fields] AND "disease"[All Fields] AND "chronic"[All Fields] AND "obstructive"[All Fields]) OR "chronic obstructive pulmonary disease"[All Fields] OR "copd"[All Fields]) AND ("humans"[MeSH Terms] AND (English[lang] OR Dutch[lang]) AND ("2000"[PDAT] : "2013"[PDAT])))

\section{Fifth step - Developing a scale to assess the burden of COPD and a tool to measure patients' integrated health status}

Our decision to develop a new instrument to measure the burden of COPD was based on the instruments identified in the literature review. Furthermore, the Dutch expert team wrote an algorithm to guide healthcare providers and patients towards a treatment plan based on patients' integrated health status. This algorithm is based on an algorithm presented in the MARCH study that used the Clinical COPD Questionnaire $(\mathrm{CCQ})^{10}$ and is supplemented with other items and information from current guidelines. The Maastricht University centre for data and information management (MEMIC) built a computer program that includes a visualisation with balloons to communicate the results of the algorithm with patients. 


\section{RESULTS}

\section{First step - Defining burden of COPD}

The Dutch expert team formulated the following definition of the burden of COPD:

"Burden of disease is the physical, emotional, psychological and/or social experiences of a patient with COPD. These experiences influence the patient's ability to cope with the consequences of COPD and its treatment.

\section{Second step - Content validity}

During the interviews with patients, patients' experiences were categorised into three domains: physical (e.g. coughing, fatigue, dyspnoea and weight loss), psychological (e.g. feeling down, feeling tense, anxiety, grief, and acceptance difficulties) and social experiences (e.g. feeling limited in going on vacation, in contact with friends and family, and in going to parties or a bar or restaurant).

Healthcare providers also described the problems and complaints patients mention during consultations. In addition to physical complaints, such as fatigue, dyspnoea, coughing and producing phlegm, they also mentioned psychological factors such as depression and anxiety. Furthermore, they described limitations that patients experience in their daily and social lives.

The interviews confirmed that the findings were consistent with the definition and ideas of the Dutch expert group.

\section{Third step - Requirements for measuring burden of COPD}

The expert group formulated nine requirements for the integrated tool, as shown in Box 2.2. All requirements were obligatory, except for requirements $4 a$ and 9 . Requirement $7 b$ was obligatory if the questionnaire did not meet requirement $4 a$.

\section{Fourth step - Systematic review}

We performed a literature review and screened the titles and abstracts in the resulting articles $(n=5014)$ for tools that measure quality of life, health status or disease severity in patients with COPD. After studying the identified articles, we manually searched the reference lists in the articles. A total of 21 instruments were found. ${ }^{11-45}$ 
Box 2.2 Requirements for measuring burden of COPD

The instrument should meet the following requirements:

1. include indicators that provide insight into impairments, disabilities, complaints and quality of life resulting from COPD;

2. measure the physical, emotional, psychological and social experiences of patients with COPD;

3. based on patient input;

4. easy for both patient and caregiver to manage and should therefore:

a. take no more than a few minutes to complete;

b. have an easy score calculation;

c. have the potential to be self-administered by patients.

5. responsive to change in patients;

6. able to measure differences between patients;

7. have a visual display including:

a. subscores of the different domains and a total score;

b. minimum and maximum length variants.

8. able to guide treatment;

9. possibility to connect with generic Quality of Life instruments such as the SF36 (i.e. capable of obtaining and calculating QALYs (Quality Adjusted Life Years; societal perspective)).

We used smiley faces to record whether or not a requirement was met. A happy smiley face indicated when the requirement was met, an unhappy smiley face when the requirement was not met and a neutral smiley face when the literature was inconclusive. For example, the Dyspnoea, airflow Obstruction, Smoking status and Exacerbation frequency (DOSE) index and Health-Activity-Dyspnoea-Obstruction (HADO) index received a neutral smiley for requirement $4 c$, because only a part of the index can be completed by the patient himself.

As shown in Figure 2.1, we found no instrument that met all the requirements listed in the preceding third step.

\section{Fifth step - Development of a scale to assess the burden of COPD and of a tool to measure the integrated health status of a patient}

The literature review revealed that the currently available instruments do not fully measure burden of disease as per our definition. As shown in Figure 2.1, the CCQ met most, but not all, requirements. The CCQ has shown good validity, reliability and responsiveness at group and individual level. ${ }^{11,46}$ 


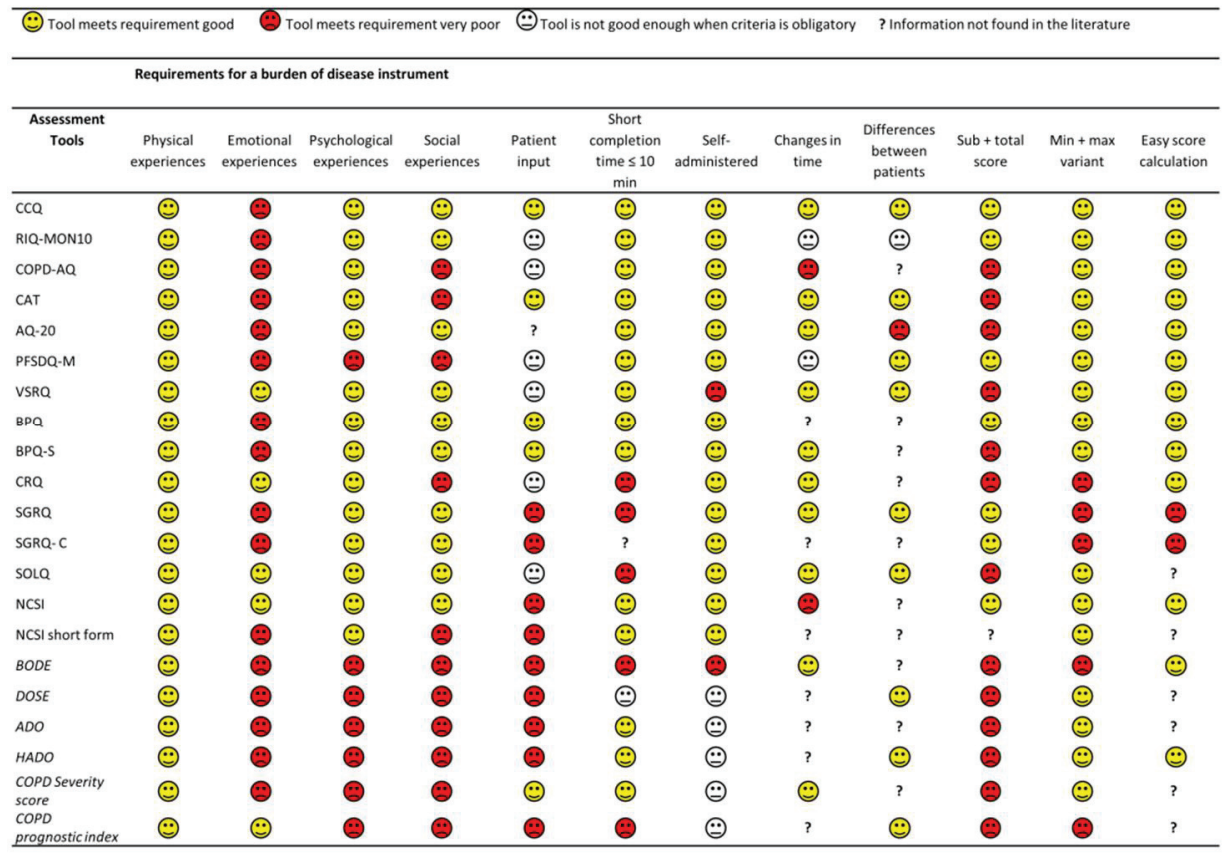

Figure 2.1 An overview of HRQOL instruments in relation to requirements for a burden of disease instrument

The CCQ was also reviewed by the International Primary Care Respiratory Group (IPCRG) and it scored excellent on validity/reliability, responsiveness, use in a primary care population, its practicality/easiness to administer, its availability in other languages, and additionally it was tested in practice. ${ }^{47}$ Therefore, the CCQ was considered to be closest to reflecting the concept of burden of COPD. It was used as a basis for the new scale, the Assessment of Burden of COPD (ABC)-scale. It was adapted by adding questions for the lacking domains of fatigue ${ }^{48}$ and emotions.

Three items were added to measure emotional experiences. These items are based on the distress screener, a three-item questionnaire measuring listlessness, worry and feeling tense taken from the distress subscale of the four-dimensional symptom questionnaire (4DSQ). ${ }^{49}$ The questions from the distress screener were revised to match the format of the CCQ questions. Furthermore, a question was added about fatigue based on a study by Van Hooff and colleagues. ${ }^{50}$ This item was formulated in the same way as the questions on the CCQ to make all 14 questions in the ABC-scale consistent. Table 2.2 shows the ABC-scale. 
Table 2.2 Assessment of Burden of COPD scale

On average, during the past week,
how often did you feel:
1 Short of breath at rest?
2 Short of breath doing physical
activities?
$3 \quad \begin{aligned} & \text { Concerned about getting a cold } \\ & \text { or your breathing getting worse? }\end{aligned}$
$4 \quad \begin{aligned} & \text { Depressed (down) because of } \\ & \text { your breathing problems? }\end{aligned}$

In general, during the past week, how much of the time:

5 Did you cough?

6 Did you produce phlegm?

On average, during the past week, how limited were you in these activities because of your breathing problems:

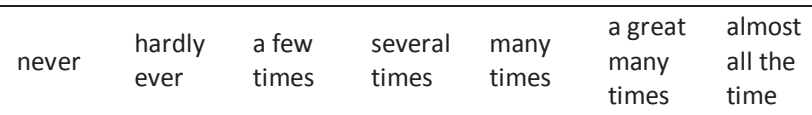

7 Strenuous physical activities (such as climbing stairs, hurrying, doing sports)?

8 Moderate physical activities (such as walking, house work, carrying things)?

9 Daily activities at home (such as dressing, washing yourself)?

10 Social activities (such as talking, being with children, visiting friends/relatives)?

How often in the past week did you suffer from:

\begin{tabular}{|c|c|c|c|c|c|}
\hline $\begin{array}{l}\text { not } \\
\text { limited } \\
\text { at all }\end{array}$ & $\begin{array}{l}\text { very } \\
\text { slightly } \\
\text { limited }\end{array}$ & $\begin{array}{l}\text { slightly } \\
\text { limited }\end{array}$ & $\begin{array}{l}\text { moder } \\
\text { ately } \\
\text { limited }\end{array}$ & $\begin{array}{l}\text { very } \\
\text { limited }\end{array}$ & $\begin{array}{l}\text { extre } \\
\text { mely } \\
\text { limited }\end{array}$ \\
\hline
\end{tabular}

11 Worry?

12 Listlessness?

13 A tense feeling?

14 Fatigue?

As integrated health status is more than the experienced burden of burden, the Dutch expert team concluded that other items should also be measured. ${ }^{9}$ Table 2.3 shows the items and dimensions for measuring integrated health status. 
Table 2.3 Dimensions of integrated health status

\begin{tabular}{|c|c|c|}
\hline Dimension: & Measured by: & Recorded by: \\
\hline Smoking status & $\begin{array}{l}\text { Does the patient smoke? If so, an average of } \\
\text { how many cigarettes in the past week? }\end{array}$ & Healthcare provider \\
\hline Exacerbations & $\begin{array}{l}\text { How many exacerbations has the patient had } \\
\text { in the past year? How many exacerbations has } \\
\text { the patient had since the last visit? }\end{array}$ & Healthcare provider \\
\hline Dyspnoea & $\begin{array}{l}\text { Medical Research Council (MRC) dyspnea } \\
\text { scale } 51\end{array}$ & Patient \\
\hline BMI & A formula, based on height and weight & Healthcare provider \\
\hline Lung function & Spirometry & Healthcare provider \\
\hline $\begin{array}{l}\text { Physical } \\
\text { activity }\end{array}$ & $\begin{array}{l}\text { Do you exercise enough according to the } \\
\text { Dutch standard (at least } 30 \text { minutes of } \\
\text { moderate intense physical exercise five days a } \\
\text { week)? }\end{array}$ & Patient \\
\hline Complaints & $A B C$ scale questions $1,2,5,6^{11}$ & Patient \\
\hline Physical health & ABC scale questions $7,8,9,10^{11}$ & Patient \\
\hline Mental health & $A B C$ scale questions $3,4^{11}$ & Patient \\
\hline Fatigue & $A B C$ scale question $14^{50}$ & Patient \\
\hline Emotions & ABC scale questions $11,12,13^{49}$ & Patient \\
\hline
\end{tabular}

To visualise the integrated health status of a patient, we developed a computer program, the ABC-tool, that visualises the outcomes of all items using balloons (see Figure 2.2). Each balloon represents an aspect of a patient's integrated health status. A high, green balloon indicates that a patient scores well on a particular item. This green balloons can be used to compliment the patient (e.g. not smoking) and to encourage the patient to continue that behaviour. A low, red balloon indicates that the patient experiences problems on that item. The red and dark-orange balloons can be discussed during consultations. In order to connect the integrated health status with the treatment of the disease, we developed an algorithm based on current healthcare standards and guidelines that provides treatment advice. This advice can guide the patient and care provider towards an integrated and personalised therapy. When discussing the balloons, a patient and healthcare provider can click on a balloon to access treatment advice. They can select a specific advice, which is then placed in the patient's treatment plan. 


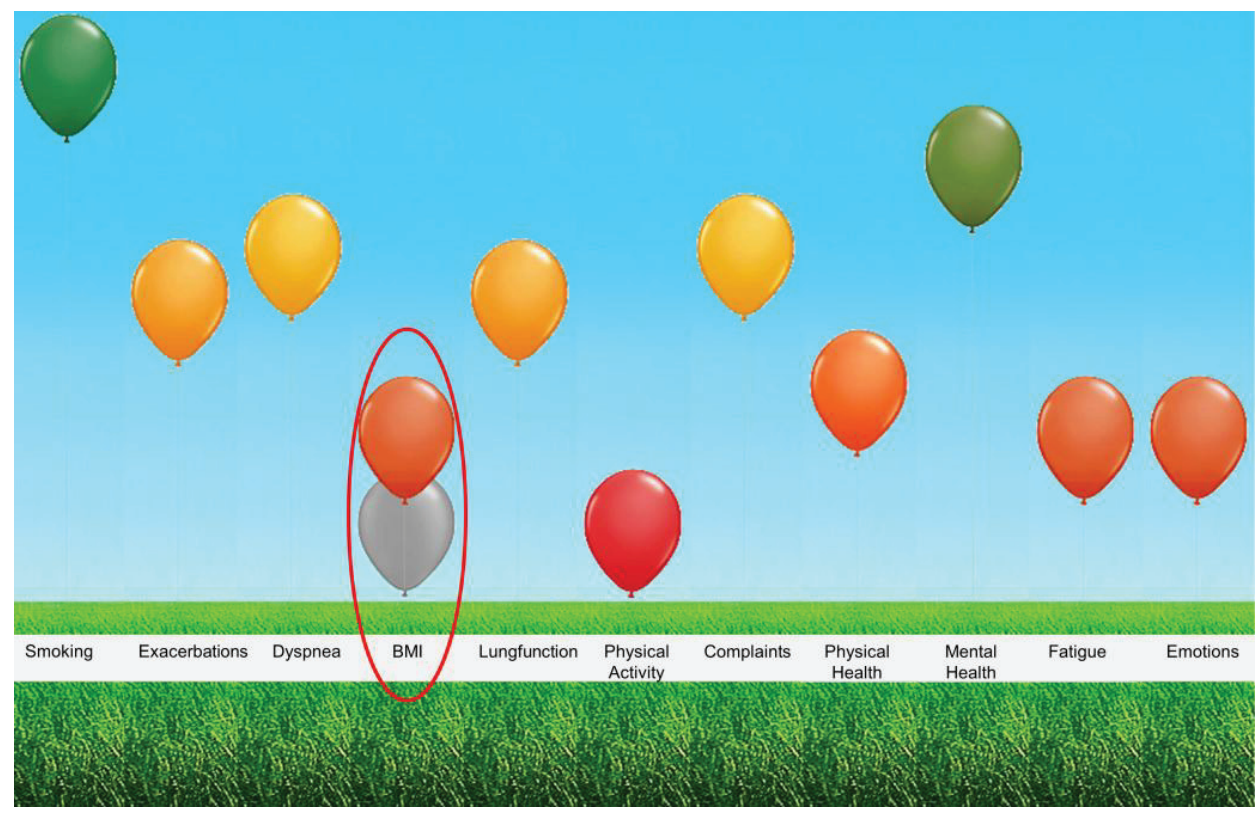

Figure 2.2 Visualisation of the dimensions influencing integrated health status (Assessment of Burden of COPD tool), changed after treatment

When treatment advice is followed and the treatment is effective, the rationale is that the balloon for that particular item (e.g. BMI) will move to a higher position when the integrated health status is measured again at a later stage, signifying that the patient scores better on that item. Box 2.3 gives an example of the treatment advice.

\section{Box 2.3 Example of treatment advice}

The balloons in Figure 2.2 show that the patients' body mass index is too low.

Therefore, the following treatment advice is provided:

Your BMI is 16.

This means you are underweight.

Treatment advices for healthcare provider (select when necessary):

Check whether the underweight or weight loss is related to COPD, or if there is another explanation.

Nutritional advice.

Refer to secondary care for further analysis of the weight loss, in accordance with the Healthcare Standard. 


\section{DISCUSSION}

This paper describes the development of the $A B C$-scale and ABC-tool. Several steps were taken to develop this scale and tool. A definition of burden of COPD and requirements for a measurement tool were formulated by involvement of experts, patients and diverse healthcare providers. We searched the literature, but we could not find an adequate measurement. We consequently concluded that an adapted questionnaire was needed, the $A B C$-scale. We added a number of items to measure patients' integrated health status. This was supplemented with a computer program that visualises the outcomes and provides a treatment algorithm, the ABC-tool.

The $A B C$-scale includes indicators that provide insight into impairments, disabilities, complaints and quality of life. It measures patients' physical (questions $1,2,5,6,7,8,9,14$ ), emotional (questions 11,12,13), psychological (questions 3,4 ) and social (question 10) experiences related to COPD. The ABC-scale is quick and easy to manage, has an easy score calculation and can be administered by patients themselves. The $A B C$-tool, including the $A B C$-scale, can be used during consultations to monitor a patient's integrated health status over time. The integrated health status is visualised using balloons (Figure 2.2). Both balloons and the treatment algorithm can help facilitate discussions between a patient and healthcare provider, guide them towards a treatment plan and evaluate the effect of the treatment.

The ABC-scale fits with the idea that the focus in treating COPD should be partly based on patient experience and not merely on physiological aspects such as airway obstruction. Research has shown that multidimensional indicators, such as the BodyMass Index, Airflow Obstruction, Dyspnoea, and Exercise Capacity (BODE) Index, ${ }^{36}$ are better predictors of morbidity and mortality than the Forced Expiratory Volume in 1 second $\left(\mathrm{FEV}_{1}\right)$ alone. Categorizing patients with COPD on the basis of self-reported dyspnea was also more closely correlated with survival than categorization based on the $\mathrm{FEV}_{1}{ }^{52}$ Exercise capacity $^{53}$ and quality of life ${ }^{34,54,55}$ also predict mortality and morbidity and healthcare resource utilization in COPD patients. Agusti and MacNee ${ }^{56}$ describe the necessity of a more personalised approach. They suggest that physicians need a 'control panel' that provides complementary and relevant information on how to manage COPD patients. The newly developed ABC-tool is consistent with this idea.

Moreover, anticipatory interventions that focus on well-being should comply with the P4 Personalised Medicine principles. ${ }^{57}$ Our tool focuses on the integrated diagnosis, treatment and (secondary) prevention of COPD. It includes a 'Personalised' approach 
with 'Predictive' markers for burden of disease that allow for 'Preventive' measurements to be taken, such as quit smoking and exacerbation reduction interventions, and requires a 'Participatory' attitude to empower both the patient and the healthcare provider. We believe that shared decision making (SDM) can only be successful if we add a fifth ' $P$ ' with a visualisation of the personalised parameters. This 'Practical' (P5) approach might be the key to successful implementation in daily practice.

The Dutch healthcare standard COPD (2010) describes the necessity of a patient with COPD taking an active role based on SDM principles. ${ }^{58}$ The patient is considered to have a certain level of responsibility in the treatment that lies within his or her possibilities. The $A B C$-tool facilitates a shift from paternalistic care to shared care (i.e. personalised patient-centred care).

The visual display of patients' integrated health status was designed to initiate discussions between care provider and patient and creates a basis for shared decision making. The patient and healthcare provider can select one balloon to further elaborate on (SDM choice phase). Clicking on a balloon gives access to treatment options (SDM option phase). The patient and provider can then decide on the treatment goal by selecting an option and placing it in the patients' treatment plan (SDM decision phase). ${ }^{59}$ The tool facilitates an active role of the patient, which means that the patient can choose a dimension for improvement by picking a red or orange balloon and subsequently be offered treatment advice. The healthcare provider can use the profile of scores on the burden of disease instrument to start discussing the patient's goals. The patient can formulate a personal goal that can be reached using the treatment options. This personal goal is important in motivating the patient to feel responsible for their own treatment and wellbeing. This may lead to better treatment effects on burden of COPD and quality of life.

\section{Limitations}

The ABC-scale was developed to create a comprehensive yet quick and simple instrument that could be used in clinical practice. The instrument was to a large extent based on expert opinions and results from the literature. However, we subsequently checked the content validity by asking patients and healthcare providers about their experiences. Nonetheless, 10 of the 14 questions originated from the CCQ and hence were driven by previous qualitative research. In that study, researchers 
conducted extensive interviews and focus group discussion, with COPD patients, to generate items for the $\mathrm{CCQ}{ }^{11}$

\section{Conclusion}

The definition of burden of disease formulated by the Dutch expert group was consistent with the experiences of COPD patients and the opinions of healthcare providers. In the literature no instruments were available for measuring all aspects of burden of COPD. An existing questionnaire (CCQ) was therefore adapted by adding the two domains of emotions and fatigue. This adapted questionnaire is called the $A B C$-scale and has been integrated into the $A B C$-tool, which displays all the relevant aspects in the treatment of COPD and provides a treatment algorithm.

\section{Recommendation}

The next step in the development of this new instrument is to perform a randomised controlled trial (RCT) that tests whether healthcare and quality of life can be improved based on the ABC-tool, encompassing the ABC-scale. 


\section{REFERENCES}

1. Mathers CD \& Loncar D. Projections of global mortality and burden of disease from 2002 to 2030. PLoS Med 2006;3:e442.

2. From the Global Strategy for Diagnosis, Management and Prevention of COPD, Global Initiative for Chronic Obstructive Lung Disease (GOLD) 2014. Available at http://www.goldcopd.org/.

3. Celli BR \& MacNee W. Standards for the diagnosis and treatment of patients with COPD: a summary of the ATS/ERS position paper. Eur Respir J 2004;23:932-946.

4. Jones P, Miravitlles M, Van der Molen T \& Kulich K. Beyond FEV1 in COPD: a review of patientreported outcomes and their measurement. Int J Chron Obstruct Pulmon Dis 2012;2012:697-709.

5. Jones PW \& Agusti AG. Outcomes and markers in the assessment of chronic obstructive pulmonary disease. Eur Respir $J$ 2006;27:822-832.

6. He QY, Zhou X, Xie CM, Liang ZA, Chen P \& Wu CG. Impact of chronic obstructive pulmonary disease on quality of life and economic burden in Chinese urban areas. Zhonghua Jie He He Hu Xi Za Zhi 2009;32:253-257.

7. Uzaslan E, Mahboub B, Beji M, Nejjari C, Tageldin MA, Khan JA, Nafti S, Obeidat NM, Sayiner A, Wali S, Rashid N \& El Hasnaoui A. The burden of chronic obstructive pulmonary disease in the Middle East and North Africa: results of the BREATHE study. Respir Med 2012;106:S45-59.

8. Von Leupoldt A \& Kenn K. The psychology of chronic obstructive pulmonary disease. Curr Opin Psychiatry 2013;26:458-463.

9. Long Alliantie Nederland. Zorgstandaard COPD. Amersfoort:Long Alliantie Nederland; 2010.

10. Kocks J, de Jong C, Berger MY, Kerstjens HAM \& van der Molen T. Putting health status guided COPD management to the test: protocol of the MARCH study. BMC Pulm Med 2013;13:1-9.

11. Van der Molen T, Willemse BW, Schokker S, Ten Hacken NH, Postma DS \& Juniper EF. Development, validity and responsiveness of the Clinical COPD Questionnaire. Health Qual Life Outcomes 2003;1.

12. Tashkin DP, Rennard S, Taylor Hays J, Lawrence D, Marton JP \& Lee TC. Lung function and respiratory symptoms in a 1 -year randomized smoking cessation trial of varenicline in COPD patients. Respir Med 2011;105:1682-1690.

13. Stallberg B, Nokela M, Ehrs PO, Hjemdal P \& Jonsson EW. Validation of the clinical COPD Questionnaire (CCQ) in primary care. Health Qual Life Outcomes 2009;7.

14. Maille AR, Koning CJ, Zwinderman AH, Willems LN, Dijkman JH \& Kaptein AA. The development of the 'Quality-of-life for Respiratory IIIness Questionnaire (QOL-RIQ): a disease-specific qualityof-life questionnaire for patients with mild to moderate chronic non-specific lung disease. Respir Med 1997;91:297-309.

15. Jacobs JE, Maille AR, Akkermans RP, van Weel C \& Grol RP. Assessing the quality of life of adults with chronic respiratory diseases in routine primary care: construction and first validation of the 10-Item Respiratory Illness Questionnaire-monitoring 10 (RIQ-MON10). Qual Life Res 2004;13:1117-1127.

16. Bailey WC, Sciurba FC, Hanania NA, Donohue JF, Ferguson GT, Zibrak JD, Sharafkhaneh A, Marcus $P$, Rosa K, Piault EC \& Martinez FJ. Development and validation of the Chronic Obstructive Pulmonary Disease Assessment Questionnaire (COPD-AQ). Prim Care Respir J 2009;18:198-207.

17. Jones PW, Harding G, Berry P, Wiklund I, Chen WH \& Kline Leidy N. Development and first validation of the COPD Assessment Test. Eur Respir J 2009;34:648-654.

18. Barley EA, Quirk FH \& Jones PW. Asthma health status measurement in clinical practice: validity of a new short and simple instrument. Respir Med 1998;92:1207-1214.

19. Hajiro T, Nishimura K, Jones PW, Tsukino M, Ikeda A, Koyama H \& Izumi T. A novel, short, and simple questionnaire to measure health-related quality of life in patients with chronic obstructive pulmonary disease. Am J Respir Crit Care Med 1999;159:1874-1878.

20. Camelier A, Rosa FW, Nascimento OA, Fernandes AL \& Jardim JR. Discriminative properties and validity of a health status questionnaire in obstructive airway disease patients: the Airway Questionnaire 20. Arch Bronconeumol 2007;43:662-668. 
21. Lareau SC, Meek PM \& Roos PJ. Development and testing of the modified version of the pulmonary functional status and dyspnea questionnaire (PFSDQ-M). Heart Lung 1998;27:159168.

22. Kovelis D, Segretti NO, Probst VS, Lareau SC, Brunetto AF \& Pitta F. Validation of the Modified Pulmonary Functional Status and Dyspnea Questionnaire and the Medical Research Council scale for use in Brazilian patients with chronic obstructive pulmonary disease. I Bras Pneumol 2008;34:1008-1018.

23. Perez T, Arnould B, Grosbois JM, Bosch V, Guillemin I, Bravo ML, Brun M \& Tonnel AB. Validity, reliability, and responsiveness of a new short Visual Simplified Respiratory Questionnaire (VSRQ) for health-related quality of life assessment in chronic obstructive pulmonary disease. Int J Chron Obstruct Pulmon Dis 2009;2009:9-18.

24. Tonnel AB, Perez T, Grosbois JM, Verkindre C, Bravo ML \& Brun M. Effect of tiotropium on health-related quality of life as a primary efficacy endpoint in COPD. Int J Chron Obstruct Pulmon Dis 2008;2008:301-310.

25. Hyland ME, Singh SJ, Sodergren SC \& Morgan MP. Development of a shortened version of the Breathing Problems Questionnaire suitable for use in a pulmonary rehabilitation clinic: a purpose-specific, disease-specific questionnaire. Qual Life Res 1998;7:227-233.

26. Guyatt GH, Berman LB, Townsend M, Pugsley SO \& Chambers LW. A measure of quality of life for clinical trials in chronic lung disease. Thorax 1987;42:773-778.

27. Williams JE, Singh SJ, Sewell L, Guyatt GH \& Morgan MD. Development of a self-reported Chronic Respiratory Questionnaire (CRQ-SR). Thorax 2001;56:954-959.

28. Rutten-van Mölken M, Roos B \& Van Noord JA. An empirical comparison of the St George's Respiratory Questionnaire (SGRQ) and the Chronic Respiratory Disease Questionnaire (CRQ) in a clinical trial setting. Thorax 1999;54:995-1003.

29. Jones PW, Quirk FH \& Baveystock CM. The St George's Respiratory Questionnaire. Respir Med 1991;85:25-31.

30. Daudey L, Peters JB, Molema J, Dekhuijzen PN, Prins JB, Heijdra YF \& Vercoulen JH. Health status in COPD cannot be measured by the St George's Respiratory Questionnaire alone: an evaluation of the underlying concepts of this questionnaire. Respir Res 2010;11:1-7.

31. Meguro M, Barley EA, Spencer S \& Jones PW. Development and Validation of an Improved, COPD-Specific Version of the St. George Respiratory Questionnaire. CHEST 2007;132:456-463.

32. Curtis JR \& Patrick DL. The assessment of health status among patients with COPD. Eur Respir J Supp/ 2003;21:36s-45s.

33. Tu SP, McDonell MB, Spertus JA, Steele BG \& Fihn SD. A new self-administered questionnaire to monitor health-related quality of life in patients with COPD. Ambulatory Care Quality Improvement Project (ACQUIP) Investigators. Chest 1997;112:614-622.

34. Fan VS, Curtis JR, Tu SP, McDonell MB \& Fihn SD. Using quality of life to predict hospitalization and mortality in patients with obstructive lung diseases. Chest 2002;122:429-436.

35. Peters JB, Daudey L, Heijdra YF, Molema J, Dekhuijzen PN \& Vercoulen JH. Development of a battery of instruments for detailed measurement of health status in patients with COPD in routine care: the Nijmegen Clinical Screening Instrument. Qual Life Res 2009;18:901-912.

36. Celli BR, Cote CG, Marin JM, Casanova C, Montes de Oca M, Mendez RA, Pinto Plata V \& Cabral HJ. The body-mass index, airflow obstruction, dyspnea, and exercise capacity index in chronic obstructive pulmonary disease. N Engl J Med 2004;350:1005-1012.

37. Ong KC, Earnest A \& Lu SJ. A multidimensional grading system (BODE index) as predictor of hospitalization for COPD. Chest 2005;128:3810-3816.

38. Martinez FJ, Han MK, Andrei AC, Wise R, Murray S, Curtis JL, Sternberg A, Criner G, Gay SE, Reilly J, Make B, Ries AL, Sciurba F, Weinmann G, Mosenifar Z, DeCamp M, Fishman AP \& Celli BR. Longitudinal change in the BODE index predicts mortality in severe emphysema. Am J Respir Crit Care Med 2008;178:491-499.

39. Puhan MA, Garcia-Aymerich J, Frey M, ter Riet G, Anto JM, Agusti AG, Gomez FP, RodriguezRoisin R, Moons KG, Kessels AG \& Held U. Expansion of the prognostic assessment of patients with chronic obstructive pulmonary disease: the updated BODE index and the ADO index. Lancet 2009;374:704-711. 
40. Esteban C, Quintana JM, Aburto M, Moraza J \& Capelastegui A. A simple score for assessing stable chronic obstructive pulmonary disease. Qjm 2006;99:751-759.

41. Esteban C, Quintana JM, Moraza J, Aburto M, Aguirre U, Aguirregomoscorta JI, Aizpiri S, Basualdo LV \& Capelastegui A. BODE-Index vs HADO-score in chronic obstructive pulmonary disease: Which one to use in general practice? BMC Med 2010;8:1-11.

42. Eisner MD, Trupin L, Katz PP, Yelin EH, Earnest G, Balmes J \& Blanc PD. Development and validation of a survey-based COPD severity score. Chest 2005;127:1890-1897.

43. Eisner MD, Omachi TA, Katz PP, Yelin EH, Iribarren C \& Blanc PD. Measurement of COPD severity using a survey-based score: validation in a clinically and physiologically characterized cohort. Chest 2010;137:846-851.

44. Omachi TA, Yelin EH, Katz PP, Blanc PD \& Eisner MD. The COPD severity score: a dynamic prediction tool for health-care utilization. COPD 2008;5:339-346.

45. Briggs A, Spencer M, Wang H, Mannino D \& Sin DD. Development and validation of a prognostic index for health outcomes in chronic obstructive pulmonary disease. Arch Intern Med 2008;168:71-79.

46. Kocks JW, Asijee GM, Tsiligianni IG, Kerstjens HA \& van der Molen T. Functional status measurement in COPD: a review of available methods and their feasibility in primary care. Prim Care Respir J 2011;20:269-275.

47. Cave AJ, Atkinson L, Tsiligianni IG \& Kaplan AG. Assessment of COPD wellness tools for use in primary care: an IPCRG initiative. Int J Chron Obstruct Pulmon Dis 2012;2012:447-456.

48. Stridsman C, Mullerova H, Skar L \& Lindberg A. Fatigue in COPD and the impact of respiratory symptoms and heart disease--a population-based study. COPD 2013;10:125-132.

49. Braam C, van Oostrom SH, Terluin B, Vasse R, de Vet HC \& Anema JR. Validation study of a distress screener. J Occup Rehabil 2009;19:231-237.

50. Van Hooff ML, Geurts SA, Kompier MA \& Taris TW. "How fatigued do you currently feel?" Convergent and discriminant validity of a single-item fatigue measure. $J$ Occup Health 2007;49:224-234.

51. Bestall JC, Paul EA, Garrod R, Garnham R, Jones PW \& Wedzicha JA. Usefulness of the Medical Research Council (MRC) dyspnoea scale as a measure of disability in patients with chronic obstructive pulmonary disease. Thorax 1999;54:581-586.

52. Nishimura K, Izumi T, Tsukino M \& Oga T. Dyspnea is a better predictor of 5-year survival than airway obstruction in patients with COPD. Chest 2002;121:1434-1440.

53. Pinto-Plata VM, Cote C, Cabral H, Taylor J \& Celli BR. The 6-min walk distance: change over time and value as a predictor of survival in severe COPD. Eur Respir J 2004;23:28-33.

54. Domingo-Salvany A, Lamarca R, Ferrer M, Garcia-Aymerich J, Alonso J, Felez M, Khalaf A, Marrades RM, Monso E, Serra-Batlles J \& Anto JM. Health-related quality of life and mortality in male patients with chronic obstructive pulmonary disease. Am J Respir Crit Care Med 2002;166:680-685.

55. Santo Tomas LH \& Varkey B. Improving health-related quality of life in chronic obstructive pulmonary disease. Curr Opin Pulm Med 2004;10:120-127.

56. Agusti A \& Macnee W. The COPD control panel: towards personalised medicine in COPD. Thorax 2013;68:687-690.

57. Agusti A, Sobradillo P \& Celli B. Addressing the complexity of chronic obstructive pulmonary disease: from phenotypes and biomarkers to scale-free networks, systems biology, and P4 medicine. Am J Respir Crit Care Med 2011;183:1129-1137.

58. Makoul G \& Clayman ML. An integrative model of shared decision making in medical encounters. Patient Educ Couns 2006;60:301-312.

59. Elwyn G, Frosch D, Thomson R, Joseph-Williams N, Lloyd A, Kinnersley P, Cording E, Tomson D, Dodd C, Rollnick S, Edwards A \& Barry M. Shared decision making: a model for clinical practice. J Gen Intern Med 2012;27:1361-1367. 



\section{CHAPTER 3}

\section{Effectiveness of the Assessment of Burden of Chronic Obstructive Pulmonary Disease $(A B C)$ tool: study protocol of a cluster randomised trial in primary and secondary care}

Published as:

Slok AHM, in 't Veen JCCM, Chavannes NH, van der Molen T, Rutten-van Mölken MPMH, Kerstjens HAM, Asijee, GM, Salomé PL, Holverda S, Dekhuijzen PNR, Schuiten $D$, van Breukelen G, Kotz D, van Schayck OCP. Effectiveness of the Assessment of Burden of Chronic Obstructive Pulmonary Disease (ABC) tool: study protocol of a cluster randomised trial in primary and secondary care. BMC Pulmonary Medicine. 2014;14:131. 


\section{ABSTRACT}

\section{Background}

Chronic Obstructive Pulmonary Disease (COPD) is a growing worldwide problem that imposes a great burden on the daily life of patients. Since there is no cure, the goal of treating COPD is to maintain or improve quality of life. We have developed a new tool, the Assessment of Burden of COPD (ABC) tool, to assess and visualise the integrated health status of patients with COPD, and to provide patients and healthcare providers with a treatment algorithm. This tool may be used during consultations to monitor the burden of COPD and to adjust treatment if necessary. The aim of the current study is to analyse the effectiveness of the $A B C$ tool compared with usual care on health related quality of life among COPD patients over a period of 18 months.

\section{Methods/Design}

A cluster randomised controlled trial will be conducted in COPD patients in both primary and secondary care throughout the Netherlands. An intervention group, receiving care based on the $A B C$ tool, will be compared with a control group receiving usual care. The primary outcome will be the change in score on a disease-specificquality-of-life questionnaire, the Saint George Respiratory Questionnaire. Secondary outcomes will be a different questionnaire (the COPD Assessment Test), lung function and number of exacerbations. During the 18 months follow-up, seven measurements will be conducted, including a baseline and final measurement. Patients will receive questionnaires to be completed at home. Additional data, such as number of exacerbations, will be recorded by the patients' healthcare providers. A total of 360 patients will be recruited by 40 general practitioners and 20 pulmonologists. Additionally, a process evaluation will be performed among patients and healthcare providers.

\section{Discussion}

The new ABC tool complies with the 2014 Global Initiative for Chronic Obstructive Lung Disease guidelines, which describe the necessity to classify patients on both their airway obstruction and a comprehensive symptom assessment. It has been developed to classify patients, but also to provide visual insight into the burden of COPD and to provide treatment advice. 


\section{BACKGROUND}

The prevalence of Chronic Obstructive Pulmonary Disease (COPD) is increasing globally due to an aging population and continued exposure to risk factors. ${ }^{1}$ COPD has a major impact on the lives of patients'. The prevalence of COPD is expected to increase, and is projected to be the fourth leading cause of death and the seventh leading cause of disability-adjusted life years (DALYs) lost worldwide by 2030 . $^{2,3}$

Since there is no cure for the disease, the goal of COPD treatment is to maintain or improve patients' quality of life. As such, the care of patients with COPD is currently shifting towards a more patient-centred model. More attention is paid to the impact of the disease on the patient's life. ${ }^{1}$ It is therefore necessary to focus on more than just airway obstruction, as measured by the forced expiratory volume in one second $\left(F E V_{1}\right)$, which has a poor correlation with many patient reported outcomes in COPD. ${ }^{4}$ Health status measurements have been propagated as an important part of managing COPD, both in primary and secondary care. ${ }^{5}$ Previous studies showed that a poor health status is a predictor for hospitalization and mortality. ${ }^{6-8}$

Health status questionnaires can also be used to determine the burden of COPD as experienced by patients. However, current health status questionnaires do not fully cover patients' experienced burden of disease. ${ }^{9}$ Hence, we developed a new tool, the Assessment of Burden of COPD (ABC) tool, which consists of three elements. The first element is the $A B C$ scale, a 14-item questionnaire that measures five different domains of the burden of disease as experienced by the patient: symptoms, functional state, mental state, emotional state, and fatigue. The second element comprises a number of additional indicators: smoking status, exacerbation history, dyspnoea, body mass index (BMI), lung function and physical activity. When combined with the $A B C$ scale an overall assessment of a patient's integrated health status is obtained. The third element is a computer program used to visualise the scores on all items into green, orange and red balloons and link treatment advice to these balloons (see Figure 3.1). ${ }^{9}$

The purpose of the $A B C$ tool is to assess the experienced burden of disease and to provide both patient and healthcare provider with a visual overview of the individual patient's burden of COPD. The tool is designed to facilitate shared decision making, in which patients and healthcare providers are both responsible for the focus of 
treatment, selecting the corresponding treatment options, formulating a personal goal and make a tailored treatment plan. ${ }^{10}$ Patients need to be encouraged to take the lead in their own treatment, and the $A B C$ tool aims to facilitate in this process. It can be used during consultations to monitor the patient's integrated health status, including the experienced burden of COPD, and to treat the patient accordingly. The development of the tool has been described elsewhere. ${ }^{9}$

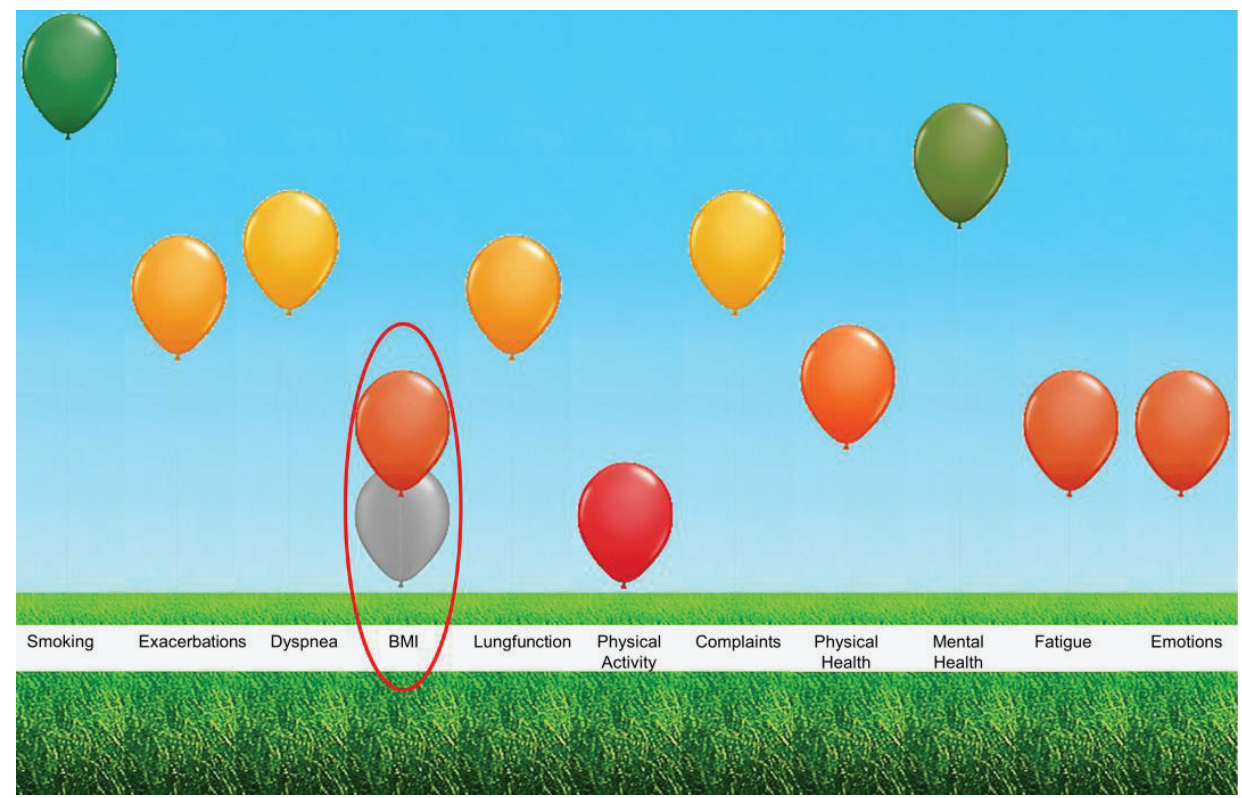

Figure 3.1 Visualisation of the dimensions influencing integrated health status (Assessment of Burden of COPD tool), changed after treatment

The reliability, validity and responsiveness of the $A B C$ scale, the first element and core component of the $A B C$ tool, still needs to be assessed. The scale is based mainly on the Clinical COPD Questionnaire (CCQ), ${ }^{11}$ so we assume that it is a valid and reliable instrument. However, to be thorough we will analyse the internal consistency and test-retest reliability. Furthermore, we will analyse the convergent validity, divergent validity, known-group differences and responsiveness.

Since the effectiveness of the $A B C$ tool has not yet been tested, we will conduct a cluster randomised controlled trial (RCT). The trial will take place in both primary and secondary care settings, to include patients with varying disease severity. We aim to evaluate the effectiveness by answering the following research question: 
In COPD patients, varying in disease severity, does application of the ABC-tool increases the percentage of patients with a clinically relevant improvement on the Saint George Respiratory Questionnaire (SGRQ), ${ }^{12}$ between baseline and 18 months follow-up, as compared with usual care?

\section{METHODS / DESIGN}

\section{Study design}

The study is a two-armed cluster RCT that compares an intervention group, using the $A B C$ tool with a control group receiving usual care. The duration of follow-up period is 18 months. During this period there are seven measurements, including a baseline and final measurement. The flow of the study is presented in Figure 3.2.

This study has been approved by the Medical Ethics Committee of Zuyderland Hospital, Heerlen, the Netherlands.

\section{Selection, recruitment and randomisation}

This study will take place in general practices and hospitals throughout the Netherlands. The researchers will contact general practitioners (GPs) and pulmonologists using a GP network (CAHAG; COPD and Asthma GP Advice Group) and the pulmonologists association (NVALT; Dutch Association of Physicians for Lung Diseases and Tuberculosis). To avoid contamination of care (i.e. patients from the control group receiving the intervention because they are treated by the same caregiver), it is vital that the randomisation between the groups takes place at caregiver-level and not at patient-level. Therefore, healthcare providers will be randomly assigned to intervention or control group in a 1:1 ratio with the help of a computer program designed by the Maastricht University Centre for Data and Information Management (MEMIC). Randomisation will be stratified by type of caregiver (GP or pulmonologist) and variable blocks of two, four or six will be used to make sure there are an equal number of caregivers from primary and secondary care in the intervention and control group. The researcher will enter the names of the healthcare providers into the computer program, which will then randomly allocate them to either the intervention or control group.

Participating healthcare providers will be asked to invite patients from their listed patient databases to participate in the trial. Patients that meet the inclusion criteria and exclusion criteria (see next paragraph) will be sent an information letter including 
an informed consent form. Healthcare providers will also directly invite patients to participate if they see them during consultations. If the patient agrees to participate in the study, an appointment will be made with the healthcare provider to discuss further details of the trial, recheck whether the patient is eligible for the study and sign the informed consent form.

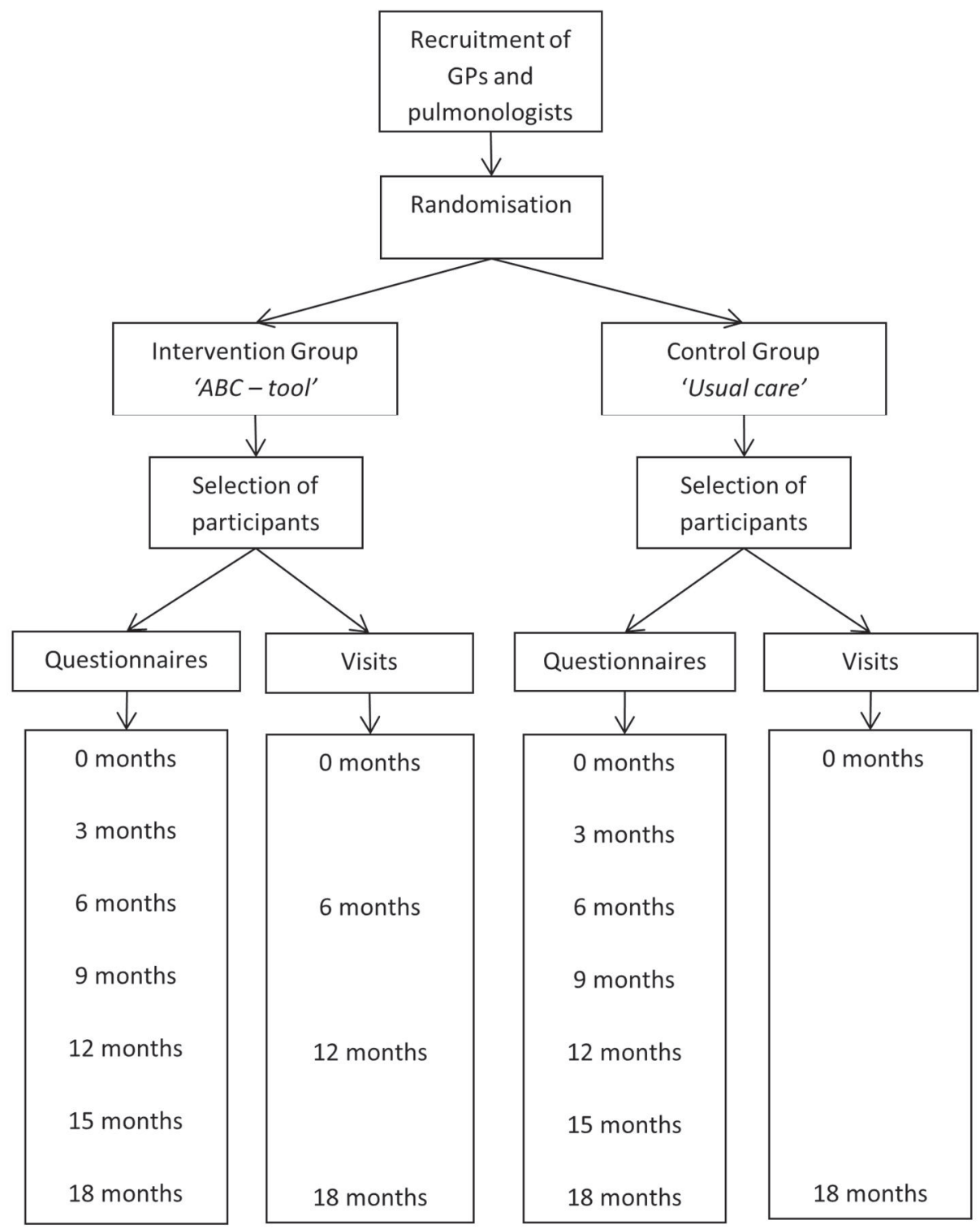

Figure 3.2 Flow of the study 


\section{Inclusion and exclusion criteria}

The inclusion criteria will be: a confirmed diagnosis of COPD (post-bronchodilator $\mathrm{FEV}_{1}$ /Forced Vital Capacity< 0.7 ) by spirometer, age 40 years or above, and the ability to understand and read the Dutch language. The exclusion criteria will be: an exacerbation less than six weeks ago, hard-drug addiction, life-threatening co-morbid conditions, and current pregnancy. Exacerbations are defined as an acute event characterised by worsening of a patient's respiratory symptoms beyond normal dayto-day variation that necessitates prednisolone and/or hospital admissions for COPD.

\section{Intervention group}

The actual intervention will be the use of the $A B C$ tool by patients and healthcare providers during routine consultations. Patients will fill out the $A B C$ scale, which measures the patient's experienced burden of COPD, in the waiting room (without supervision). ${ }^{9}$ The healthcare provider will then enter the results of the $A B C$ scale into a computer program and add the results of additional items (i.e. smoking status, exacerbation history, dyspnoea, body mass index (BMI), lung function and physical activity). These items and the $A B C$ scale together will show the integrated health status of the patient, illustrated by a visual representation with coloured balloons. The balloons represent all of the patient's health status items, including the different domains of the $A B C$ scale (see Figure 3.1). A high, green balloon means that the patient scores well on a particular item/domain; an orange balloon means an intermediate score; and a low, red balloon means that the patients scores poorly on that item/domain. Patients and healthcare providers will be prompted to discuss the balloons together, according to the principles of shared decision making (SDM), ${ }^{13}$ and will be advised to work on the items represented by the red and orange balloons. These represent the items with possible room for improvement if the right treatment is provided. Each balloon can be clicked on, showing a pop-up with treatment advice.

The algorithm behind the $A B C$ tool was developed based on a previous treatment algorithm attached to the $\mathrm{CCQ}^{14}$ and optimised for this study according to national and international guidelines. ${ }^{15-17}$ The cut-off points are based on the current Dutch COPD Healthcare Standard guidelines, ${ }^{18}$ and experts' experiences. The level of the balloon was determined by using a continuous scale to grade the displayed value. The treatment recommendations were written by pulmonologists and GPs based on the current national COPD guidelines. Two versions of the algorithm were written, one for 
the use in primary care, based on the standard of the Dutch College of General Practitioners ${ }^{15}$ and the other for the use in secondary care, based on the NVALT guidelines. ${ }^{16}$ The treatment advice was written during a number of meetings and groups discussions, and the algorithm was tested extensively by healthcare providers with different backgrounds throughout the Netherlands. Examples of the treatment advice are provided in Appendix 1.

According to the principles of shared decision making, patients and healthcare providers will be advised to discuss the possible treatment options within the patient's possibilities. One or more pieces of advice can be selected and will automatically and electronically be placed in the patient's written treatment plan. During the consultation, healthcare providers should guide patients in setting a personalised treatment goal. This personal goal should be written down as an achievable goal, in the patient's own words. The treatment plan aims to achieve the personal goal. At each follow-up moment, the intervention group will complete the $A B C$ scale and use the $A B C$ tool. The tool will show both the current balloons and the balloons from the previous consultation, displayed in grey (Figure 3.1). The tool can be used to monitor a patient's integrated health status over time and adjust the treatment as necessary.

\section{Control group}

The $A B C$ scale and tool (including its software) will only be provided in the intervention group. The patients in the control group will receive care as usual and their healthcare providers will not be instructed by the research team.

\section{Measurements}

\section{Intervention group}

Patients in the intervention group will receive individualised treatment guided by their integrated health status, as measured predominantly by the $A B C$ scale. Patients will visit their healthcare providers at least four times during the 18 months follow-up. During these consultations, healthcare providers will record lung function, number of exacerbations in the previous year and since previous visit, smoking behaviour, BMI and comorbidity. Table 3.1 shows all items of the integrated health status. Questionnaires will be sent to patients' homes at 0, 3, 6, 9, 12, 15 and 18 months (see Table 3.2). 


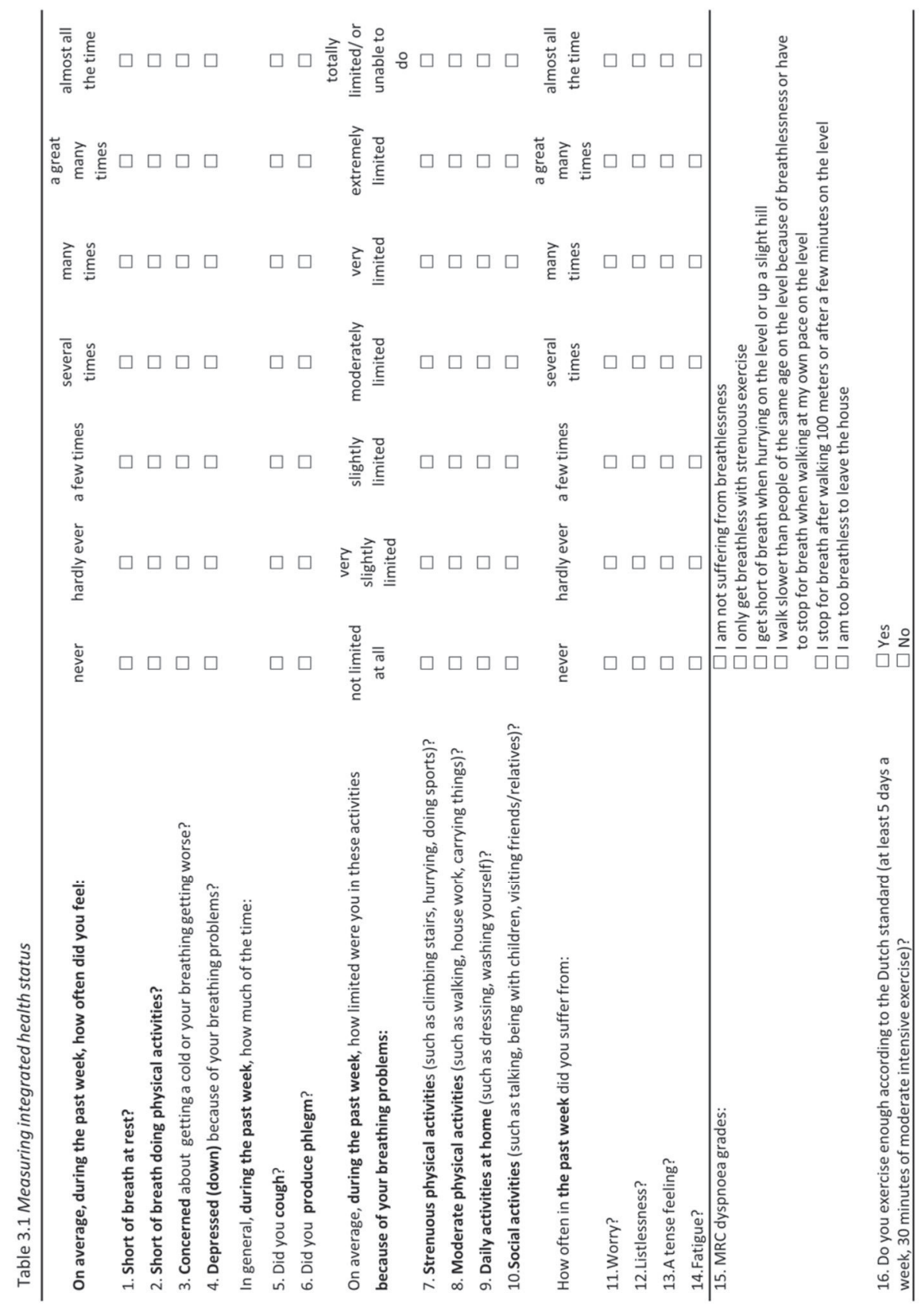


Table 3.1 Continued

17. Smoking status of the patient

18. Number of exacerbations in the previous year / since previous visit

19. Weight (in kilograms) - Height (in centimetres)

20. Relevant comorbidity

21. $\mathrm{FEV}_{1}$ in $\mathrm{ml}-\mathrm{FEV}_{1 \%}$ predicted - FER

*Patients will complete questions 1 to 16.

Healthcare providers will report parameters 17 to 21

$\begin{array}{ll}\text { Domains of the } A B C \text { scale } & \text { Questions } \\ \text { Symptoms } & 1,2,5,6 \\ \text { Functional State } & 7,8,9,10 \\ \text { Mental State } & 3,4 \\ \text { Emotions } & 11,12,13 \\ \text { Fatigue } & 14\end{array}$

\section{Control group}

Patients in the control group will receive care as usual. The patients will visit their healthcare provider for the baseline measurement ( 0 months) and the 18-month follow up. At these consultations lung function and BMI will be measured, and smoking status, comorbidity, number of exacerbations in the previous year and since previous visit will be monitored. Questionnaires will be sent to patients' homes at 0, 3, 6, 9, 12, 15 and 18 months (see Table 3.2).

\section{Outcomes}

\section{Primary outcome}

The primary outcome measure will be the proportion of patients in the intervention group with a clinically meaningful improvement on the SGRQ, ${ }^{19}$ that is, a decrease of at least 4 points between baseline and 18 month follow-up, compared with the control group.

The SGRQ consists of 50 questions with scores that range from 0 (best) to 100 (worst). Higher scores indicate more advanced impairment in health-related quality of life. ${ }^{12}$ 


\section{Time (months)}

$\begin{array}{lllllll}0 & 3 & 6 & 9 & 12 & 15 & 18\end{array}$

\section{Completed by patients at the GP practice or hospital}

Assessment of Burden of

COPD scale*

$\mathrm{X}$

Medical Research Council*

Physical activity*

$x$
$\mathrm{X}$

$\mathrm{X}$

$\mathrm{X}$
$\mathrm{X}$

$\mathrm{X}$

$\mathrm{X}$
$\mathrm{X}$

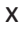

\section{Completed by patients at home}

Demographics

The Saint George

Respiratory Questionnaire

COPD Assessment Test

EuroQol5d-5 level

Questionnaire

Patients Assessment Chronic

Illness Care questionnaire

Healthcare use, medication use

Employment status, absence

from paid work
$\mathrm{X}$

$\mathrm{X}$

X

X

X

$\mathrm{X}$

X

X

$\mathrm{x}$

$x$

$\mathrm{X}$

$x$

X

X

X

X

X

X

X

vention group only

\section{Secondary outcomes}

1. The net proportion of patients in the intervention group with a clinically meaningful change of 4 points on the SGRQ between baseline and 18 month follow-up, ${ }^{19}$ compared with the control group. The net proportion will be calculated by subtracting the percentage of patients improved by 4 points on the SGRQ from the percentage of patients decreased by 4 points.

2. The difference in the proportion of patients from the intervention group and control group with a clinically meaningful improvement of at least 4 points on the SGRQ (a decrease in the SGRQ score), between baseline and 6 months and between baseline and 12 months follow-up.

3. The absolute difference SGRQ score at 18-month follow-up between the intervention group and control group. 
4. Health related quality of life will also be measured by the COPD Assessment Test (CAT). ${ }^{20}$ Differences on total scores will be calculated between baseline and 12 months follow-up and between baseline and 18 months follow-up. The CAT is an eight item questionnaire with scores ranging from 0 to 40 , with higher scores indicating greater impairment of health related quality of life. ${ }^{20}$

Differences in number of exacerbations and lung function, as recorded by the healthcare providers, will be calculated between the two groups, with respect to the number of exacerbations at a given time point and to change over time.

5. An economic evaluation will be performed at 6 and 12 months. This evaluation will compare differences in costs with differences in effects (Cost Effectiveness Analysis) and quality adjusted life years (Cost Utility Analysis).

Questionnaires will be used to record visits to physicians and healthcare providers, medication use, hospital admissions, employment status and absence from paid work every three months. For the economic evaluation, costs will be calculated from a healthcare perspective and a societal perspective.

The EuroQol5d-5 level Questionnaire (EQ-5d-5L) measures the generic healthrelated quality of life. The EQ-5D-5L consists of 5 dimensions to describe health mobility, self-care, every day activities, pain/discomfort and anxiety/depression each with five levels of functioning (e.g. no problems, slight problems, moderate problems, severe problems, unable to/severe problems). ${ }^{21}$ The domain descriptions are combined with population-based values to derive a health utility index. ${ }^{22}$ In addition to the descriptive system and the off-the-shelf value sets, the EQ-5D-5L includes a visual analogue scale (VAS) that individuals can use to rate their own health on a scale from 0 (worst imaginable health) to 100 (best imaginable health).

6. The process evaluation will consist of two parts: patients' evaluation of the level of integrated healthcare will be measured at baseline, 12 months and the final visit (18 months), using the Patients Assessment Chronic Illness Care questionnaire $(\mathrm{PAClC}) .^{23}$ The $\mathrm{PACIC}$ is a 20 item questionnaire, with a five point response scale (ranging from 1 = 'almost never' to 5 = 'almost always'). Higher scores represent a more frequent presence of the aspect of structured chronic care. Furthermore, treatment plans (recorded in the $A B C$ tool) will be compared qualitatively with the delivered care to patients (as reported by the patients).

A process evaluation among healthcare providers includes assessing factors that may have hindered or facilitated the implementation of the $A B C$ tool in the 
management of COPD care. This evaluation, among approximately 10 to 15 participating healthcare providers, will be performed by means of semistructured group interviews and individual interviews. Questions that will be discussed include; "How easy is it to use the ABC-tool?", "How did patients react on the visual display?", and "What barriers did you encounter when using the $A B C$ scale and the $A B C$ tool?". The methods for the process evaluation will be described elsewhere in more detail.

\section{Sample size calculation}

The required sample size of 360 patients (180 patients per arm) is based on the following assumptions:

1) A clinical response (a clinically meaningful improvement of at least 4 points ${ }^{19}$ ) of $50 \%$ in the treated arm versus $30 \%$ in the control $\operatorname{arm}^{24,25}$ (implying an effect size $d=0.42$ for the clinical response), and a power of $80 \%$ to detect a difference in the clinical response rate of the primary outcome between the treated and control arm with a two-tailed alpha of 5\%. This assumption gives a sample size of 180 patients in total (90 patients per arm), ignoring at first the design effect due to clustering of patients within physicians.

2) The number of participating GPs will be about twice as large as the number of pulmonologists.

3) An estimated availability of 5 patients per GP and 8 patients per pulmonologist on average. This, together with assumptions 1 and 2, gives a total of $20 \mathrm{GPs}$ and 10 pulmonologists. However, the following three steps result in a sample size which is twice as large, that is 40 GPs and 20 pulmonologists.

4) An intraclass correlation coefficient (ICC) of 0.05 , meaning that about $5 \%$ of the total outcome variation within each arm is between GPs and between pulmonologists, instead of between patients of the same physician. Literature suggests that an ICC of 0.05 is a good default value for trials in primary care. ${ }^{26-28}$ Combined with assumptions 2 and 3, and allowing for $10 \%$ more clusters (healthcare providers) to compensate the power loss due to variation in cluster size, that is, in number of patients included per healthcare provider, this ICC of 0.05 implies a design effect of $1.38{ }^{29}$ The number of clusters must thus be multiplied with 1.38 . 
5) A dropout rate of $25 \%$ of patients and/or clusters, to be compensated by multiplying the number of clusters to be included by 1.33 (since $75 \%$ of 1.33 is 1). Dropouts will be included into the analyses (intention to treat), but contribute less to the power due to missing data, hence the present correction.

6) Data analysis of the primary outcome with the recommended PQL2 (penalized quasi-likelihood) estimation method which requires a further multiplication of the number of clusters with a factor of $1.10 .^{30}$

Combining assumptions 4,5 and 6 gives a multiplication factor of $1.38 * 1.33 * 1.10=$ 2 for the number of GPs and pulmonologists as computed in steps 1 to 3, leading to the planned sample size of 40 GPs, 20 pulmonologists and 360 patients in total.

\section{Statistical analysis}

All baseline variables and outcomes will be summarised with descriptive tables and, in the case of repeated measures, plotted against time per treatment arm.

The primary and first two secondary outcomes are binary outcomes and will be analysed with mixed logistic regression, using PQL2 or numerical integration as method of estimation.

All quantitative outcomes will be analysed with mixed linear regression, with physician, patient and measurement as three levels at which sampling error occurs, and as predictors treatment arm, time point of measurement, treatment by time interaction, patient demographics and other prognostic variables. Generalised linear mixed models with negative binomial distribution will be used to estimate the adjusted difference in exacerbations. Costs will also be analysed with generalised linear mixed models using a log-normal distribution or gamma distribution. A p-value of $<0.05$ will be considered statistically significant.

All data will be analysed according to the intention-to-treat principle, including all randomised healthcare providers and patients. To prevent missing data, patients will receive reminders for the questionnaires if they do not return the questionnaire within three weeks. If necessary, multiple imputation to cope with missing values will be used. $^{31}$ 


\section{DISCUSSION}

This paper describes the design of a cluster RCT to evaluate the effectiveness of the newly developed $A B C$ tool. The development of the tool was based on the insight that the severity of COPD has to be determined by both the severity of the airway obstruction and the burden of disease. The 2014 guidelines of the Global Initiative for Chronic Obstructive Lung Disease (GOLD), recommend a comprehensive symptom assessment in determining the severity of COPD. ${ }^{17}$ The guidelines also introduced a combined COPD assessment resulting in an ABCD classification. This novel classification integrates symptom severity as measured by $\mathrm{mMRC}^{32} \mathrm{CCQ}^{11}$ or $\mathrm{CAT}^{20}$ versus prognostic indicators of pathophysiologic severity assessed by airflow obstruction and exacerbation history. ${ }^{33}$

The $A B C$ tool offers a different operationalisation of this new approach and goes beyond classification. The strength of the tool is that it provides a profile of scores on many different domains of COPD-related health. The tool not only focuses on the quantification of the burden of COPD, but determines the actual integrated health status.

In addition, it provides a treatment algorithm which gives the patient and healthcare provider insight into treatment options accordingly. The tool offers a visual display of the integrated health status using balloons to show the scores on the different domains of the $A B C$ scale and additional items such as smoking status and exacerbation history.

Furthermore, the algorithm provides treatment advice, including pharmacologic options as well as non-pharmacologic options, to formulate a personalised treatment goal and treatment plan. The tool is designed to provide insight into the patient's individual burden of COPD and therefore enables to make a tailored treatment plan and to make the patient feel co-responsible for their own treatment, using principles of shared decision making. ${ }^{13}$

An important issue during the process of designing the study was the selection of an appropriate primary outcome measure. It is more common to use objective parameters, such as the airway obstruction, as primary outcomes. ${ }^{34}$ However, airway obstruction is hypothesised to correlate poorly with health status and/or quality-oflife. ${ }^{4}$ We therefore decided to use a health-related quality-of-life questionnaire. Since treatment in the intervention arm is based on the outcomes of this new instrument, which is based on the CCQ, a different quality-of-life instrument will be used to 
measure the primary outcome. We decided to use the SGRQ, ${ }^{12}$ a disease-specific quality-of-life instrument. We hypothesise that the use of the $A B C$ tool in daily care will have a positive effect on the quality-of-life of COPD patients. As the CAT is part of the assessment according to the GOLD guidelines, ${ }^{17}$ we decided to use it as a secondary outcome measure.

The trial will be conducted throughout the Netherlands, in both primary and secondary care. This will make it possible to evaluate the effectiveness of the $A B C$ tool on the health status of patients with different COPD severities. Conducting the study in many clusters throughout the Netherlands might lead to a higher external validity of the results. Furthermore, it might help facilitating the process of implementation. If the results of this trial are as expected, it will be advised to implement the $A B C$ tool in routine care. To facilitate this, it is recommended to adopt the tool in the registration systems of healthcare providers and in healthcare standards. Using the tool in routine care provides structure in each consultation, and more insight for patients in all factors related to COPD. It might help healthcare providers to discuss difficult issues with their patients related to COPD, such as emotions, smoking cessation and impact of COPD on daily life. Furthermore, it might lead to more commitment of the patient and taking the lead in their own treatment, increasing their self-management. 


\section{REFERENCES}

1. Vestbo J, Hurd SS, Agusti AG, Jones PW, Vogelmeier C, Anzueto A, Barnes PJ, Fabbri LM, Martinez FJ, Nishimura M, Stockley RA, Sin DD \& Rodriguez-Roisin R. Global strategy for the diagnosis, management, and prevention of chronic obstructive pulmonary disease: GOLD executive summary. Am J Respir Crit Care Med 2013;187:347-365.

2. Lozano R, Naghavi M, Foreman K, Lim S, Shibuya K, Aboyans V, \& et.al. Global and regional mortality from 235 causes of death for 20 age groups in 1990 and 2010: a systematic analysis for the Global Burden of Disease Study 2010. Lancet 2012;380:2095-2128.

3. Mathers CD \& Loncar D. Projections of global mortality and burden of disease from 2002 to 2030. PLoS Med 2006;3:e442.

4. Tsiligianni I, Kocks J, Tzanakis N, Siafakas N \& van der Molen T. Factors that influence diseasespecific quality of life or health status in patients with COPD: a review and meta-analysis of Pearson correlations. Prim Care Respir J 2011;20:257-268.

5. Santo Tomas LH \& Varkey B. Improving health-related quality of life in chronic obstructive pulmonary disease. Curr Opin Pulm Med 2004;10:120-127.

6. Domingo-Salvany A, Lamarca R, Ferrer M, Garcia-Aymerich J, Alonso J, Felez M, Khalaf A, Marrades RM, Monso E, Serra-Batlles J \& Anto JM. Health-related quality of life and mortality in male patients with chronic obstructive pulmonary disease. Am J Respir Crit Care Med 2002;166:680-685.

7. Antonelli-Incalzi R, Pedone C, Scarlata S, Battaglia S, Scichilone N, Forestiere F \& Bellia V. Correlates of mortality in elderly COPD patients: focus on health-related quality of life. Respirology 2009;14:98-104.

8. Fan VS, Curtis JR, Tu SP, McDonell MB \& Finn SD. Using quality of life to predict hospitalization and mortality in patients with obstructive lung diseases. Chest 2002;122:429-436.

9. Slok AHM, In 't Veen JCCM, Chavannes NH, van der Molen T, Rutten-van Mölken MPMH, Kerstjens HAM, Salome PL, Holverda S, Dekhuijzen PNR, Schuiten D, Asijee GM \& van Schayck OCP. Development of the Assessment of Burden of COPD tool: an integrated tool to measure the burden of COPD. npj Prim Care Respir Med 2014;24:14021.

10. Elwyn G, Frosch D, Thomson R, Joseph-Williams N, Lloyd A, Kinnersley P, Cording E, Tomson D, Dodd C, Rollnick S, Edwards A \& Barry M. Shared decision making: a model for clinical practice. $J$ Gen Intern Med 2012;27:1361-1367.

11. Van der Molen T, Willemse BW, Schokker S, Ten Hacken NH, Postma DS \& Juniper EF. Development, validity and responsiveness of the Clinical COPD Questionnaire. Health Qual Life Outcomes 2003;1.

12. Jones PW, Quirk FH \& Baveystock CM. The St George's Respiratory Questionnaire. Respir Med 1991;85:25-31.

13. Makoul G \& Clayman ML. An integrative model of shared decision making in medical encounters. Patient Educ Couns 2006;60:301-312.

14. Kocks J, de Jong C, Berger MY, Kerstjens HAM \& van der Molen T. Putting health status guided COPD management to the test: protocol of the MARCH study. BMC Pulm Med 2013;13:1-9.

15. Smeele IJM, Van Weel C, Van Schayck CP, Van der Molen T, Thoonen B, Schermer T, Sachs APE, Muris JWM, Chavannes NH, Kolnaar BGM, Grol MH \& Geijer RMM. NHG Standaard- COPD [Dutch national guideline COPD in primary care]. 2007;50:362-379.

16. Dekhuijzen PNR, Broeders MEAC, Grol MH \& Tuut MK. Richtlijn Diagnostiek en behandeling van COPD. Kwaliteitsinstituut voor de Gezondheidszorg CBO;2010.

17. From the Global Strategy for Diagnosis, Management and Prevention of COPD, Global Initiative for Chronic Obstructive Lung Disease (GOLD) 2014. Available at http://www.goldcopd.org/.

18. Long Alliantie Nederland. Zorgstandaard COPD. Amersfoort:Long Alliantie Nederland; 2010.

19. Jones PW. St. George's Respiratory Questionnaire: MCID. Copd 2005;2:75-79.

20. Jones PW, Harding G, Berry P, Wiklund I, Chen WH \& Kline Leidy N. Development and first validation of the COPD Assessment Test. Eur Respir J 2009;34:648-654. 
21. Herdman M, Gudex C, Lloyd A, Janssen M, Kind P, Parkin D, Bonsel G \& Badia X. Development and preliminary testing of the new five-level version of EQ-5D (EQ-5D-5L). Qual Life Res 2011;20:1727-1736.

22. van Hout B, Janssen MF, Feng YS, Kohlmann T, Busschbach J, Golicki D, Lloyd A, Scalone L, Kind P \& Pickard AS. Interim scoring for the EQ-5D-5L: mapping the EQ-5D-5L to EQ-5D-3L value sets. Value Health 2012;15:708-715.

23. Glasgow RE, Wagner EH, Schaefer J, Mahoney LD, Reid RJ \& Greene SM. Development and validation of the Patient Assessment of Chronic Illness Care (PACIC). Med Care 2005;43:436-444.

24. Tashkin D \& Kesten S. Long-term treatment benefits with tiotropium in COPD patients with and without short-term bronchodilator responses. Chest 2003;123:1441-1449.

25. Casaburi R, Mahler DA, Jones PW, Wanner A, San PG, ZuWallack RL, Menjoge SS, Serby CW \& Witek T, Jr. A long-term evaluation of once-daily inhaled tiotropium in chronic obstructive pulmonary disease. Eur Respir J 2002;19:217-224.

26. Adams G, Gulliford MC, Ukoumunne OC, Eldridge S, Chinn S \& Campbell MJ. Patterns of intracluster correlation from primary care research to inform study design and analysis. J Clin Epidemiol 2004;57:785-794.

27. Eldridge SM, Ashby D, Feder GS, Rudnicka AR \& Ukoumunne OC. Lessons for cluster randomized trials in the twenty-first century: a systematic review of trials in primary care. Clin Trials 2004;1:80-90.

28. van Breukelen GJ \& Candel MJ. Efficient design of cluster randomized and multicentre trials with unknown intraclass correlation. Stat Methods Med Res 2011;24:540-556

29. van Breukelen GJ \& Candel MJ. Calculating sample sizes for cluster randomized trials: we can keep it simple and efficient! J Clin Epidemiol 2012;65:1212-1218.

30. Candel MJ \& Van Breukelen GJ. Sample size adjustments for varying cluster sizes in cluster randomized trials with binary outcomes analyzed with second-order PQL mixed logistic regression. Stat Med 2010;29:1488-1501.

31. Bodnera TE. What Improves with Increased Missing Data Imputations? Struct Equ Modeling 2008;15:651-675.

32. Bestall JC, Paul EA, Garrod R, Garnham R, Jones PW \& Wedzicha JA. Usefulness of the Medical Research Council (MRC) dyspnoea scale as a measure of disability in patients with chronic obstructive pulmonary disease. Thorax 1999;54:581-586.

33. Hurst JR, Vestbo J, Anzueto A, Locantore N, Mullerova H, Tal-Singer R, Miller B, Lomas DA, Agusti A, Macnee W, Calverley P, Rennard S, Wouters EF \& Wedzicha JA. Susceptibility to exacerbation in chronic obstructive pulmonary disease. N Engl J Med 2010;363:1128-1138.

34. Cazzola M, MacNee W, Martinez FJ, Rabe KF, Franciosi LG, Barnes PJ, Brusasco V, Burge PS, Calverley PM, Celli BR, Jones PW, Mahler DA, Make B, Miravitlles M, Page CP, Palange P, Parr D, Pistolesi M, Rennard SI, Rutten-van Mölken MP, Stockley R, Sullivan SD, Wedzicha JA \& Wouters EF. Outcomes for COPD pharmacological trials: from lung function to biomarkers. Eur Respir $J$ 2008;31:416-469. 


\section{CHAPTER

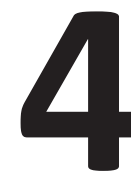

\section{The Assessment of Burden of COPD (ABC) Scale: A Reliable and Valid Questionnaire}

Published as:

Slok AHM, Bemelmans TCH, Kotz D, van der Molen T, Kerstjens HAM, In 't Veen JCCM, Chavannes NH, Asijee GM, Rutten-van Mölken MPMH, Schayck, OCP. The Assessment of Burden of COPD $(A B C)$ scale: a reliable and valid questionnaire. COPD: Journal Of Chronic Obstructive Pulmonary Disease. 2016;13(4):431-438. 


\section{ABSTRACT}

The newly developed Assessment of Burden of COPD (ABC) scale is a 14-item selfadministered questionnaire which measures the physical, psychological, emotional and/or social burden as experienced by patients with chronic obstructive pulmonary disease (COPD). The $A B C$ scale is part of the $A B C$ tool that visualises the outcomes of the questionnaire. The aim of this study was to assess the reliability and construct validity of the $A B C$ scale.

This multi-centre survey study was conducted in the practices of 19 general practitioners and 9 pulmonologists throughout the Netherlands. Next to the $A B C$ scale, patients with COPD completed the Saint George Respiratory Questionnaire (SGRQ).

Reliability analyses were performed with data from 162 cases. Cronbach's alpha was 0.91 for the total scale. Test-retest reliability, measured at a two week interval $(n=137)$, had an intra-class correlation coefficient of 0.92 . Analyses for convergent validity were performed with data from 133 cases. Discriminant and known-groups validity was analysed with data from 162 cases. The $A B C$ scale total score had a strong correlation with the total score of the SGRQ $(r=0.72, p<0.001)$ but a weak correlation with the forced expired volume in 1 second predicted $(r=-0.28, p<0.001)$. Subgroups with more severe disease, defined by GOLD-stage, frequency of exacerbations, activity level and depression scored statistically significantly $(p<0.05)$ worse on almost all domains of the $A B C$ scale than the less severe subgroups.

The $A B C$ scale seems a valid and reliable tool with good discriminative properties. 


\section{INTRODUCTION}

Chronic obstructive pulmonary disease (COPD) is a common preventable and treatable lung disease, characterised by airflow limitation that is not completely reversible. ${ }^{1,2}$ COPD is a major health concern worldwide and is projected to become the number four most important cause of death, and the $7^{\text {th }}$ leading cause of disability-adjusted life years (DALY's) worldwide by 2030, worse than ranks five and eleven in 2002, respectively. ${ }^{3}$

The Dutch care guidelines for the management of COPD have embraced the concept 'burden of disease' to stimulate a holistic assessment of the burden of COPD as experienced by the patient, followed by more personalised care management. ${ }^{4} \mathrm{~A}$ Dutch national expert research team, commissioned by the Dutch Lung Alliance, has defined burden of disease as the physical, psychological, emotional and/or social burden as experienced by the patient, ${ }^{5}$ and this definition encompasses considerably more than airway obstruction alone. To measure the burden of COPD this definition needed to be operationalised into a measurement scale. A questionnaire was deemed to be the most suitable method for this purpose.

The Dutch national expert research team also formulated a number of conditions this questionnaire had to meet to operationalise the burden of disease concept (e.g., it should provide insight in the (pathophysiologic) impairments, disabilities and complaints due to COPD, it should be based on input by patients and it should be easily manageable). A systematic review of the literature was performed for existing COPD quality of life/health status questionnaires, but none of these encompassed all of the aspects of the definition of the burden of COPD and fulfilled all the conditions formulated by the Dutch national expert research team. ${ }^{5}$ However, the Clinical COPD Questionnaire (CCQ), a 10 item self-administered questionnaire encompassed most of these aspects and conditions, and was adapted into the new Assessment of Burden of COPD ( $A B C)$ scale. This new questionnaire was created by combining the 10 items of the CCQ with the 3 items of the Distress-screener (a short screening tool for early identification of distress), ${ }^{6}$ and by adding an item to measure fatigue. ${ }^{5}$ This resulted in a 14-item scale comprised of 5 domains. Each item can be answered using a Likert scale, ranging from 0 (asymptomatic/no limitation) to 6 (extremely symptomatic/total limitation). The sub-score of each of the domains and the total score can be calculated 
by adding the value of the answers and dividing them by the number of items. A low score on the $A B C$ scale indicates a low experienced burden of COPD.

The $A B C$ scale is the core part of the Assessment of Burden of COPD (ABC) tool. This tool visualises the questionnaire scores and adds more objective indicators of the burden of COPD (i.e., smoking status, lung function, exacerbation history) to provide an overview of the individual patient's integrated health status. The questionnaire scores and objective indicators are visualised using balloons. When a patient is doing well on a certain domain, the balloon is shown at the top end in green. When a patient is not doing well, the balloon is shown at the bottom end in red. The scores in between are visualised with orange balloons in different shades. For example, when a patients scores high on the emotion domain, the balloon is shown at the bottom end in red (see Figure 4.1). The tool has been developed to guide patients with COPD and healthcare providers into making a personal treatment plan. It facilitates in shared decision making between patients and healthcare providers and formulating a personal goal. The tool is also supposed to be used to monitor a patient's experienced burden of disease, since the scores of previous visit can also be displayed (in grey balloons; see Figure 4.1, showing a grey balloon at the symptoms domain). This provides the healthcare provider and patient the possibility to discuss progression or deterioration.

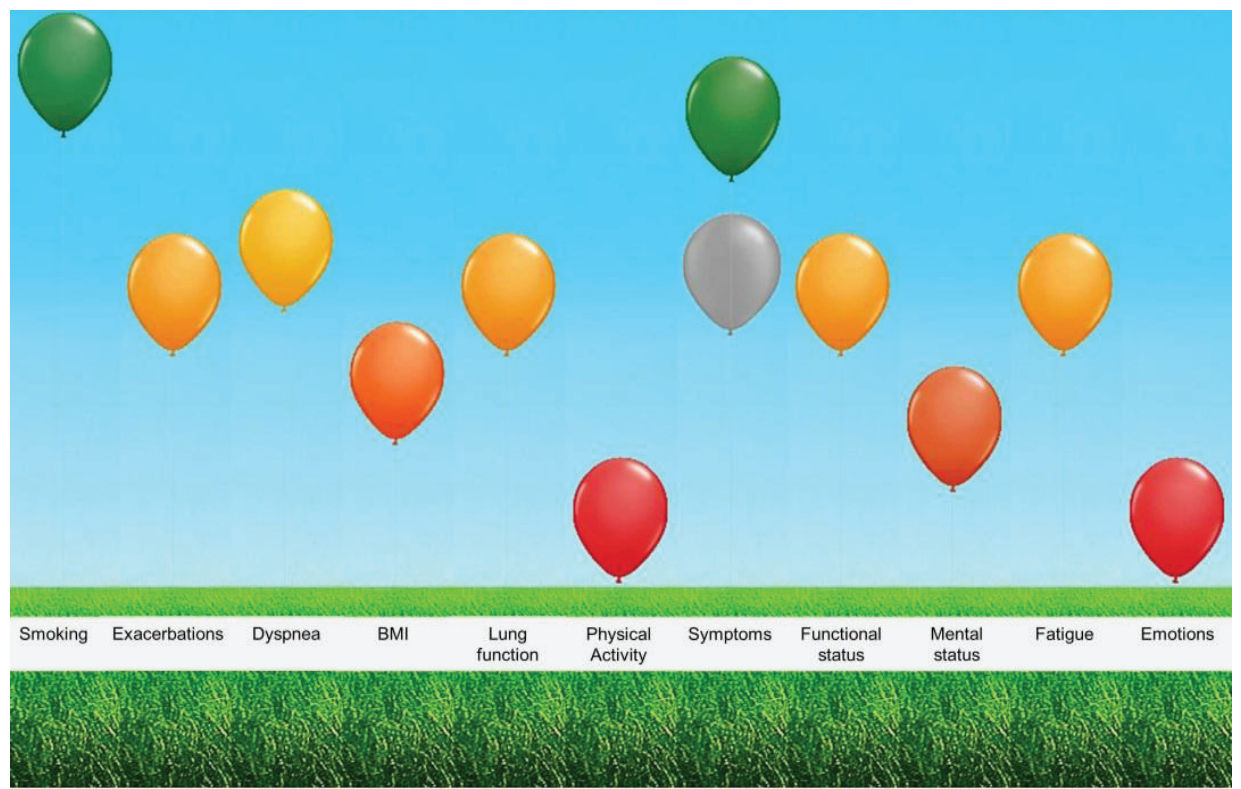

Figure 4.1 Visualisation of the integrated health status, including the five domains of the ABC scale, and including a grey balloon 
Since the scores on the questionnaire determine the position of the balloons, and because four questions were added to the original $\mathrm{CCQ}$, the reliability and validity of the new $A B C$ scale needed to be assessed.

This paper aims to evaluate the $A B C$ scale by:

1. Assessing the internal consistency of the total $A B C$ scale and its individual domains

2. Assessing the test-retest reliability of the $A B C$ scale

3. Assessing the construct validity of the $A B C$ scale

\section{METHODS}

\section{Study design}

This research was part of a large two-armed randomised controlled trial assessing the effectiveness of the Assessment of Burden of Chronic Obstructive Pulmonary Disease $(A B C)$ tool; the study protocol of this cluster randomised trial has been published elsewhere. ${ }^{7}$ The study was approved by the Medical Ethics committee of Zuyderland Hospital, Heerlen, the Netherlands. This research is performed with data collected in the practices of 19 general practitioners and 9 pulmonologists in the Netherlands, who were included in the intervention group of the study.

\section{Setting and subject}

The study population consisted of patients recruited by primary and secondary care providers spread across the Netherlands between 01-02-2013 and 01-10-2013. Inclusion criteria were spirometrically confirmed diagnosis of COPD (post bronchodilator forced expiratory volume in 1 second $\left(\mathrm{FEV}_{1}\right)$ / forced vital capacity $(\mathrm{FVC})<0.7)$, age $>40$ years, and the ability to understand and read Dutch. Exclusion criteria were: exacerbation of COPD less than 6 weeks ago, hard drug addiction, lifethreatening co-morbid condition, and pregnancy.

All patients provided written informed consent prior to participation in the study.

\section{Data collection}

\section{Questionnaires}

Next to the $A B C$ scale, all patients completed the Saint George's Respiratory Questionnaire (SGRQ), ${ }^{8}$ and the Hospital Anxiety and Depression Scale (HADS). ${ }^{9}$ 


\section{$A B C$ scale}

The $A B C$ scale is a 14-item self-administered questionnaire which has recently been developed to measure the burden of COPD. ${ }^{5}$ It has a total score and five domain scores: symptoms (four items), functional status (four items), mental status (two items), emotions (three items) and fatigue (one item). All scores range from 0 to 6 ( $0=$ no burden of disease, $6=$ highest possible burden of disease).

The $A B C$ scale was completed on paper in the waiting room of the practices of the healthcare providers, at two occasions with an interval of two weeks, without supervision. Treatment did not change between these two measurements. With regard to handling missing data, the original rules of the $C C Q,{ }^{10}$ of which the $A B C$ scale is largely composed, were followed and similarly extended to the additional two domains. No missing data was accepted for the mental status and fatigue domains; for the other domains one missing value was tolerated. The score for a single missing item from a subscale was inferred by using the mean of the remaining items in the specific domain of that patient. If the tolerated amount of missing data was exceeded, the domain was judged as invalid, and total score could not be calculated.

The total score of the $A B C$ scale was calculated by adding the sum scores of the five domains and dividing them by five. The domain scores were calculated by adding the items of the domain and dividing them by the number of items of that domain.

SGRQ

The SGRQ, ${ }^{8}$ a 50-item disease-specific health status questionnaire, consists of three different subscales: symptoms (eight items), activity (sixteen items) and impact (twenty-six items), and includes specific item-weights which can be summated and divided by the maximum score to obtain a total score. Each of the sub-scores and the total score range from 0 to $100(0=$ no impairment). Missing data were handled as described in the SGRQ manual. ${ }^{11}$

\section{HADS}

The HADS, a 14-item screening scale for anxiety and depression comprises two subscales: anxiety ( 7 items) and depression ( 7 items). This questionnaire was originally developed for hospital outpatient settings, ${ }^{9}$ but proved valid also for use in general practice patients in the Netherlands. ${ }^{12,13}$ All item-scores range from 0 to 3 ( $0=$ no signs of depression/anxiety). The depression subscale-score is calculated as the sum of the 
depression item scores, and a cut-off score of 8 or higher was used to discriminate between patients with depression or borderline depression and patients with no depression. ${ }^{13}$ Missing data was handled as described in the HADS manual. ${ }^{14}$

The SGRQ and HADS were completed at home, on paper or online (as chosen by the patient).

\section{Other measurements}

Lung function parameters ( $\mathrm{FEV}_{1}$ (in $\mathrm{mL}$ and as percentage (\%) of predicted) and FVC) were measured by the healthcare providers using a spirometer according to the appropriate clinical guidelines. ${ }^{1}$ Data concerning the number of COPD-exacerbations in the past year were recorded by the healthcare providers using the electronic registration program of this study. ${ }^{7}$

\section{Data analysis}

\section{Reliability}

Reliability can be divided into internal consistency and test-retest reliability. ${ }^{15}$

To determine internal consistency, Cronbach's alpha ${ }^{16}$ was calculated for the total ABC scale and for each of the five subscales. Since Cronbach's alpha increases with the number of items of a scale, $\alpha \geq 0.90$ for the 14-item ABC scale was deemed acceptable, as compared to $\alpha \geq 0.70$ for each of the subscales. ${ }^{17}$

The 2-week test-retest reliability was expressed in terms of the intraclass correlation coefficient (ICC). The first measurement was 2 weeks before baseline (T0). No changes in therapy were made between these two moments. A good reliability $(I C C \geq 0.9)^{18,19}$ between both assessments ( $t=0$ and $t=-2$ weeks) was hypothesised for the total score of the $A B C$ scale.

\section{Construct Validity}

Construct validity is defined as 'the degree to which the scores of an instrument are consistent with hypotheses based on the assumption that the Health Relatedquestionnaire validly measures the construct to be measured'. ${ }^{15}$ The assessment of construct validity was subdivided into convergent validity, discriminant validity and known-groups validity. 
For the assessment of convergent validity, it was hypothesised that the $A B C$ scale would show a strong correlation with an established COPD quality of life questionnaire. It would be ideal to compare the $A B C$ scale with a gold standard. ${ }^{20}$ However, since no gold standard for measuring burden of COPD currently exists, the correlation between the total score of the $A B C$ scale and the total score of the SGRQ ${ }^{8}$ was calculated, as is common practice when assessing validity of a COPD quality of life questionnaire. ${ }^{21-23}$ As both the $A B C$ scale and the SGRQ can be regarded health status instruments, it was hypothesised these would show a strong correlation $(r \geq 0.70)^{24}$ when evaluated by Pearson's correlation coefficient.

Since both questionnaires (SGRQ and $A B C$ scale) were administered at different locations at different time points, patients were only included in the analyses if the questionnaires were completed within an interval of one month.

For assessment of the discriminant validity, a weak correlation was presumed with lung function (i.e. $\mathrm{FEV}_{1 \%}$ predicted), similar to findings of earlier studies. ${ }^{25-29}$ It was hypothesised that Pearson's correlation coefficient would be $\leq 0.35 .^{24}$

In case of non-normally distributed data, Spearman's rank correlation coefficient was calculated and an equally weak correlation was assumed.

To test known groups validity, four pairs of groups were created based on (1) the number of exacerbations in the past year ( $\geq 2$ vs $<2$ per year), (2) the disease stage, as defined by the Global Initiative for Chronic Obstructive Lung Disease (GOLD) in $2010^{1}$ (stage $3+4$ vs stage $1+2$, see Table 4.1 ), (3) level of physical activity as assessed by activity subscale of the SGRQ (in-active vs active (median as cut off point)), and (4) depression assessed by the depression subscale of the Hospital Anxiety and Depression Scale (HADS) (depressed or borderline depressed vs non-depressed). ${ }^{9}$ It was hypothesised that: patients with a history of frequent exacerbations would show a statistically significant higher (i.e. worse) score on the symptoms domain of the $A B C$ scale, patients with a higher GOLD classification would show a higher score on the domains functional status and fatigue of the $A B C$ scale, less active patients would score higher on the domain functional status and depressed or borderline depressed patients would show a higher score on the mental state and emotional domains than their respective counterparts. Differences between each group in the known groups analysis were evaluated by performing independent-sample t-tests. In case of nonnormally distributed data, the Mann-Whitney-U test was used. 
A p-value $<0.05$ was considered statistically significant. The software used for statistical analysis was IBM SPSS Statistics version 21.0.

\section{RESULTS}

A total of 173 patients from 19 primary care practices and 9 pulmonology outpatient hospital practices contributed data for the study. Since there were eleven cases missing in one or more variables, analyses for the internal consistency were performed on 162 complete cases. Characteristics of the study population are presented in Table 4.1.

The number of patients that completed both measurements of the ABC scale was 137. Thus, the test-retest reliability analysis was performed with these 137 cases. Analyses for the convergent validity were performed with 133 complete cases who completed the $A B C$ scale and the SGRQ within an interval of one month. Discriminant validity and known-groups validity were analysed with the complete 162 cases.

At baseline, patients' total score on the $A B C$ scale ranged from 0.0 to 4.6 . The scores of the subdomains ranged from 0.0 to 5.0 in the functional status domain, and 0.0 to 6.0 in the other domains.

Table 4.1. Baseline characteristics of the study population ( $n=162)$

\begin{tabular}{|c|c|}
\hline Male sex, $n(\%)$ & $83(51.2)$ \\
\hline Age, years, mean (SD) & $64.2(8.6)$ \\
\hline \multicolumn{2}{|l|}{ Recruiting healthcare provider } \\
\hline General practitioners, $n(\%)$ & $88(54.3)$ \\
\hline Pulmonologist, $n$ (\%) & $74(45.7)$ \\
\hline \multicolumn{2}{|l|}{ Diagnosed COPD since, $n(\%)$} \\
\hline$<1$ year & $11(6.8)$ \\
\hline 1- 3 year(s) & $39(24.1)$ \\
\hline$>3$ years & 99 (61.1) \\
\hline Unknown & $13(8.0)$ \\
\hline $\mathrm{FEV}_{1} / \mathrm{FVC}$ ratio, mean (SD) & $48.7(12.8)$ \\
\hline $\mathrm{FEV}_{1}, \%$ predicted, mean (SD) & $57.2(17.8)$ \\
\hline \multicolumn{2}{|l|}{ GOLD stage, $n(\%)$} \\
\hline $1\left(\mathrm{FEV}_{1}>80 \%\right.$ predicted $)$ & $14(8.6)$ \\
\hline $2\left(\mathrm{FEV}_{1} 50-80 \%\right.$ predicted) & 89 (54.9) \\
\hline 3 (FEV $130-50 \%$ predicted) & $50(30.9)$ \\
\hline $4\left(\mathrm{FEV}_{1}<30 \%\right.$ predicted $)$ & $9(5.6)$ \\
\hline
\end{tabular}


Table 4.1 (continued)

Number of exacerbations/year, $n$ (\%)

0

1

$74(45.7)$

2

$45(27.8)$

$>2$

$21(13.0)$

$22(13.6)$

$A B C$ scale $T 0$, mean (SD)

Total score

$1.71(0.89)$

Symptoms

$2.18(1.07)$

Functional state

$1.68(1.06)$

Mental state

$0.91(1.02)$

Emotions

$1.39(1.13)$

Fatigue

$2.36(1.38)$

ABC scale T- 2 wks, mean (SD)*

Total score

$1.68(0.83)$

Symptoms

$2.11(0.95)$

Functional state

$1.61(1.06)$

Mental state

$0.83(1.00)$

Emotions

$1.47(1.18)$

Fatigue

2.39 (1.35)

SGRQ total score, mean (SD)

39.66 (17.64)

$S G R Q$ activity domain score

$44.46(23.55)$

HADS total score, mean (SD)

$9.45(7.00)$

HADS depression subscale

$4.34(3.61)$

HADS anxiety subscale

$5.11(3.96)$

${ }^{a} \mathrm{SD}=$ standard deviation ${ }^{\mathrm{b}} \mathrm{TO}$ : baseline measurement of $\mathrm{ABC}$ scale together with all other questionnaires (demographics, SGRQ, HADS); T-2wks: measurement of ABC scale only, 2 weeks prior to T0. ${ }^{\mathrm{c}}{ }^{*} \mathrm{n}=137$

\section{Reliability}

\section{Internal Consistency}

Cronbach's alpha was 0.91 (95\% Confidence Interval $(\mathrm{Cl})$ : $0.88,0.93$ ) for the 14 -item $A B C$ scale total score. Internal consistencies of the domains symptoms (4 items), functional status ( 4 items), mental status ( 2 items) and emotions ( 3 items) were 0.76 (95\% Cl: 0.68,0.81), 0.89 (95\% Cl: 0.87,0.92), 0.73 (95\% Cl: 0.64,0.80), 0.87 (95\% Cl: $0.83,0.90)$ respectively. Since the domain fatigue consisted of only one item, no internal consistency could be calculated.

\section{Test-retest reliability}

The ICC was $0.92(95 \% \mathrm{Cl}: 0.88,0.94)$ for the total score of the two consecutive ABC scales taken two weeks apart. 


\section{Construct validity}

\section{Convergent and discriminant validity}

The $A B C$ scale total score and the total score of the SGRQ showed a significant correlation of $r=0.72$ (95\% Cl: $0.61,0.86 ; p$ value: $<0.001)$. The $A B C$ scale score and the $\mathrm{FEV}_{1}$ (\% predicted) showed a significant, but weak, correlation $(r=-0.28(95 \% \mathrm{Cl}:-0.43$, $-0.13 ; p$ value $<0.001$ ). A table including correlations between sub-scores of the domains is available for reference in Table 4.2.

\section{Known group validity}

Results of the known groups analyses are presented in Table 4.3. Patients with a history of frequent exacerbations showed a significantly higher score on the symptoms domain of the ABC scale. Patients with a higher GOLD classification had a significantly higher score on the domain functional state, but not on the domain fatigue. In-active patients had a significantly higher score on the domain functional state. Patients with depression or borderline depression had a significantly higher score on both the mental state and emotions sub-domains.

\section{DISCUSSION}

This study shows a good internal consistency for the total $A B C$ scale and its' individual domains. Furthermore, the test-retest reliability showed an excellent correlation (ICC $=0.92)$ between the measurements with a two-week interval. As hypothesised, the ABC scale correlated strongly with the SGRQ ( $r=0.72)$ and weakly with the $\mathrm{FEV}_{1} \%$ predicted $(r=-0.28) .{ }^{27,30}$ Although, the different domains of the scale had good discriminative properties (compared by median and mean scores), in accordance with our hypothesis, this was not the case for the fatigue domain when patients were grouped according to their GOLD stage. Patients in GOLD stages 3 and 4 did not have a significantly higher score on the fatigue domain than the patients in GOLD stages 1 and 2. Additional analyses however showed a significantly higher score of the fatigue domain in the inactive patients, in the frequent exacerbators and also in depressed and borderline depressed patients, consistent with other studies, ${ }^{31-34}$ see Table 4.3. 


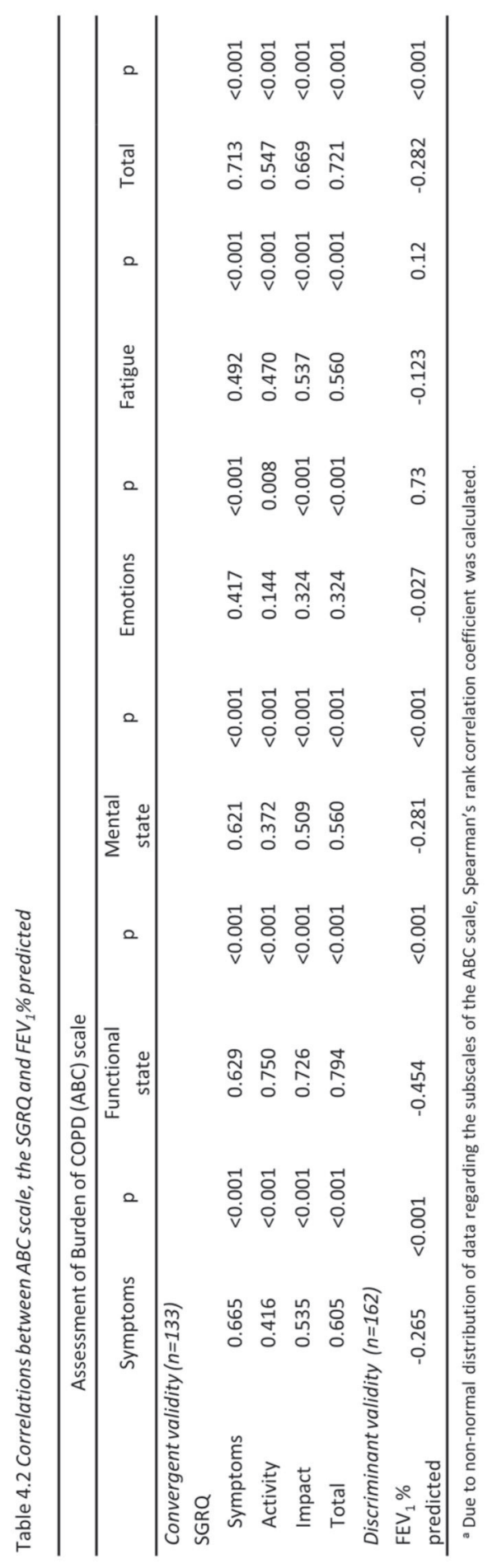




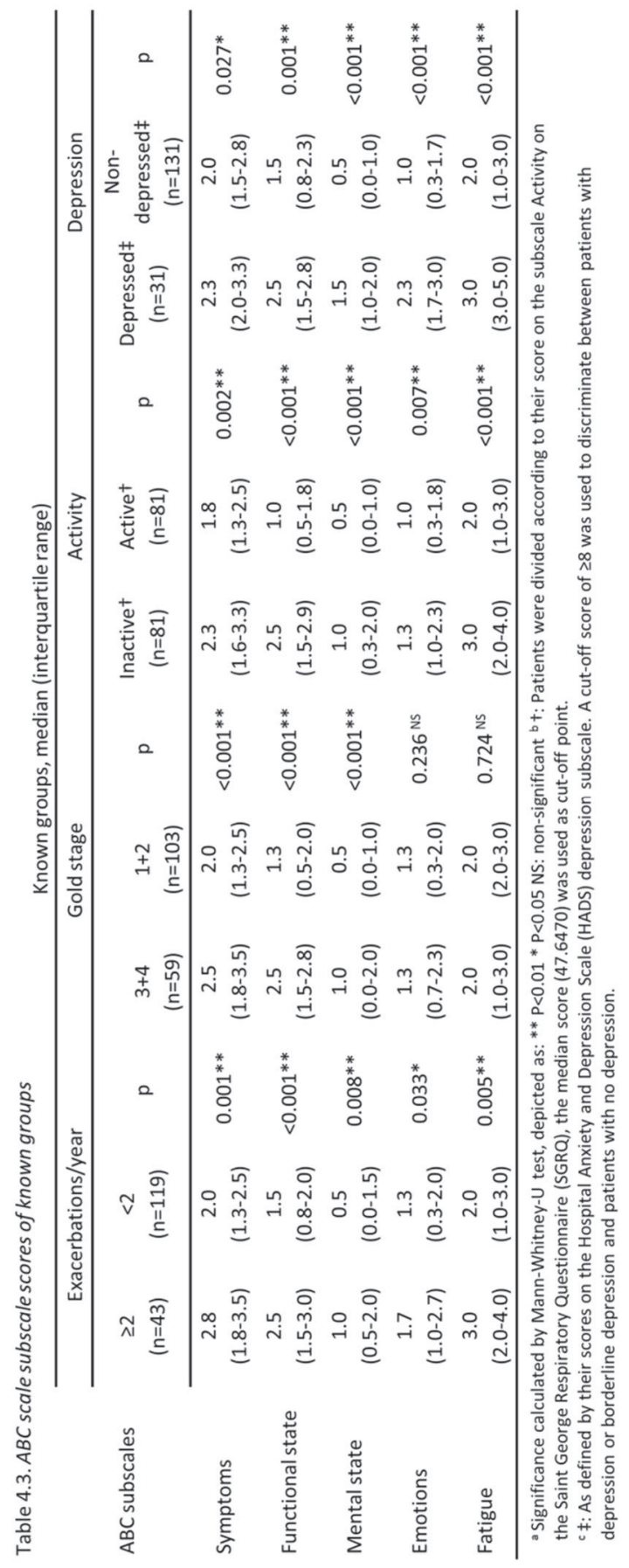


The $A B C$ scale is the first questionnaire that attempts to fully comply with the definition of burden of disease as the physical, psychological, emotional and/or social burden as experienced by the patient. It is an adaptation of the $C C Q$, with the addition of the domains emotions and fatigue. ${ }^{5}$ The addition of the two domains did not change the outcomes of the validity and reliability analyses, as the reported values and correlation coefficients for reliability and validity of the $A B C$ scale were comparable with the values reported in articles assessing the psychometrics of the CCQ. ${ }^{21,23}$

The $A B C$ scale is not developed to replace the $C C Q$ in the measurement of health status in daily clinical practice. The $A B C$ scale is developed to be an important part of the $A B C$ tool. This tool encompasses a visualisation of the scores in terms of a balloondiagram and an algorithm that gives personal treatment advice based on the integrated health status of the patient, defined as the $A B C$ scale score and the additional items; smoking status, exacerbations, dyspnoea (as evaluated by the MRC $\mathrm{scale}^{35}$ ), body mass index (BMI), lung function parameters, and physical activity. Use of the $A B C$ tool facilitates more personalised treatment of COPD. The ABC tool and its relation to the $A B C$ scale are described elsewhere. ${ }^{5}$

\section{Strengths and limitations}

One could argue about the generalisability of the study population. There were relatively few patients with GOLD stage 1 and relatively many GOLD 3 patients as compared to the general COPD population of the Netherlands $(8.6 \%$ vs. $28 \%$ and $30.9 \%$ vs. $15 \%$ respectively). ${ }^{36}$ The most obvious reason for this imbalance is that almost half of the patients were recruited from pulmonologists' practices and therefore had worse lung function parameters, while the majority of the general COPD population of the Netherlands are treated by their primary care physician. This is unlikely to have influenced the results, since there was an adequate number of patients from each of the GOLD stages 1-3, and, as shown, $\mathrm{FEV}_{1}$ on which the GOLD stages are based does not correlate well with burden of COPD.

A possible limitation of this study is the different locations at which the questionnaires were filled out. Due to the design of the study, the SGRQ and the HADS were filled out at home, while the $A B C$ scale was filled out in the waiting room of the healthcare providers practice (but without supervision), also resulting in a different time of 
administration. Since health status changes over time, it would have been ideal to complete both the SGRQ and the ABC scale at the same time point for assessing their correlation. Due to this different time points of administration we only included patients in the analyses with a difference in administration-time of no longer than one month. Analyses with the full sample $(n=162)$ yielded similar results as the sub-sample analyses. The different locations could also have resulted in a different completion behaviour. However, patients came to the practices for their regular monitoringappointment and not specifically for the study. Furthermore, this applied for all patients participating in the study. Another possible limitation of this study is the lack of monitoring the patients' clinical status, in the two weeks between the two measurements to perform the test-retest analysis. We therefore did not have information about whether patients were clinically stable between those two weeks. A major strength is the small number of missing data in the SGRQ and HADS. There were 173 patients who filled out questionnaires, and since only 11 cases missed one or more baseline variables, analyses could be performed with 162 cases. This can partly be explained by the fact that approximately one third of the patients completed the SGRQ and the HADS in an online program, which ensured that patients were unable to continue the questionnaire if questions were left unanswered.

There was a larger amount of missing data for the first ABC-scale that was specifically added to assess the 2-week test-retest analysis (36 cases). This can partly be explained by the two visits to the practice required to fill out both $A B C$-scales. Not every patient filled out this first $A B C$-scale. Another ten of the first $A B C$ scales were lost while being mailed to the researcher. However, there is no reason to believe there is a systematic error due to missing data in all of the analyses.

Another important strength of this study is its sample size $(n=162)$; this is large as compared to the validity testing of the CCQ $(n=119),{ }^{23}$ and especially compared to the test-retest reliability ( $A B C$ scale $n=137, C C Q ; n=20)$. Furthermore, the sample is highly representative for the Dutch COPD population, because the data originated from both primary and secondary care patients which were distributed all over the Netherlands, which decreases any possible regional influence.

\section{Implications for clinical practice/research}

This study shows that the $A B C$ scale has good reliability and validity. It can be deployed within the $A B C$ tool to measure the health status of the patient, to provide 
insight in the personal burden of COPD and to support the development of a personalised treatment plan to decrease this burden. Together with the $A B C$ tool it can be used to facilitate the dialogue about burden of COPD and to evaluate the effectiveness of the interventions.

The responsiveness of the $A B C$ scale needs to be determined to see how the $A B C$ scale score reflects change over time and the effect of treatment interventions. This information is essential for usability in daily practice. A study evaluating these characterisations is currently ongoing.

Additional research will be performed to determine the importance of the items and domains of the $A B C$ scale from a patient's perspective, by means of a Discrete Choice Experiment.

\section{Conclusion}

The $A B C$ scale is a 14-item self-administered questionnaire that measures the burden of disease in patients with COPD. Data presented in this study supports the reliability and convergent and discriminant validity of the $A B C$ scale for use in patients with COPD both in primary care and in secondary care. Known groups analyses showed the ability of the $A B C$ scale to differentiate among different groups of patients. Additional studies regarding the responsiveness and the minimally clinical important difference, are needed before it can be implemented in daily care as a method towards more personalised COPD care. 


\section{REFERENCES}

1. From the Global Strategy for the Diagnosis, Management and Prevention of COPD, Global Initiative for Chronic Obstructive Lung Disease (GOLD). Updated 2016.

http://www.goldcopd.org/uploads/users/files/WatermarkedGlobal\%20Strategy\%202016(1).pdf.

2. Celli BR \& MacNee W. Standards for the diagnosis and treatment of patients with COPD: a summary of the ATS/ERS position paper. Eur Respir J 2004;23:932-946.

3. Mathers CD \& Loncar D. Projections of global mortality and burden of disease from 2002 to 2030. PLoS Med 2006;3:e442.

4. Long Alliantie Nederland. Zorgstandaard COPD. Amersfoort:Long Alliantie Nederland; 2010.

5. Slok AHM, In 't Veen JCCM, Chavannes NH, van der Molen T, Rutten-van Mölken $M P M H$, Kerstjens HAM, Salome PL, Holverda S, Dekhuijzen PNR, Schuiten D, Asijee GM \& van Schayck OCP. Development of the Assessment of Burden of COPD tool: an integrated tool to measure the burden of COPD. npj Prim Care Respir Med 2014;24:14021.

6. Braam C, van Oostrom SH, Terluin B, Vasse R, de Vet HC \& Anema JR. Validation study of a distress screener. J Occup Rehabil 2009;19:231-237.

7. Slok AHM, In 't Veen JCCM, Chavannes NH, van der Molen T, Mölken MPMH, Kerstjens HAM, Asijee GM, Salome PL, Holverda S, Dekhuijzen PNR, Schuiten D, van Breukelen G, Kotz D \& van Schayck OCP. Effectiveness of the Assessment of Burden of Chronic Obstructive Pulmonary Disease $(A B C)$ tool: study protocol of a cluster randomised trial in primary and secondary care. BMC Pulm Med 2014;14:131.

8. Jones PW, Quirk FH, Baveystock CM \& Littlejohns P. A self-complete measure of health status for chronic airflow limitation. The St. George's Respiratory Questionnaire. Am Rev Respir Dis 1992;145:1321-1327.

9. Zigmond AS \& Snaith RP. The Hospital Anxiety and Depression Scale. Acta Psychiatr Scand 1983;67:361-370.

10. Van der Molen T \& Kocks JW. CCQ: Missing Data rule. Available from: http://ccq.nl/?page_id=15.

11. Jones PW \& Forde Y. St George's Respiratory Questionnaire Manual. London:St. George's University of London; 2009.

12. Spinhoven P, Ormel J, Sloekers P, Kempen G, Speckens A \& Hemert Av. A validation study of the Hospital Anxiety and Depression Scale (HADS) in different groups of Dutch subjects. Psychol Med 1997;27:363-370.

13. Bjelland I, Dahl AA, Haug TT \& Neckelmann D. The validity of the Hospital Anxiety and Depression Scale: An updated literature review. J Psychosom Res 2002;52:69-77.

14. GL Assessment, How should missing data be treated? Frequently Asked Questions. Available from: http://www.gl-assessment.co.uk/products/hospital-anxiety-and-depressionscale/hos pital-anxiety-and-depression-scale-faqs\#FAQ4. Accessed on 21-01-2014.

15. Mokkink LB, Terwee CB, Patrick DL, Alonso J, Stratford PW, Knol DL, Bouter LM \& de Vet HC. The COSMIN study reached international consensus on taxonomy, terminology, and definitions of measurement properties for health-related patient-reported outcomes. J Clin Epidemiol 2010;63:737-745.

16. Cronbach L. Coefficient alpha and the internal structure of tests. Psychometrika 1951;16:297334.

17. Cortina JM. What is coefficient alpha? An examination of theory and applications. J Appl Psychol 1993;78:98.

18. Hays RD, Anderson R \& Revicki D. Psychometric considerations in evaluating health-related quality of life measures. Qual Life Res 1993;2:441-449.

19. McGraw KO \& Wong S. Forming inferences about some intraclass correlation coefficients. Psychol Methods 1996;1:30.

20. Terwee CB, Mokkink LB, van Poppel MN, Chinapaw MJ, van Mechelen W \& de Vet HC. Qualitative attributes and measurement properties of physical activity questionnaires: a checklist. Sports Medx 2010;40:525-537.

21. Stallberg B, Nokela M, Ehrs PO, Hjemdal P \& Jonsson EW. Validation of the clinical COPD Questionnaire (CCQ) in primary care. Health Qual Life Outcomes 2009;7. 
22. Jones PW, Harding G, Berry P, Wiklund I, Chen WH \& Kline Leidy N. Development and first validation of the COPD Assessment Test. Eur Respir J 2009;34:648-654.

23. Van der Molen T, Willemse B, Schokker S, Ten Hacken N, Postma D \& Juniper E. Development, validity and responsiveness of the Clinical COPD Questionnaire. Health Qual Life Outcomes 2003;1:13.

24. Taylor R. Interpretation of the correlation coefficient: a basic review. J Diagn Med Sonogr 1990;6:35-39.

25. Rutten-van Mölken M, Roos B \& Van Noord JA. An empirical comparison of the St George's Respiratory Questionnaire (SGRQ) and the Chronic Respiratory Disease Questionnaire (CRQ) in a clinical trial setting. Thorax 1999;54:995-1003.

26. Papadopoulos G, Vardavas Cl, Limperi M, Linardis A, Georgoudis G \& Behrakis P. Smoking cessation can improve quality of life among COPD patients: validation of the clinical COPD questionnaire into Greek. BMC Pulm Med 2011;11:13.

27. Curtis JR, Deyo RA \& Hudson LD. Pulmonary rehabilitation in chronic respiratory insufficiency. 7. Health-related quality of life among patients with chronic obstructive pulmonary disease. Thorax 1994;49:162-170.

28. Hajiro T, Nishimura K, Jones PW, Tsukino M, Ikeda A, Koyama H \& Izumi T. A novel, short, and simple questionnaire to measure health-related quality of life in patients with chronic obstructive pulmonary disease. Am J Respir Crit Care Med 1999;159:1874-1878.

29. Miravitlles M, Molina J, Naberan K, Cots JM, Ros F \& Llor C. Factors determining the quality of life of patients with COPD in primary care. Ther Adv Respir Dis 2007;1:85-92.

30. Nishimura K, Izumi T, Tsukino M \& Oga T. Dyspnea is a better predictor of 5-year survival than airway obstruction in patients with COPD. Chest 2002;121:1434-1440.

31. Baltzan MA, Scott AS, Wolkove N, Bailes S, Bernard S, Bourbeau J \& Maltais F. Fatigue in COPD: prevalence and effect on outcomes in pulmonary rehabilitation. Chron Respir Dis 2011;8:119128.

32. Baghai-Ravary R, Quint JK, Goldring JJ, Hurst JR, Donaldson GC \& Wedzicha JA. Determinants and impact of fatigue in patients with chronic obstructive pulmonary disease. Respir Med 2009;103:216-223.

33. Kapella MC, Larson JL, Patel MK, Covey MK \& Berry JK. Subjective fatigue, influencing variables, and consequences in chronic obstructive pulmonary disease. Nurs Res 2006;55:10-17.

34. Lewko A, Bidgood PL \& Garrod R. Evaluation of psychological and physiological predictors of fatigue in patients with COPD. BMC Pulm Med 2009;9:47.

35. Bestall JC, Paul EA, Garrod R, Garnham R, Jones PW \& Wedzicha JA. Usefulness of the Medical Research Council (MRC) dyspnoea scale as a measure of disability in patients with chronic obstructive pulmonary disease. Thorax 1999;54:581-586.

36. Hoogendoorn M, Feenstra TL, Schermer TR, Hesselink AE \& Rutten-van Mölken MP. Severity distribution of chronic obstructive pulmonary disease (COPD) in Dutch general practice. Respir Med 2006;100:83-8. 


\section{CHAPTER}

\section{Effectiveness of the Assessment of Burden of COPD $(A B C)$ tool on health-related quality of life in patients with COPD: a cluster randomised controlled trial in primary and hospital care}

Published as:

Slok AHM, Kotz D, van Breukelen G, Chavannes NH, Rutten-van Mölken MPMH, Kerstjens HAM, van der Molen T, Asijee GM, Dekhuijzen PNR, Holverda S, Salomé PL, Goossens LMA, Twellaar M, in 't Veen JCCM, van Schayck OCP. Effectiveness of the Assessment of Burden of COPD $(A B C)$ tool on health-related quality of life in patients with COPD: a cluster randomised controlled trial in primary and hospital care. BMJ Open. 2016;6(7):e011519. 


\section{ABSTRACT}

\section{Objective}

Assessing the effectiveness of the Assessment of Burden of COPD (ABC) tool on disease specific quality of life in patients with chronic obstructive pulmonary disease (COPD) measured with the St. George's Respiratory Questionnaire (SGRQ), compared with usual care.

\section{Methods}

A pragmatic cluster randomised controlled trial, in 39 Dutch primary care practices and 17 hospitals, with 357 patients with COPD (post bronchodilator FEV 1 /FVC ratio $<0.7)$, aged $\geq 40$ years, who could understand and read the Dutch language. Healthcare providers were randomly assigned to the intervention or control group. The intervention group applied the $A B C$ tool, which consists of a short validated questionnaire assessing the experienced burden of COPD, objective COPD parameters (eg, lung function) and a treatment algorithm including a visual display and treatment advice. The control group provided usual care. Researchers were blinded to group allocation during analyses. Primary outcome was the number of patients with a clinically relevant improvement in SGRQ score between baseline and 18-month follow-up. Secondary outcomes were the COPD Assessment Test (CAT) and the Patient Assessment of Chronic Illness Care (PACIC; a measurement of perceived quality of care).

\section{Results}

At 18-month follow-up, 34\% of the 146 patients from 27 healthcare providers in the intervention group showed a clinically relevant improvement in the SGRQ, compared with $22 \%$ of the 148 patients from 29 healthcare providers in the control group (OR $1.85,95 \% \mathrm{Cl} 1.08$ to 3.16$)$. No difference was found on the CAT ( -0.26 points (scores ranging from 0 to 40$) ; 95 \% \mathrm{Cl}-1.52$ to 0.99 ). The $\mathrm{PACIC}$ showed a higher improvement in the intervention group ( 0.32 points (scores ranging from 1 to 5 ); $95 \% \mathrm{Cl} 0.14$ to $0.50)$.

\section{Conclusions}

This study showed that use of the $A B C$ tool may increase quality of life and perceived quality of care. 


\section{INTRODUCTION}

Chronic obstructive pulmonary disease (COPD) is a chronic disease with millions of sufferers worldwide. This number is expected to increase, mainly due to an aging population and an increase in smoke exposure in women. ${ }^{1-3}$

COPD has a major impact on daily life and quality of life that goes beyond airway limitation. $^{4-8}$ The Global Initiative for Chronic Obstructive Lung Disease (GOLD) guideline recommends a combined assessment of COPD using the so-called 'ABCD' classification model, which, apart from spirometry, assesses future risk (exacerbations) and current burden/impact of disease using questionnaire data. ${ }^{3}$ However, tools advocated to assess the burden of COPD only measure a limited number of aspects and do not provide a visual display to educate and involve patients in their treatment. Perhaps even more importantly, the way in which to make use of the patient-reported outcomes or the impact of assessing the burden of disease in this way on outcomes of care has not been tested at all. Therefore, the Assessment of Burden of COPD (ABC) tool was developed, ${ }^{9}$ an innovative tool measuring and visualising integrated health status. An important part of the tool is the $A B C$ scale (see Chapter 2, Table 2.2), which is largely based on the Clinical COPD Questionnaire (CCQ), ${ }^{10}$ and which measures the experienced burden of COPD. The CCQ was adapted by adding 4 questions to the existing 10 questions, to comply with the definition of burden of COPD, which was formulated by an expert team and confirmed by patients and healthcare providers. ${ }^{9}$ The $A B C$ scale consists of five domains (ie, symptoms, functional state, mental state, emotions and fatigue), ${ }^{9}$ and shows excellent reliability and validity. ${ }^{11}$ This scale is combined with other parameters (ie, lung function, exacerbations, body mass index, comorbidity, smoking status and self-reported level of physical activity) to assess the integrated health status of a patient with COPD. The $A B C$ tool visualises the outcome (using balloons, see Figure 5.1) and therewith promotes awareness for patient and healthcare provider, and offers a treatment algorithm. Moreover, it provides the opportunity to support personalised care planning including a personal treatment goal. When a balloon is selected, an evidence-based treatment advice is shown, which the patient and healthcare provider can discuss. They can then decide on a treatment plan together through shared decision-making (see Box 5.1). 
The majority of treatment options include lifestyle changes, such as smoking cessation and increasing physical activity, which requires commitment, engagement and selfmanagement skills of patients. ${ }^{12,13}$ The $A B C$ tool can be used as a communication tool in primary and hospital care (ie, in patients with mild/moderate and severe/very severe (OPD), and it also provides the opportunity to monitor progression or deterioration by displaying the balloons of previous visits in grey (see Figure 5.1). We hypothesised that giving patients the possibility and the responsibility in setting personal treatment goals and making their own treatment plan will influence selfmanagement, facilitate and stimulate behavioural change, and eventually lead to an improved quality of life.

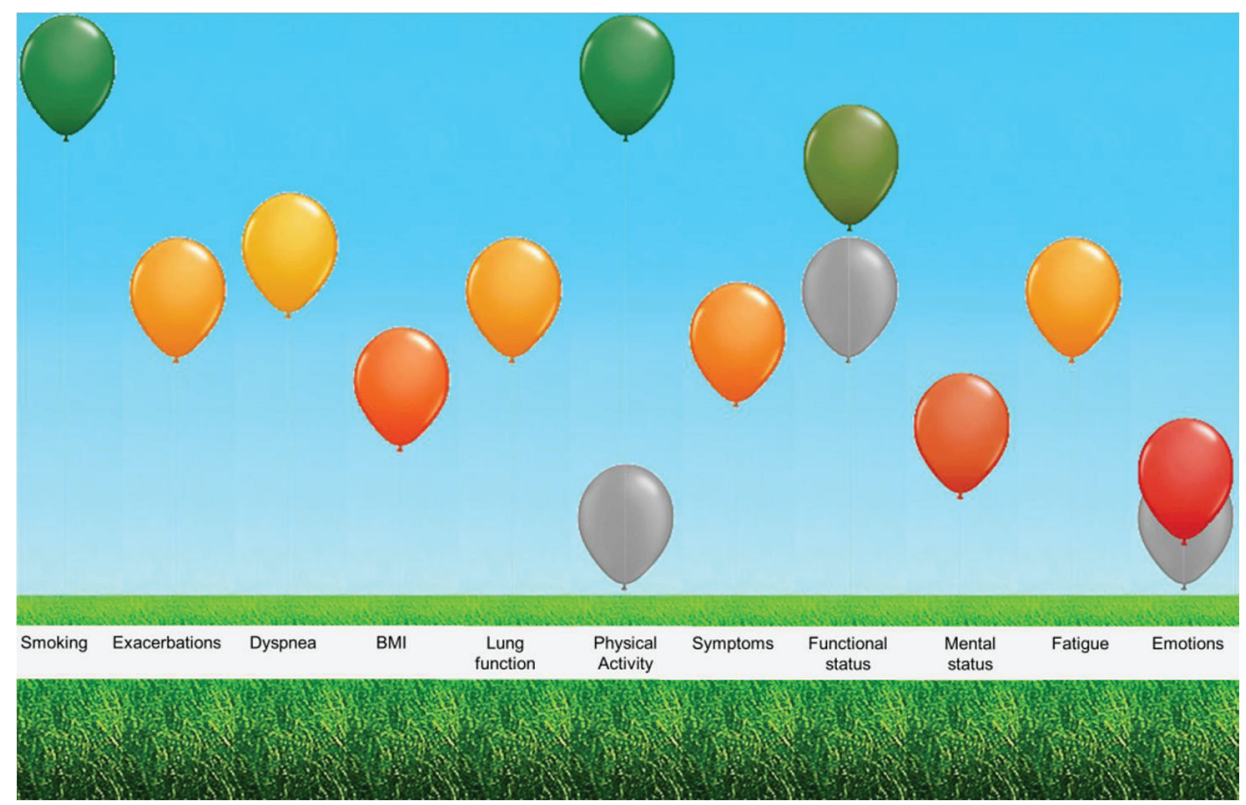

Figure 5.1 Visualisation of the integrated health status of a patient with COPD

The green balloons towards the top of the figure indicate a satisfactory score in that domain, whereas the red balloons signify a low score and orange balloons an intermediate score. Grey balloons are the balloons of previous visits which provide the opportunity to monitor over time. The five domains of experienced burden of COPD, as measured with the $A B C$ scale, are represented by the last five balloons, symptoms, functional status, mental status, fatigue and emotions. Dyspnoea (evaluated by the Medical Research Council (MRC) scale ${ }^{18}$ ) and level of physical activity are also reported by the patients. Smoking status, exacerbations, body mass index (BMI) and lung function are reported by the healthcare providers.

The primary aim of this study was to assess the effectiveness of using the $A B C$ tool in patients with COPD on disease-specific quality of life based on the St. George's Respiratory Questionnaire (SGRQ), ${ }^{14}$ over a period of 18 months compared with a 
control group receiving usual care. Secondary outcomes were quality of life based on the COPD Assessment Test (CAT) ${ }^{15}$ and the patients' perceived quality of care as assessed with the Patient Assessment of Chronic Illness Care (PACIC). ${ }^{16}$

\section{METHODS}

\section{Study design, setting and patients}

The current study was a pragmatic, two-armed, cluster randomised controlled trial, conducted in 56 healthcare centres (39 primary care, 17 hospital care) across the Netherlands from March 2013 to May 2015 (Netherlands Trial Register, NTR3788). Ethics approval was obtained from the Medical Ethics Committee of Zuyderland Hospital, Heerlen, the Netherlands. A detailed protocol of this study has been published elsewhere. ${ }^{17}$ Informed consent was signed by patients prior to enrolment.

Healthcare providers were recruited by the researchers, with no specific criteria or prerequisites. These healthcare providers recruited patients, who were eligible to participate if they had a spirometry-confirmed diagnosis of COPD (post-bronchodilator Forced Expiratory Volume in 1 second $\left(\mathrm{FEV}_{1}\right)$ /Forced Vital Capacity $\left.(\mathrm{FVC})<0.7\right)$, were 40 years of age or over, and could understand and read the Dutch language. Exclusion criteria were as follows: exacerbation $<6$ weeks before initiation of the study, an addiction to hard drugs, a life-threatening comorbid condition or pregnancy at the start of the study. ${ }^{17}$ Eligibility criteria were checked by the healthcare providers.

\section{Randomisation and masking}

We randomised at the level of healthcare providers to prevent contamination. Block randomisation of healthcare centres (random blocks of 2, 4 and 6), stratified by healthcare setting (ie, primary vs hospital care), was performed by the researchers using a computer program developed by the Maastricht University Centre for Data and Information Management (MEMIC). Blinding of healthcare professionals and patients was not possible due to the nature of the intervention, but the study team was blind to the nature of the treatment arms in the dataset. Unblinding was performed after unanimous agreement on data cleaning, handling of missing data, statistical analyses and conclusions drawn for the primary outcome. 


\section{Intervention}

Healthcare providers (ie, general practitioners (GPs), practice nurses, pulmonologists and nurse specialists) were instructed to use the $A B C$ tool during their routine consultations. As described in the study protocol, patients should visit their healthcare providers at least four times during the 18-month follow-up. ${ }^{17}$ Therefore healthcare providers were instructed to invite patients for consultation at least once every 6 months. In each consultation, patients were asked to fill out the $A B C$ scale, ${ }^{9}$ report their dyspnoea using the Medical Research Council (MRC) dyspnoea scale ${ }^{18}$ and selfreport their level of physical activity. Healthcare providers were instructed to obtain some additional parameters (ie, lung function, exacerbations, body mass index, comorbidity and smoking status) and enter these into the computer program. The program displayed the results as balloons (see Figure 5.1 for an example). The colours and altitude of the balloons and corresponding implications could then be discussed, and consequently, patients and healthcare providers could decide on a treatment plan together. Patients were encouraged to formulate a personal treatment goal, in their own words, and a specific treatment plan in accordance with this goal (Box 5.1 provides an example). It was possible to print out an overview of the balloons, the personal goal and the treatment plan at the end of the consultation. The $A B C$ tool is also meant to be used to monitor patients' health status: previous results are displayed using grey balloons, resulting in the possibility to discuss progress and deterioration of different parameters and to evaluate treatment success.

Box 5.1 Example of a patient's personal goal and treatment plan

\section{Patient Ms A:}

This patient completed the ABC scale, the MRC-scale and reported her level of physical activity. Additional parameters were reported by the healthcare provider. The $A B C$ tool is shown in Figure 5.1. The patient decides, together with the GP, to increase her level of physical activity.

Treatment plan:

Patient will raise her level of physical activity. Evaluation in 3 months.

Personal goal:

Walking my dog, three times a day, every day, for at least 15 min each time.

\section{Control}

Healthcare providers in the control group were instructed to provide care as usual to their patients, as described in the Dutch COPD healthcare guidelines. ${ }^{19,20}$ These 
guidelines are in line with guidelines from the European Respiratory Society, the American Thoracic Society ${ }^{4}$ and the GOLD ${ }^{3}$ guideline. The ABC scale and tool were not used in the control group.

\section{Measurements}

Health-related quality of life data were collected at four different points in time: at baseline and at 6-month, 12-month and 18-month follow-up. A set of questionnaires, that is, SGRQ, CAT and PACIC, was sent by the researchers and completed by patients at home without supervision, either on paper or online (as preferred by the patient). Patients received reminders if they had not returned the questionnaires within 3 weeks.

The SGRQ ${ }^{21,22}$ is a disease-specific measure of health status with scores ranging from 0 to 100 (=maximum impairment). Missing data were handled as described in the SGRQ Manual. $^{23}$

The CAT is another disease-specific questionnaire with scores ranging from 0 to 40, where higher scores indicate greater impairment of health-related quality of life. Scores were calculated if no more than two items were missing. ${ }^{15}$

The PACIC is a validated questionnaire that assesses patients' perceptions of the quality of care they have received in the past 6 months. Scores range from 1 to 5 , with higher scores representing higher perceived quality of care. ${ }^{16}$ As no specific missing data rules are provided for the PACIC, it was decided to only include patients in the analyses if at least $50 \%$ of the questions were completed. ${ }^{24}$

Objective parameters (ie, lung function and exacerbations) were entered by the healthcare providers into the registration system developed for this trial. Reminders to report the outcomes were sent twice during the 18-month follow-up.

\section{Outcomes}

The primary outcome measure was a clinically relevant improvement on the SGRQ, ${ }^{14}$ defined as a decrease of at least four points on the total score of the SGRQ between baseline and the 18-month follow-up. 
Secondary outcomes were as follows:

7. Clinically relevant improvement on the SGRQ between baseline and 6 months and between baseline and 12 months.

8. Clinically relevant deterioration on the SGRQ between baseline and 6 months, baseline and 12 months and baseline and 18 months.

9. SGRQ total score at 18 months.

10. CAT score at 18 months.

11. PACIC score at 12 months and at 18 months.

According to our research protocol ${ }^{17}$ two other clinical outcomes were to be used, that is, lung function and exacerbation rate. Data for these analyses had to be reported by healthcare providers. However, in the control group, these data were reported for only one-third of the patients, a problem encountered because of the pragmatic design of the study. Owing to this large amount of missing data it was decided not to address these two outcomes.

\section{Sample size}

The sample size calculation ${ }^{17}$ indicated that a total of 360 patients (180 patients per arm) were required to detect a difference in the response rate on the primary outcome between the intervention and control group (ie, $50 \%$ vs $30 \%$ patients with a clinically relevant improvement of at least four points in the intervention group and control group, respectively ${ }^{14}$ ), with an attrition rate of $25 \%$, a power of $80 \%$ to detect this difference and a two-tailed $\alpha$ of $5 \%$. We estimated that 40 GPs (average of 5 patients per GP) and 20 pulmonologists (average of 8 patients per pulmonologist) were required. A detailed description of the sample size calculation can be found in Chapter 3.

\section{Statistical analyses}

Data were analysed according to the intention-to-treat principle, that is, all available data of all randomised healthcare providers and patients were included in the analysis, using maximum likelihood inference with mixed regression for repeated measures. To address the primary outcome and the first two secondary outcomes (see above), change scores in the SGRQ were calculated by subtracting the baseline score from the scores at the 6-month, 12-month and 18-month follow-up. These change scores were then dichotomised into improved (ie, a decrease of four points or more on the SGRQ total score ${ }^{14}$ ) versus not improved, and into deteriorated (ie, an 
increase of four points or more on the SGRQ total score ${ }^{14}$ ) versus not deteriorated. The relationship between treatment and SGRQ improvement (yes or no) was then analysed with mixed logistic regression, taking into account that the times of measurement (change after 6, 12 and 18 months) were nested within patients, and patients were nested within healthcare providers (three levels). Treatment arm (ie, intervention group vs control group), time, treatment by time interaction and covariates were incorporated into the model as predictors. Covariates included in the analyses were age, sex, smoking status at baseline and healthcare setting (ie, primary care vs hospital care). This analysis was repeated three times for the outcome clinically relevant SGRQ improvement yes/no, with 18 months (primary outcome) and 6 and 12 months (secondary outcomes) as reference time points, respectively, in order to estimate and test the treatment effect in a simple way for each time point (primary: 18 months, secondary: 6 and 12 months).

The same analyses were repeated for the outcome clinically relevant SGRQ deterioration yes/no.

To address the other secondary outcomes -the SGRQ total score, CAT total score and PACIC total score- analyses were performed with mixed linear regression, with cluster, patient and measurements as three levels. Predictors used in the model were time using dummy coding with baseline as the reference category, and dummy indicators for the 12-month and 18-month follow-up, and for SGRQ and CAT also a dummy indicator for the 6-month follow-up, treatment by time interaction and the same covariates as mentioned above. The interaction effect of treatment with the dummy indicator for 18 months represents the group difference in change from baseline to 18 months, and likewise for the other two treatment by time dummy interaction terms. Further, given that baseline is the reference time point, the treatment effect itself is the group difference at baseline ( 0 months), which can be expected to be zero due to the randomised treatment assignment. If this treatment effect was indeed not significant, then it was removed from the mixed model. The treatment by time interaction effect then became equivalent to the treatment effect at follow-up adjusted for the baseline as a covariate. ${ }^{25-27}$

The primary treatment effect and the effect on improvement after 6 and 12 months were tested using $\alpha=0.05$ (two-tailed) following the protocol. However, in view of multiple testing, treatment effects on the other secondary outcomes were required to 
be significant at $\alpha=0.01$. All analyses were performed using IBM SPSS Statistics for Windows, version 21.0.

\section{Sensitivity analyses}

For the purpose of sensitivity analysis for the primary outcome, a mixed logistic regression analysis was also performed on only those patients for whom an SGRQ score at baseline and at 18 months had been recorded, allowing computation of change without borrowing information from other patients or other points in time in case of a missing value at 18 months. Hence, patients were nested in clusters and the dependent variable was a dichotomous change score at 18 months (ie, improved vs not improved). The results of this analysis were compared with those of the intentionto-treat analysis including all available measurements of all patients.

\section{RESULTS}

A total of 62 healthcare providers were randomised into the two treatment groups: 42 from primary care and 20 from hospital care. Three healthcare providers from primary care and three from hospital care did not include any patients. Figure 5.2 shows the study flowchart with the number of healthcare providers and patients included in the study and randomised in the intervention or control group. In the intervention group the average age of the healthcare providers was 50.4 years $(S D=8.3)$ and in the control group it was 50.3 years ( $S D=7.5)$. The average number of years of work experience with patients with COPD in the intervention group was 15.1 years $(S D=8.9)$ and in the control group it was 11.6 years $(S D=7.5)$. In the intervention group and control group the numbers of male healthcare providers were six and nine, respectively.

Thirteen patients dropped out before the baseline measurement and were excluded from the analyses. A total of 357 patients completed at least one set of questionnaires. At 18 months, 305 patients, from 56 clusters, completed the study (of these 305 patients 11 patients did not complete the SGRQ at baseline).

The baseline characteristics of the 357 patients included in the intervention group and control group are shown in Table 5.1. Patients from the intervention group showed a somewhat lower $\mathrm{FEV}_{1} / \mathrm{FVC}$ ratio, and $\mathrm{FEV}_{1} \%$. 


\section{Intervention compliance}

To check for intervention compliance, we looked at the number of times the $A B C$ scale was completed, the number of times a treatment plan was made and the number of times a personal goal was formulated per patient according to the registration system of the $A B C$ tool (example in Figure 5.1 and Box 5.1). On average, in 18 months patients completed the $A B C$ scale 2.7 times $(S D=1.3)$. Furthermore, on average, a treatment plan was recorded 2.4 times $(S D=1.3)$, and a personal goal was formulated 2.3 times $(\mathrm{SD}=1.3)$.

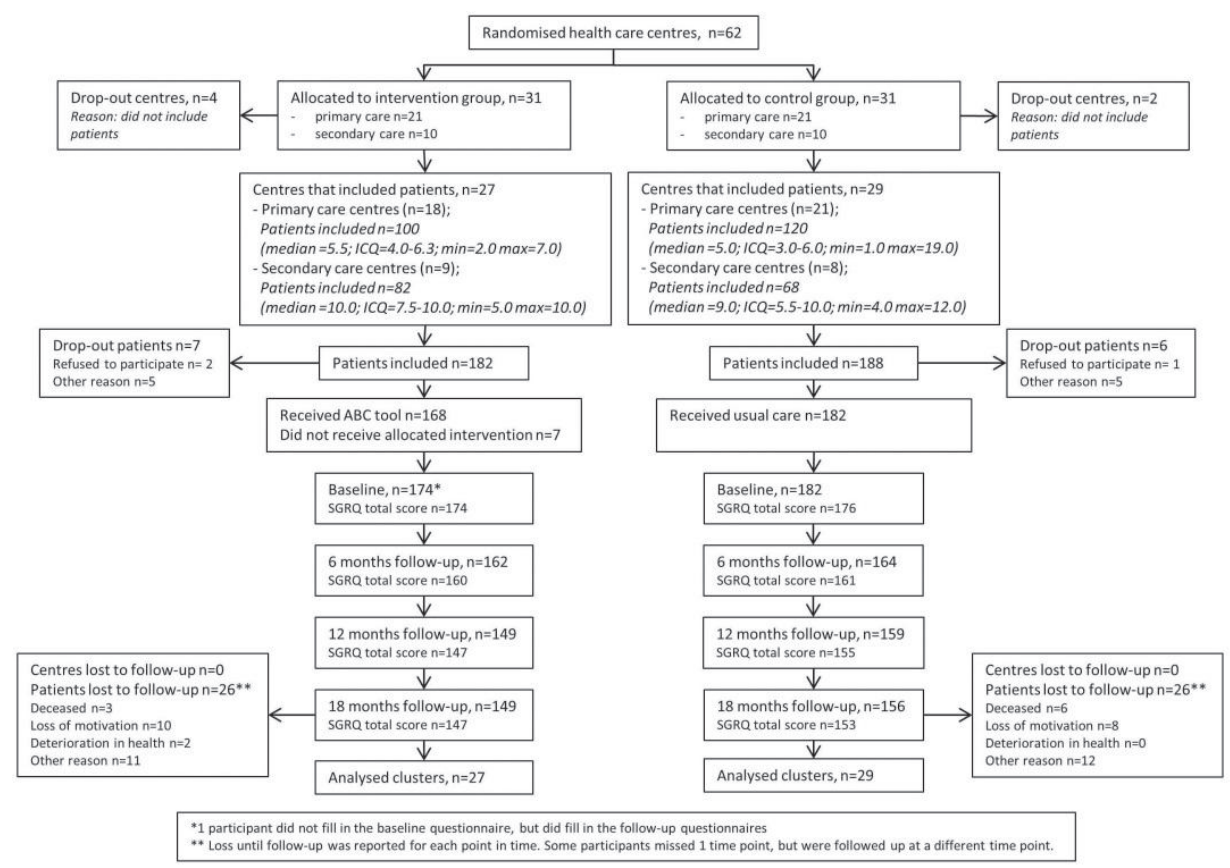

Figure 5.2 Flowchart of patients in the study 
Table 5.1 Patients' baseline characteristics

\begin{tabular}{|c|c|c|}
\hline & $\begin{array}{l}\text { Intervention } \\
\text { group }(n=175)\end{array}$ & $\begin{array}{l}\text { Control group } \\
(n=182)\end{array}$ \\
\hline Age, years, mean (SD) & $64.8(8.7)$ & $65.8(8.8)$ \\
\hline Sex, male, \% (n) & $52.6(92)$ & $60.4(110)$ \\
\hline \multicolumn{3}{|l|}{ Recruiting healthcare provider } \\
\hline Primary care, $\%(n)$ & $54.9(96)$ & $63.7(116)$ \\
\hline Hospital care, \% (n) & $45.1(79)$ & $36.3(66)$ \\
\hline $\mathrm{FEV}_{1} / \mathrm{FVC}$ ratio, mean (SD) & $48.5(12.8)$ & $52.1(11.8)$ \\
\hline $\mathrm{FEV}_{1}, \%$ predicted, mean (SD) & $56.6(17.8)$ & $62.3(19.8)$ \\
\hline \multicolumn{3}{|l|}{ GOLD stage, $\%(n)$} \\
\hline $1\left(\mathrm{FEV}_{1}>80 \%\right.$ predicted $)$ & $8.6(15)$ & $17.0(31)$ \\
\hline $2\left(\mathrm{FEV}_{1} 50-80 \%\right.$ predicted $)$ & $48.6(85)$ & $46.7(85)$ \\
\hline $3\left(\mathrm{FEV}_{1} 30-50 \%\right.$ predicted) & $30.9(54)$ & $24.2(44)$ \\
\hline $4\left(\mathrm{FEV}_{1}<30 \%\right.$ predicted $)$ & $5.1(9)$ & $2.7(5)$ \\
\hline Missing & $6.9(12)$ & $9.3(17)$ \\
\hline \multicolumn{3}{|l|}{ Diagnosed with COPD since, $\%$ (n) } \\
\hline $1-3$ year(s) & $33.1(58)$ & $26.4(48)$ \\
\hline$>3$ years & $62.3(109)$ & $67.0(122)$ \\
\hline Unknown & $4.6(8)$ & $6.6(12)$ \\
\hline \multicolumn{3}{|c|}{ Number of exacerbations in last year, \% (n) } \\
\hline 0 & $44.0(77)$ & $49.5(90)$ \\
\hline 1 & $26.3(46)$ & $24.7(45)$ \\
\hline 2 & $12.0(21)$ & $10.4(19)$ \\
\hline$>2$ & $13.7(24)$ & $7.7(14)$ \\
\hline Missing & $4.0(7)$ & 7.7 (14) \\
\hline \multicolumn{3}{|l|}{ Smoking status, \% (n) } \\
\hline Current smoker & $32.6(57)$ & $24.7(45)$ \\
\hline Ex-smoker & $60.0(105)$ & $60.4(110)$ \\
\hline Never smoked & $5.1(9)$ & $4.4(8)$ \\
\hline Missing & $2.3(4)$ & $10.4(19)$ \\
\hline Pack-years smoking, mean (SD) & $33.2(28.3)$ & $30.8(23.7)$ \\
\hline \multicolumn{3}{|l|}{ Baseline SGRQ, mean (SD) } \\
\hline Symptoms & $49.9(22.2)$ & $44.2(25.5)$ \\
\hline Activity & $44.6(23.8)$ & $41.4(24.3)$ \\
\hline Impact & $24.6(14.7)$ & $22.8(15.1)$ \\
\hline Total & $39.7(17.8)$ & $36.2(19.3)$ \\
\hline
\end{tabular}




\section{Primary outcome: improvement after 18 months}

In the intervention group, 49 (33.6\%) patients showed a clinically relevant improvement, as defined by an improvement of at least four points, on the SGRQ after 18 months, compared with $33(22.3 \%)$ patients in the control group. The adjusted odds of a clinically relevant improvement after 18 months was 1.85 times as high ( $95 \% \mathrm{Cl} 1.08$ to $3.16, \mathrm{p}=0.02$ ) in the intervention group as in the control group (Figure 5.3). The outcome variation between care providers was 0.035 ( $p=0.75$ ), giving an intraclass correlation coefficient (ICC) of 0.01 according to the ICC definition for binary outcomes in Hedeker. ${ }^{28}$

As sensitivity analysis, a mixed logistic regression analysis was subsequently performed with the 294 cases with complete data on the SGRQ at baseline and after 18 months, disregarding the measurements after 6 and 12 months, so that clinical improvement was solely based on SGRQ at baseline and after 18 months, without borrowing information from other points in time or patients. This analysis yielded similar results as the previously mentioned mixed logistic, repeated-measures analysis of the primary analysis (adjusted OR $1.78,95 \% \mathrm{Cl} 1.02$ to $3.10, \mathrm{p}=0.04$ ).

Furthermore, since there seemed to be an imbalance between groups at baseline with respect to $\mathrm{FEV}_{1 \%}$ and the $\mathrm{FEV}_{1} / \mathrm{FVC}$ ratio, we repeated the primary intention-to-treat analysis with $\mathrm{FEV}_{1 \%}$ predicted and $\mathrm{FEV}_{1} / \mathrm{FVC}$ ratio added to the model as covariates. This analysis also resulted in significantly higher odds of improvement for the intervention group (adjusted OR $1.90,95 \% \mathrm{Cl} 1.07$ to $3.38, \mathrm{p}=0.03$ ).

\section{Secondary outcomes}

\section{Improvement in SGRQ}

After 6 months, there was no statistically significant difference between groups with respect to the proportion of patients with a clinically relevant improvement in SGRQ (adjusted $\mathrm{OR}=1.30,95 \% \mathrm{Cl} 0.79$ to $2.13, \mathrm{p}=0.30$ ). After 12 months, the adjusted odds of a minimal clinically relevant improvement in SGRQ was 2.03 times as high $(95 \% \mathrm{Cl}$ 1.20 to $3.41, p<0.01$ ) in the intervention group as in the control group (see Figure 5.3).

\section{Deterioration in SGRQ}

The adjusted odds ratio of the outcome clinically relevant deterioration in SGRQ was 0.96 after 6 months $(95 \% \mathrm{Cl} 0.59$ to $1.58, \mathrm{p}=0.87)$. After 12 months, the adjusted odds of a deterioration in the intervention group was 0.60 times as small as in the control group $(95 \% \mathrm{Cl} 0.36$ to $1.00, \mathrm{p}=0.04)$. After 18 months the difference between the 
intervention group and the control group was in the same direction as the difference after 12 months (adjusted $\mathrm{OR}=0.64,95 \% \mathrm{Cl} 0.39$ to $1.04, \mathrm{p}=0.07$; see Figure 5.3 ).

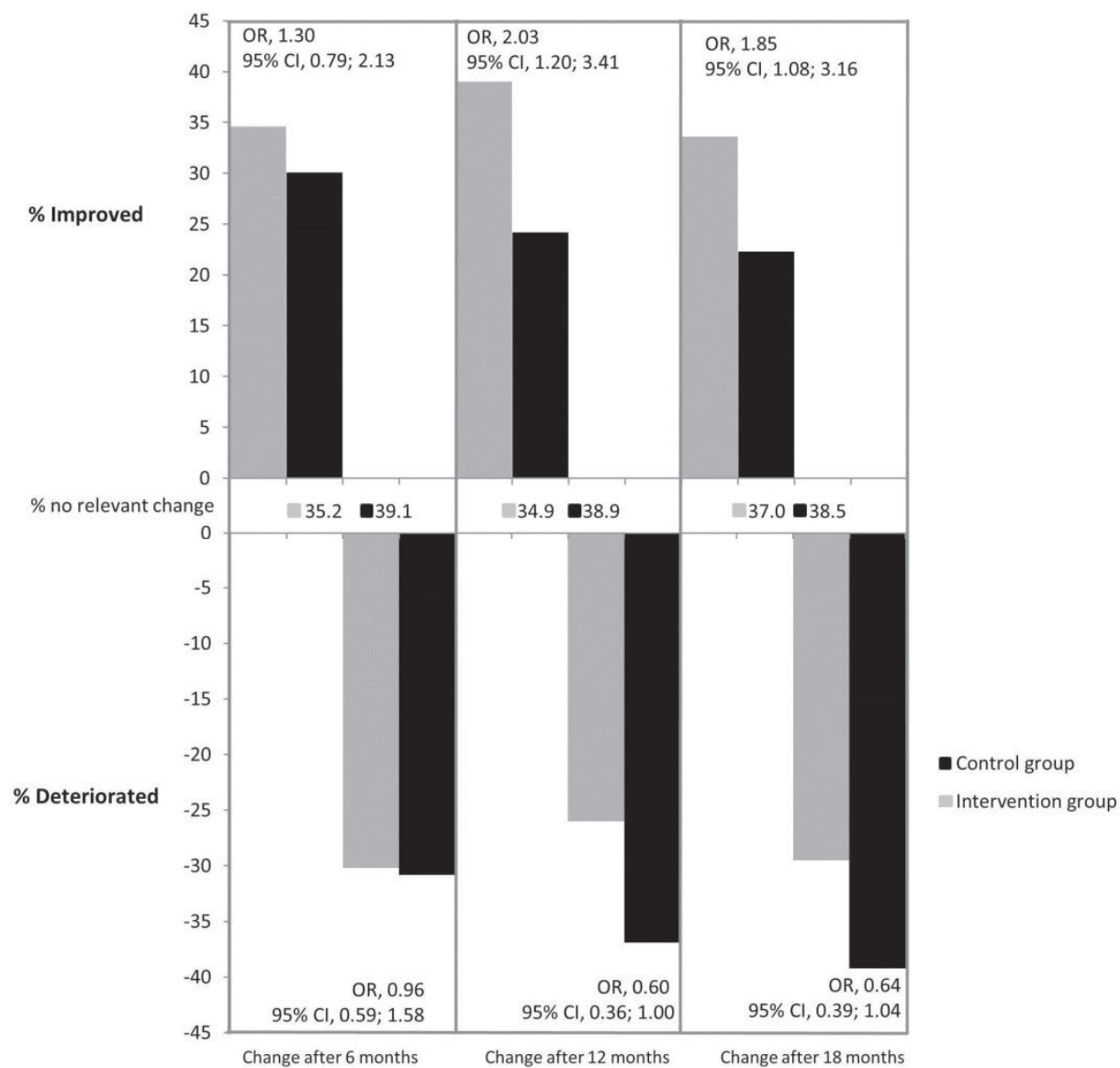

Figure 5.3 Comparison of clinically relevant improvement and deterioration on the SGRQ, after 6, 12 and 18 months between the intervention and control group.

\section{$S G R Q$ (continuous score)}

Table 5.2 shows the difference between treatment arms with respect to SGRQ total score and domain scores at 6-month, 12-month and 18-month follow-up, based on the final mixed model, that is, after deleting the group effect at baseline, which was not significant ( $p=0.195$; for details, see the Statistical Analyses paragraph in the Methods section). There was no significant difference between treatment arms on the total score after 6 months ( -0.90 points, $95 \% \mathrm{Cl}-2.85$ to $1.05, p=0.37)$, but there was a 
significant difference after 12 months ( -2.96 points, $95 \% \mathrm{Cl}-4.99$ to $-0.93, \mathrm{p}<0.01)$ and after 18 months (-3.08 points, $95 \% \mathrm{Cl}-5.36$ to $-0.80, \mathrm{p}<0.01)$. There was no outcome variation between healthcare providers, giving an ICC of 0.00 . These results indicate that treatment according to the $A B C$ tool was associated with better quality of life.
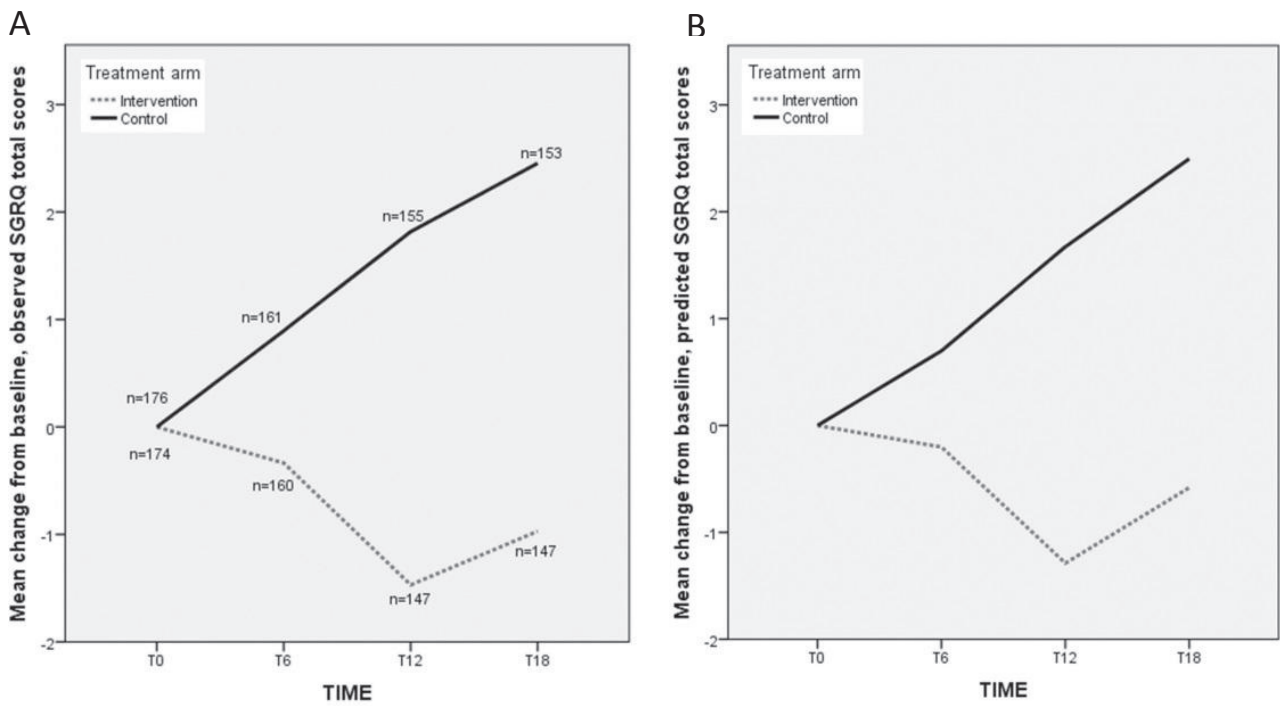

Figure 5.4 (A) Mean change in observed SGRQ total scores at 6-month, 12-month and 18-month follow-up compared with baseline, with a higher score indicating worse quality of life. (B) Mean change in predicted SGRQ total scores at 6-month,12-month and 18-month follow-up compared with baseline, with a higher score indicating worse quality of life.

For completeness, we mention that the mixed regression analysis with the treatment effect at baseline still in the model gave very similar effect sizes and the same conclusions about the significance of each effect.

Figure 5.4A shows the change of the observed means in SGRQ total score after 6month, 12-month and 18-month follow-up compared with baseline measurement, for both groups. Since observed means can be biased due to dropout, Figure 5.4B shows the change in predicted values based on the mixed regression model, which is much less prone to selection bias. The two plots showed almost the same pattern, that is, an increase in group difference in favour of intervention up to month 12 and maintenance of that difference till 18 months. 
Additional analyses of the subdomains of the SGRQ showed that, after 18 months, the intervention group had a better score on the symptom domain $(-4.52$ points, $95 \% \mathrm{Cl}$ -8.15 to $-0.89, p=0.015)$. However, this was just short of significance when taking the more stringent significance level of $1 \%$ into account. There was a significant difference in favour of the intervention group on the subdomain impact $(-2.59$ points, $95 \% \mathrm{Cl}$ -4.66 to $-0.52, p=0.01)$, but not on the activity domain $(-2.34$ points, $95 \% \mathrm{Cl}-5.52$ to $0.83, p=0.15)$.

Table 5.2 Effect of treatment ( $A B C$ tool) on the total score and subdomains of the SGRQ at different points in time, as established with mixed linear regression correcting for age, gender, healthcare setting, and smoking status, $n=334$

\begin{tabular}{|c|c|c|c|c|c|c|}
\hline & \multirow{2}{*}{$\begin{array}{l}\text { Observed score } \\
\text { in intervention } \\
\text { group, mean } \\
\text { (SD) }\end{array}$} & \multirow{2}{*}{$\begin{array}{c}\text { Observed } \\
\text { score in } \\
\text { control group, } \\
\text { mean (SD) }\end{array}$} & \multirow[b]{2}{*}{$\beta^{*}$} & \multicolumn{2}{|c|}{$95 \% \mathrm{Cl}$} & \multirow[b]{2}{*}{$\mathrm{p}$ Value } \\
\hline & & & & Lower & Upper & \\
\hline \multicolumn{7}{|c|}{ SGRQ symptoms } \\
\hline 6 months & $48.81(22.83)$ & 43.15 (26.19) & -0.83 & -3.95 & 2.30 & 0.602 \\
\hline 12 months & $44.65(21.58)$ & $45.63(26.27)$ & -5.50 & -8.92 & -2.07 & 0.002 \\
\hline 18 months & 46.16 (23.69) & $45.33(26.46)$ & -4.52 & -8.15 & -0.89 & 0.015 \\
\hline \multicolumn{7}{|l|}{ SGRQ activity } \\
\hline 6 months & $45.35(24.54)$ & $43.36(25.96)$ & -0.86 & -3.74 & 2.02 & 0.557 \\
\hline 12 months & $44.66(24.92)$ & $43.62(26.86)$ & -1.12 & -4.00 & 1.77 & 0.447 \\
\hline 18 months & 44.23 (26.59) & $43.72(27.45)$ & -2.34 & -5.52 & 0.83 & 0.147 \\
\hline \multicolumn{7}{|l|}{ SGRQ impact } \\
\hline 6 months & $25.45(16.24)$ & 23.14 (15.92) & 0.23 & -1.82 & 2.29 & 0.822 \\
\hline 12 months & $24.43(15.94)$ & 24.51 (15.59) & -1.46 & -3.42 & 0.50 & 0.144 \\
\hline 18 months & $23.86(15.58)$ & $24.68(17.36)$ & -2.59 & -4.66 & -0.52 & 0.014 \\
\hline \multicolumn{7}{|c|}{ SGRQ total score } \\
\hline 6 months & $39.88(20.29)$ & 36.79 (20.29) & -0.90 & -2.85 & 1.05 & 0.365 \\
\hline 12 months & $37.91(18.33)$ & $38.10(20.80)$ & -2.96 & -4.99 & -0.93 & 0.004 \\
\hline 18 months & 38.39 (19.26) & $37.84(21.92)$ & -3.08 & -5.36 & -0.80 & 0.008 \\
\hline
\end{tabular}

$* \beta=$ mixed linear regression weight for treatment at that point in time. $\beta<0$ indicates a lower score in the intervention group. Lower scores or negative change scores indicate a higher quality of life based on the SGRQ. Effects in this table are based on the mixed model after deleting the treatment effect at baseline, which was never significant. Effects before deleting the treatment effect were very similar and agreed with the present table in terms of significance yes/no. 


\section{COPD Assessment Test}

The total CAT scores of the treatment groups after 18 months did not differ significantly from each other ( -0.26 points: $95 \% \mathrm{Cl}-1.52$ to $0.99, p=0.68)$. There was no outcome variation between healthcare providers, thus yielding an ICC of 0.00 .

\section{Patient Assessment of Chronic Illness Care}

The analyses of the PACIC total score showed that treatment had a significant effect after 18 months on the total score of 0.32 points $(95 \% \mathrm{Cl} 0.14$ to $0.50, p<0.01$; see Table 5.3). The outcome variation between healthcare providers was $0.886(p=0.08)$, yielding an ICC of 0.05 .

Table 5.3 Effect of treatment ( $A B C$ tool) on the total score and subdomains of the PACIC at different points in time, as established with mixed linear regression correcting for age, gender, healthcare setting, and smoking status, $n=331$

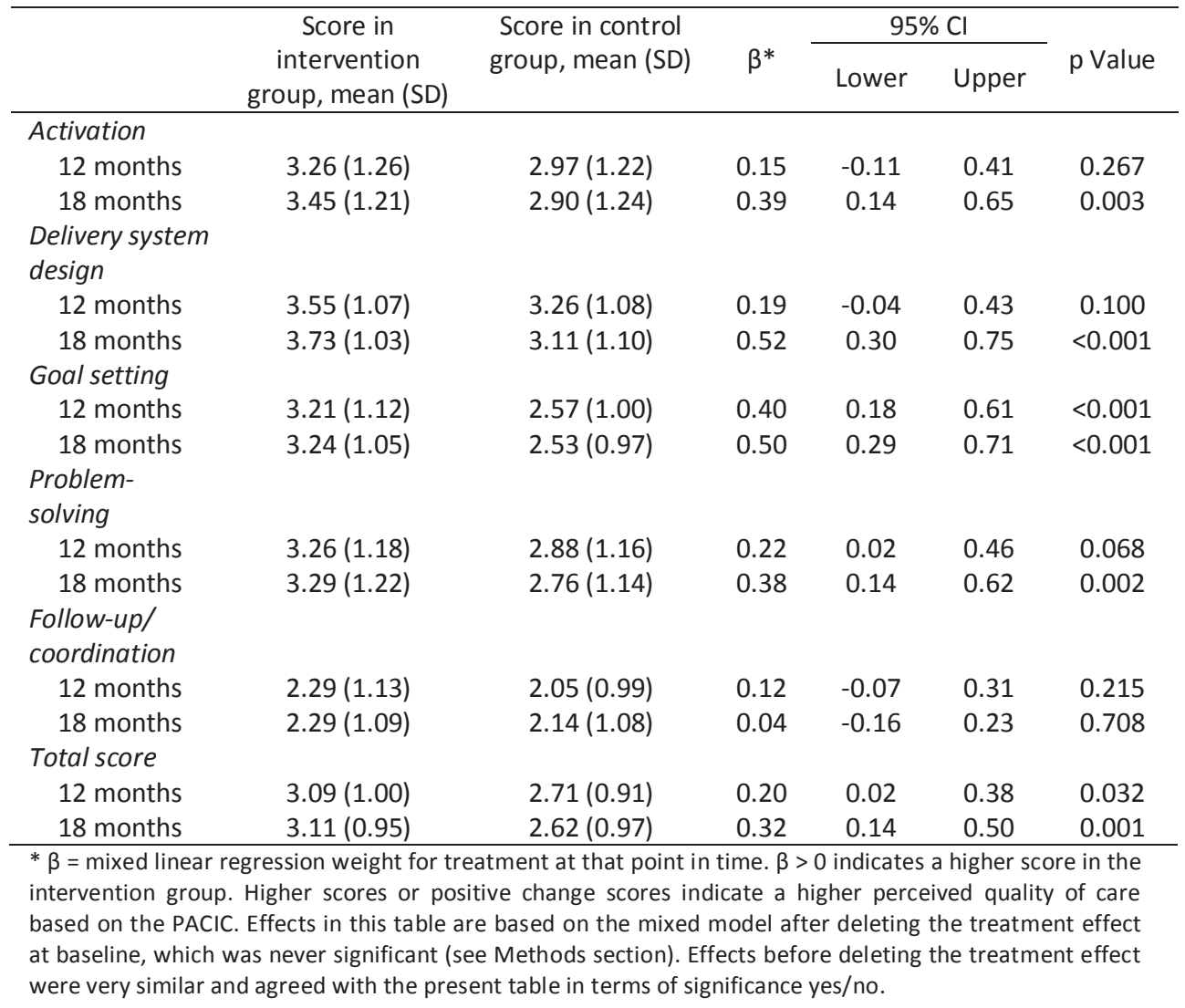


Analyses of the subdomains showed a significant difference between treatment arms at 18 months in all domains $(p<0.01)$, except for the 'follow-up/coordination' domain (see Table 5.3). These results indicate that treatment according to the $A B C$ tool increased perceived quality of care as compared to the control group. Table 5.3 also displays the results after 12 months.

\section{DISCUSSION}

\section{Main findings}

We were able to analyse three different outcome measures related to disease-specific quality of life and perceived quality of care. We found significant differences between intervention and control arm on the SGRQ and the PACIC, but not on the CAT.

\section{St. George's Respiratory Questionnaire}

The use of the $A B C$ tool in daily care resulted in more patients experiencing an improved disease-specific quality of life as measured by the SGRQ after a period of 18 months, compared with usual care. This result was also found after 12 months, but not after 6 months. The latter might be explained by the fact that the collaboration between patient and healthcare provider using the $A B C$ tool requires time and experience to work optimally and that interventions often also require a behavioural change of the patient. The additional analyses of the different domains of the SGRQ showed that there was mainly an improvement in the symptom domain and the impact domain, but these associations are just short of significance when taking the more stringent significance level of $1 \%$ into account to correct for multiple testing of secondary outcomes.

\section{COPD Assessment Test}

We expected to find results on the CAT comparable with the SGRQ since both questionnaires are strongly correlated ${ }^{29-31}$ and in previous studies the CAT and the SGRQ usually showed similar results. ${ }^{32-34}$

Additionally, a systematic review about the $\mathrm{CAT}^{29}$ found that the CAT is a reliable, valid, and responsive instrument. Our study however did not indicate any differences between the treatment arms, which might relate to the fact that most studies evaluating the responsiveness of the CAT focused on patients with acute exacerbations and on patients receiving pulmonary rehabilitation interventions. ${ }^{35-38}$ In our study, the $A B C$ tool was used in stable patients from primary and hospital care. 
This might indicate that the CAT, compared with the SGRQ, is less sensitive to change in more stable situations than the SGRQ.

\section{Patient Assessment of Chronic Illness Care}

In evaluating the effect of the $A B C$ tool on patients' perceived quality of care (using the $\mathrm{PACIC}$ ), a significantly better response was found in the $\mathrm{ABC}$-guided group compared to the control group. Positive effects on quality of care were perceived in patient activation, decision support, goal setting, and problem-solving, which could be expected from the person-centred COPD approach with the $A B C$ tool. When developing the $A B C$ tool the main goal was to make a tool that measures burden of COPD, and additionally visualises the integrated health status and provides a treatment algorithm. Furthermore, the tool had to provide room for writing down a treatment plan including a personal treatment goal. All of these components are considered to be important in order to involve the patient in the decision making process and help them take control of the disease, eventually leading to improved self-management and a better quality of life. ${ }^{39-41}$

\section{This research in the context of other research}

In 2013 Agusti and MacNee advocated more personalised medicine for patients with $\mathrm{COPD}^{42}$ by suggesting that healthcare providers need a 'control panel' for the assessment and management of COPD. To our knowledge, apart from the ABC tool, only one other instrument has been developed for that purpose, ${ }^{43}$ although this tool has not yet been evaluated in a randomised trial.

In the management of COPD, interventions are necessary to reduce its burden and prevent its progression. ${ }^{44,45}$ Although no interventions like the $A B C$ tool were found in literature, ${ }^{9}$ many studies have been described evaluating the effect of behavioural interventions in patients with COPD on disease-specific quality of life. These studies show varying results, due to different populations, methods and interventions. ${ }^{46-54}$ In many cases, no clinically relevant or statistically significant effect on the SGRQ was found. ${ }^{50,53-55}$ Interventions that did result in significant effects on the SGRQ were often much more demanding and intensive, such as pulmonary rehabilitation programmes, ${ }^{46,47}$ integrated disease management programmes, ${ }^{48}$ thorough proactive self-management education, ${ }^{49}$ or weekly home visits by health professionals. ${ }^{50}$ The $A B C$ tool however, is a much more simple and easy-to-use visual approach that can be 
deployed as a communication tool in routine COPD care, facilitating shared decisionmaking. ${ }^{56-58}$

\section{Strengths and limitations}

A strength of the study was the fact that it was executed in almost every province of the Netherlands, in primary and hospital care, providing information about the effects of the intervention in different settings and disease severities. This has positive consequences for the generalisability of the results and potential implementation of the $A B C$ tool. Usual care was based on national guidelines which are in line with international guidelines. However, different usual care in other countries cannot be excluded, which might affect the generalisability to some extent of our results towards other countries.

An additional strength was the pragmatic design to test the effectiveness of the $A B C$ tool in real-life routine practice, which makes the results more applicable to daily primary and hospital care. However, the pragmatic approach also presented challenges. First, the use of the $A B C$ tool was not actively promoted during the study, which meant that $4 \%$ of the patients did not receive the intervention. Second, healthcare providers were not actively stimulated to practice using the tool (if they requested the opportunity to practice, a dummy account was provided), since we believed using the tool would be a self-explanatory. It is conceivable that with more training with the $A B C$ tool, the effect might have been even greater, and more training might be warranted when implementing the tool with less motivated/experienced healthcare providers.

Owing to an error in data collection, smoking status was not recorded in all patients in the control group at baseline. However, at the 15-month and 18-month follow-up, smoking status was recorded and these data were used to impute the baseline status in patients with missing smoking status at baseline. To validate this imputed baseline smoking status, Cohen's kappa measure of agreement was calculated between the observed and the imputed smoking status in patients with available baseline data. Kappa was 0.86 , indicating good agreement, and it was therefore concluded that missing smoking status at baseline could be replaced with data at the 15-month or 18month follow-up. 
Perhaps due to randomisation at cluster level instead of individual patient level, there was some imbalance between both groups at baseline. The intervention group showed a lower initial lung function. In order to detect any possible confounding from this imbalance, we repeated the primary analysis with $\mathrm{FEV}_{1 \%}$ predicted and forced expiratory ratio (FER) as covariates in the model. This analysis yielded similar results. Additionally, on the symptom domain of the SGRQ, the intervention group seemed to score worse at baseline. However, this difference was not significant and we corrected for this difference by calculating change scores. Therefore, we conclude that the results remain unchanged, despite these imbalances.

When calculating the required sample size, the expected proportions of patients improved were difficult to estimate, since little evidence was available on the effect of disease management interventions on disease-specific quality of life as measured by the SGRQ. ${ }^{59}$ Therefore, the expected proportions of patients improved were solely based on results of previous drug trials. ${ }^{60,61}$ The results from our trial showed that the proportion of patients improved by four points - our primary outcome - was $33.6 \%$ in the intervention group compared with $22.3 \%$ in the control group. Although this difference was smaller than estimated for the sample size calculation, it was a statistically significant difference. This is at least partly due to the fact that the actual dropout rate and ICC (18\% and 0.01 , respectively) were lower than expected in the study planning stage ( $25 \%$ and 0.05 , respectively). The smaller than expected difference in the proportion of patients improved ( $11.3 \%$ observed vs $20 \%$ expected) may partly be due to the fact that, instead of for example a single drug intervention, a high variety of interventions were possible in this trial, which might dilute the effect. Another possible explanation is the fact that the group COPD patients included in the study was a stable group with better quality of life and therefore lower baseline SGRQ total scores than in other studies, leaving less room for improvement. ${ }^{62-65}$

Furthermore, no blinding and allocation concealment was possible due to the nature of the intervention. However, the researchers performed the analyses on a blinded dataset and were therefore unaware of the coding of treatment arm until unanimous conclusions had been drawn about the results by all authors. 


\section{Implications}

This study showed a promising development towards person-centred care. Visualisation of the integrated health status seems to be a valid contribution to efforts to place patients in the driver seat of care planning, together with their healthcare provider. Future research should focus on replication of this trial, in other settings and perhaps for other diseases as well, to investigate the underlying mechanisms of the effect of the $A B C$ tool and especially the visually facilitated shared decision-making.

\section{Conclusion}

Our trial results indicate that the $A B C$ tool has an added value for patients with COPD. Patients treated with the $A B C$ tool were more likely to report clinically relevant improvement in quality of life, as measured by the SGRQ, compared with patients treated with usual care. Patients also perceived quality of care as better when the ABC tool was applied. Further research is necessary to replicate the results and further investigate the added value of the $A B C$ tool in different settings. 


\section{REFERENCES}

1. Mannino DM, Homa DM, Akinbami U, Ford ES \& Redd SC. Chronic obstructive pulmonary disease surveillance--United States, 1971-2000. MMWR Surveill Summ 2002;51:1-16.

2. Feenstra TL, van Genugten ML, Hoogenveen RT, Wouters EF \& Rutten-van Mölken MP. The impact of aging and smoking on the future burden of chronic obstructive pulmonary disease: a model analysis in the Netherlands. Am J Respir Crit Care Med 2001;164:590-596.

3. From the Global Strategy for Diagnosis, Management and Prevention of COPD, Global Initiative for Chronic Obstructive Lung Disease (GOLD) 2014. Available at http://www.goldcopd.org/.

4. Celli BR \& MacNee W. Standards for the diagnosis and treatment of patients with COPD: a summary of the ATS/ERS position paper. Eur Respir J 2004;23:932-946.

5. Gruffydd-Jones K. A national strategy for the management of chronic obstructive pulmonary disease (COPD) in England: aiming to improve the quality of care for patients. Prim Care Respir J 2008;17 Suppl 1:S1-8.

6. Seemungal TA, Donaldson GC, Paul EA, Bestall JC, Jeffries DJ \& Wedzicha JA. Effect of exacerbation on quality of life in patients with chronic obstructive pulmonary disease. Am $J$ Respir Crit Care Med 1998;157:1418-1422.

7. Miravitlles M, Ferrer M, Pont A, Zalacain R, Alvarez-Sala JL, Masa F, Verea H, Murio C, Ros F \& Vidal R. Effect of exacerbations on quality of life in patients with chronic obstructive pulmonary disease: a 2 year follow up study. Thorax 2004;59:387-395.

8. Miravitlles M, Molina J, Naberan K, Cots JM, Ros F \& Llor C. Factors determining the quality of life of patients with COPD in primary care. Ther Adv Respir Dis 2007;1:85-92.

9. Slok AHM, In 't Veen JCCM, Chavannes NH, van der Molen T, Rutten-van Mölken MPMH, Kerstjens HAM, Salome PL, Holverda S, Dekhuijzen PNR, Schuiten D, Asijee GM \& van Schayck OCP. Development of the Assessment of Burden of COPD tool: an integrated tool to measure the burden of COPD. npj Prim Care Respir Med 2014;24:14021.

10. Van der Molen T, Willemse BW, Schokker S, Ten Hacken NH, Postma DS \& Juniper EF. Development, validity and responsiveness of the Clinical COPD Questionnaire. Health Qual Life Outcomes 2003;1.

11. Slok AHM, Bemelmans TCH, Kotz D, Van der Molen T, Kerstjens HAM, in 't Veen JCCM, Chavannes NH, Asijee GM, Rutten-van Mölken MPMH \& van Schayck CP. The Assessment of Burden of COPD (ABC) scale: a reliable and valid questionnaire. COPD 2016; 13:431-438.

12. Bourbeau J, Nault D \& Dang-Tan T. Self-management and behaviour modification in COPD. Patient Educ Couns 2004;52:271-277.

13. Hill K, Vogiatzis I \& Burtin C. The importance of components of pulmonary rehabilitation, other than exercise training, in COPD. Eur Respir Rev 2013;22:405-413.

14. Jones PW. St. George's Respiratory Questionnaire: MCID. Copd 2005;2:75-79.

15. Jones PW, Harding G, Berry P, Wiklund I, Chen WH \& Kline Leidy N. Development and first validation of the COPD Assessment Test. Eur Respir J 2009;34:648-654.

16. Glasgow RE, Wagner EH, Schaefer J, Mahoney LD, Reid RJ \& Greene SM. Development and validation of the Patient Assessment of Chronic Illness Care (PACIC). Med Care 2005;43:436-444.

17. Slok AHM, In 't Veen JCCM, Chavannes NH, van der Molen T, Mölken MPMH, Kerstjens HAM, Asijee GM, Salome PL, Holverda S, Dekhuijzen PNR, Schuiten D, van Breukelen G, Kotz D \& van Schayck OCP. Effectiveness of the Assessment of Burden of Chronic Obstructive Pulmonary Disease $(A B C)$ tool: study protocol of a cluster randomised trial in primary and secondary care. BMC Pulm Med 2014;14:131.

18. Bestall JC, Paul EA, Garrod R, Garnham R, Jones PW \& Wedzicha JA. Usefulness of the Medical Research Council (MRC) dyspnoea scale as a measure of disability in patients with chronic obstructive pulmonary disease. Thorax 1999;54:581-586.

19. Long Alliantie Nederland. Zorgstandaard COPD. Amersfoort:Long Alliantie Nederland.; 2010.

20. Smeele IJM, Van Weel C, Van Schayck CP, Van der Molen T, Thoonen B, Schermer T, Sachs APE, Muris JWM, Chavannes NH, Kolnaar BGM, Grol MH \& Geijer RMM. NHG Standaard- COPD [Dutch national guideline COPD in primary care]. 2007;50:362-379. 
21. Jones PW, Quirk FH \& Baveystock CM. The St George's Respiratory Questionnaire. Respir Med 1991;85:25-31.

22. Jones PW, Quirk FH, Baveystock CM \& Littlejohns P. A self-complete measure of health status for chronic airflow limitation. The St. George's Respiratory Questionnaire. Am Rev Respir Dis 1992;145:1321-1327.

23. Jones PW \& Forde Y. St George's Respiratory Questionnaire Manual. London:St. George's University of London; 2009.

24. Smidth $M$, Olesen F, Fenger-Gron $M$ \& Vedsted P. Patient-experienced effect of an active implementation of a disease management programme for COPD - a randomised trial. BMC family practice 2013;14:147.

25. Laird NM \& Wang F. Estimating rates of change in randomized clinical trials. Control Clin Trials 1990;11:405-419.

26. Liu GF, Lu K, Mogg R, Mallick M \& Mehrotra DV. Should baseline be a covariate or dependent variable in analyses of change from baseline in clinical trials? Stat Med 2009;28:2509-2530.

27. van Breukelen GJ. ANCOVA Versus CHANGE From Baseline in Nonrandomized Studies: The Difference. Multivariate Behav Res 2013;48:895-922.

28. Hedeker D. A mixed-effects multinomial logistic regression model. Stat Med 2003;22:1433-1446.

29. Gupta N, Pinto LM, Morogan A \& Bourbeau J. The COPD assessment test: a systematic review. Eur Respir J 2014;44:873-884.

30. Tsiligianni IG, van der Molen T, Moraitaki D, Lopez I, Kocks JW, Karagiannis K, Siafakas N \& Tzanakis N. Assessing health status in COPD. A head-to-head comparison between the COPD assessment test (CAT) and the clinical COPD questionnaire (CCQ). BMC Pulm Med 2012;12:20.

31. Sarioglu N, Hismiogullari AA, Bilen C \& Erel F. Is the COPD assessment test (CAT) effective in demonstrating the systemic inflammation and other components in COPD? Rev Port Pneumol 2015;22:11-17.

32. Siler TM, Kerwin E, Singletary K, Brooks J \& Church A. Efficacy and Safety of Umeclidinium Added to Fluticasone Propionate/Salmeterol in Patients with COPD: Results of Two Randomized, Double-Blind Studies. Copd 2015;13:1-10.

33. Mendoza L, Horta P, Espinoza J, Aguilera M, Balmaceda N, Castro A, Ruiz M, Diaz O \& Hopkinson NS. Pedometers to enhance physical activity in COPD: a randomised controlled trial. Eur Respir J 2015;45:347-354.

34. Ghobadi H, Lari SM, Pourfarzi F, Mahmoudpour A \& Ghanei M. The effects of atorvastatin on mustard-gas-exposed patients with chronic obstructive pulmonary disease: A randomized controlled trial. J Res Med Sci 2014;19:99-105.

35. Dodd JW, Hogg L, Nolan J, Jefford H, Grant A, Lord VM, Falzon C, Garrod R, Lee C, Polkey MI, Jones PW, Man WD \& Hopkinson NS. The COPD assessment test (CAT): response to pulmonary rehabilitation. A multicentre, prospective study. Thorax 2011;66:425-429.

36. Jones PW, Harding G, Wiklund I, Berry P, Tabberer M, Yu R \& Leidy NK. Tests of the responsiveness of the COPD assessment test following acute exacerbation and pulmonary rehabilitation. Chest 2012;142:134-140.

37. Dodd JW, Marns PL, Clark AL, Ingram KA, Fowler RP, Canavan JL, Patel MS, Kon SS, Hopkinson NS Polkey MI, Jones PW \& Man WD. The COPD Assessment Test (CAT): short- and medium-term response to pulmonary rehabilitation. Copd 2012;9:390-394.

38. Kon SS, Clark AL, Dilaver D, Canavan JL, Patel MS, Polkey MI \& Man WD. Response of the COPD Assessment Test to pulmonary rehabilitation in unselected chronic respiratory disease. Respirology 2013;18:974-977.

39. Joosten EA, DeFuentes-Merillas L, de Weert GH, Sensky T, van der Staak CP \& de Jong CA. Systematic review of the effects of shared decision-making on patient satisfaction, treatment adherence and health status. Psychother Psychosom 2008;77:219-226.

40. Bodenheimer T, Wagner EH \& Grumbach K. Improving primary care for patients with chronic illness: the chronic care model, Part 2. JAMA 2002;288:1909-1914.

41. Cicutto L, Brooks D \& Henderson K. Self-care issues from the perspective of individuals with chronic obstructive pulmonary disease. Patient Educ Couns 2004;55:168-176.

42. Agusti A \& Macnee W. The COPD control panel: towards personalised medicine in COPD. Thorax 2013;68:687-690. 
43. Peters JB, Daudey L, Heijdra YF, Molema J, Dekhuijzen PN \& Vercoulen JH. Development of a battery of instruments for detailed measurement of health status in patients with COPD in routine care: the Nijmegen Clinical Screening Instrument. Qual Life Res 2009;18:901-912.

44. Coultas D, Frederick J, Barnett B, Singh G \& Wludyka P. A randomized trial of two types of nurseassisted home care for patients with COPD. Chest 2005;128:2017-2024.

45. Oga T, Tsukino M, Hajiro T, Ikeda A \& Nishimura K. Analysis of longitudinal changes in dyspnea of patients with chronic obstructive pulmonary disease: an observational study. Respir Res 2012;13:85.

46. van Wetering CR, Hoogendoorn M, Mol SJ, Rutten-van Mölken MP \& Schols AM. Short- and longterm efficacy of a community-based COPD management programme in less advanced COPD: a randomised controlled trial. Thorax 2010;65:7-13.

47. Boxall AM, Barclay L, Sayers A \& Caplan GA. Managing chronic obstructive pulmonary disease in the community. A randomized controlled trial of home-based pulmonary rehabilitation for elderly housebound patients. J Cardiopulm Rehabil 2005;25:378-385.

48. Chavannes NH, Grijsen M, van den Akker M, Schepers H, Nijdam M, Tiep B \& Muris J. Integrated disease management improves one-year quality of life in primary care COPD patients: a controlled clinical trial. Prim Care Respir J 2009;18:171-176.

49. Koff PB, Jones RH, Cashman JM, Voelkel NF \& Vandivier RW. Proactive integrated care improves quality of life in patients with COPD. Eur Respir J 2009;33:1031-1038.

50. Bourbeau J, Julien M, Maltais F, Rouleau M, Beaupre A, Begin R, Renzi P, Nault D, Borycki E, Schwartzman K, Singh R, Collet JP \& Chronic Obstructive Pulmonary Disease axis of the Respiratory Network Fonds de la Recherche en Sante du Q. Reduction of hospital utilization in patients with chronic obstructive pulmonary disease: a disease-specific self-management intervention. Arch Intern Med 2003;163:585-591.

51. Monninkhof E, van der Valk P, van der Palen J, van Herwaarden C \& Zielhuis G. Effects of a comprehensive self-management programme in patients with chronic obstructive pulmonary disease. Eur Respir J 2003;22:815-820.

52. Kruis AL, Boland MR, Assendelft WJ, Gussekloo J, Tsiachristas A, Stijnen T, Blom C, Sont JK, Rutten-van Mölken MP \& Chavannes NH. Effectiveness of integrated disease management for primary care chronic obstructive pulmonary disease patients: results of cluster randomised trial. Bmj 2014;349:g5392.

53. Zwerink M, Brusse-Keizer M, van der Valk PD, Zielhuis GA, Monninkhof EM, van der Palen J, Frith PA \& Effing T. Self management for patients with chronic obstructive pulmonary disease. Cochrane Database Syst Rev 2014;3:CD002990.

54. Hermiz O, Comino E, Marks G, Daffurn K, Wilson S \& Harris M. Randomised controlled trial of home based care of patients with chronic obstructive pulmonary disease. Bmj 2002;325:938.

55. Kruis AL, Smidt N, Assendelft WJ, Gussekloo J, Boland MR, Rutten-van Mölken M \& Chavannes $\mathrm{NH}$. Integrated disease management interventions for patients with chronic obstructive pulmonary disease. Cochrane Database Syst Rev 2013;10:CD009437.

56. Oliver SM. Living with failing lungs: the doctor-patient relationship. Fam Pract 2001;18:430-439.

57. Makoul G \& Clayman ML. An integrative model of shared decision making in medical encounters. Patient Educ Couns 2006;60:301-312.

58. Elwyn G, Frosch D, Thomson R, Joseph-Williams N, Lloyd A, Kinnersley P, Cording E, Tomson D, Dodd C, Rollnick S, Edwards A \& Barry M. Shared decision making: a model for clinical practice. J Gen Intern Med 2012;27:1361-1367.

59. Lemmens KM, Nieboer AP \& Huijsman R. A systematic review of integrated use of diseasemanagement interventions in asthma and COPD. Respir Med 2009;103:670-691.

60. Tashkin D \& Kesten S. Long-term treatment benefits with tiotropium in COPD patients with and without short-term bronchodilator responses. Chest 2003;123:1441-1449.

61. Casaburi R, Mahler DA, Jones PW, Wanner A, San PG, ZuWallack RL, Menjoge SS, Serby CW \& Witek T, Jr. A long-term evaluation of once-daily inhaled tiotropium in chronic obstructive pulmonary disease. Eur Respir J 2002;19:217-224.

62. Rutten-van Mölken M, Roos B \& Van Noord JA. An empirical comparison of the St George's Respiratory Questionnaire (SGRQ) and the Chronic Respiratory Disease Questionnaire (CRQ) in a clinical trial setting. Thorax 1999;54:995-1003. 
63. Tashkin DP, Celli B, Senn S, Burkhart D, Kesten S, Menjoge S, Decramer M \& Investigators US. A 4-year trial of tiotropium in chronic obstructive pulmonary disease. N Engl J Med 2008;359:15431554.

64. Spencer S, Calverley PM, Sherwood Burge P, Jones PW \& Disease ISGISiOL. Health status deterioration in patients with chronic obstructive pulmonary disease. Am J Respir Crit Care Med 2001;163:122-128.

65. Jones PW \& Bosh TK. Quality of life changes in COPD patients treated with salmeterol. Am J Respir Crit Care Med 1997;155:1283-1289. 


\section{CHAPTER}

\section{'To use or not to use': A qualitative study to evaluate experiences of healthcare providers and patients with the Assessment of Burden of COPD $(A B C)$ tool}

Slok AHM, Twellaar M, Jutbo L, Kotz D, Chavannes NH, Holverda S, Salomé PL, Dekhuijzen PNR, Rutten-van Mölken MPMH, Schuiten D, in 't Veen JCCM, van Schayck OCP. To use or not to use: experiences of healthcare professionals and patients with the Assessment of Burden of COPD (ABC) tool. Accepted for publication in npj Primary Care Respiratory Medicine 


\section{ABSTRACT}

In the management of chronic conditions, such as chronic obstructive pulmonary disease (COPD), there is a shift from doctor-driven care to patient-centred integrated care with active involvement of and self-management by the patient. A recently developed tool, the Assessment of Burden of COPD (ABC) tool, can be used in this transition to facilitate self-management support and shared decision-making. We performed a qualitative study, in which we collected and analysed data using the methods of conventional content analyses. We performed in-depth interviews consisting of mainly open questions. Fifteen healthcare providers and 21 patients were interviewed who had worked with the $A B C$ tool in daily care. In general, participants responded positively to the tool. Healthcare providers felt the visual representation provided was effective and comprehensible for patients and provided them insight into their disease, a finding which patients confirmed. If patients were allowed to choose between a consultation with or without the $A B C$ tool, the majority would prefer using the tool: it provides them with an overview and insight, which makes it easier to discuss all relevant topics related to COPD. The tool can provide structure in consultations, and is compatible with the concepts of "motivational interviewing" and "individualised care-planning". Suggestions for improvement related to content and layout. So far, the tool has only been available as a stand-alone online program, that is not connected to the electronic medical record systems. It was therefore suggested that the tool be integrated into the systems to enhance its usability and its uptake by healthcare providers. 


\section{INTRODUCTION}

In chronic conditions such as chronic obstructive pulmonary disease (COPD), there is a shift from doctor-driven care towards more patient-centred integrated care with active involvement of and self-management by the patient. ${ }^{1,2}$ This requires patients to take a more active role in managing their own disease. ${ }^{3,4}$ Self-management ${ }^{5}$ and shared decision-making ${ }^{6-8}$ appear to be essential to learning to cope with the disease, ${ }^{9}$ improving health status, ${ }^{10,11}$ reducing the use of care services and hospital admissions. ${ }^{10-12}$ This process requires a behavioural change on the part of both healthcare providers and patients.

In Western countries, healthcare providers are becoming increasingly better trained in this transition, for example by acquiring the skills of motivational interviewing, ${ }^{13}$ and integrating the different components of shared decision-making into their consultations. ${ }^{14}$ Despite this training, healthcare providers and patients are often not yet used to this approach. ${ }^{15}$ Patients need to be properly educated in order to manage their disease effectively, ${ }^{9}$ though knowledge alone is not enough to change behaviour. ${ }^{16}$ They should also be encouraged and trained to take control of their illness, its treatment and consequences. ${ }^{2}$ In addition, patients need to receive support in their new and active role in shared decision-making.

This process, which is a joint venture between healthcare provider and patient, is likely to be facilitated by the recently developed assessment of burden of COPD (ABC) tool. The $A B C$ tool is currently developed as a stand-alone online computer program that healthcare providers can access using login codes they received from the researchers prior to the study. The $A B C$ tool starts with a patients' reported burden of COPD, using the $A B C$ scale. By adding other parameters to the $A B C$ scale, such as smoking status and lung function parameters, the integrated health status of a COPD patient is assessed. The $A B C$ tool then visualises this integrated health status by means of a balloon diagram (see Figure 6.1). ${ }^{17}$ The scores of the current assessment are shown with the coloured balloons and the scores of the previous visit are shown with grey balloons, which aids in monitoring any changes in the patients' status. The balloon diagram facilitates communication between the healthcare provider and patient on health-related topics that affect the patient's COPD burden. 


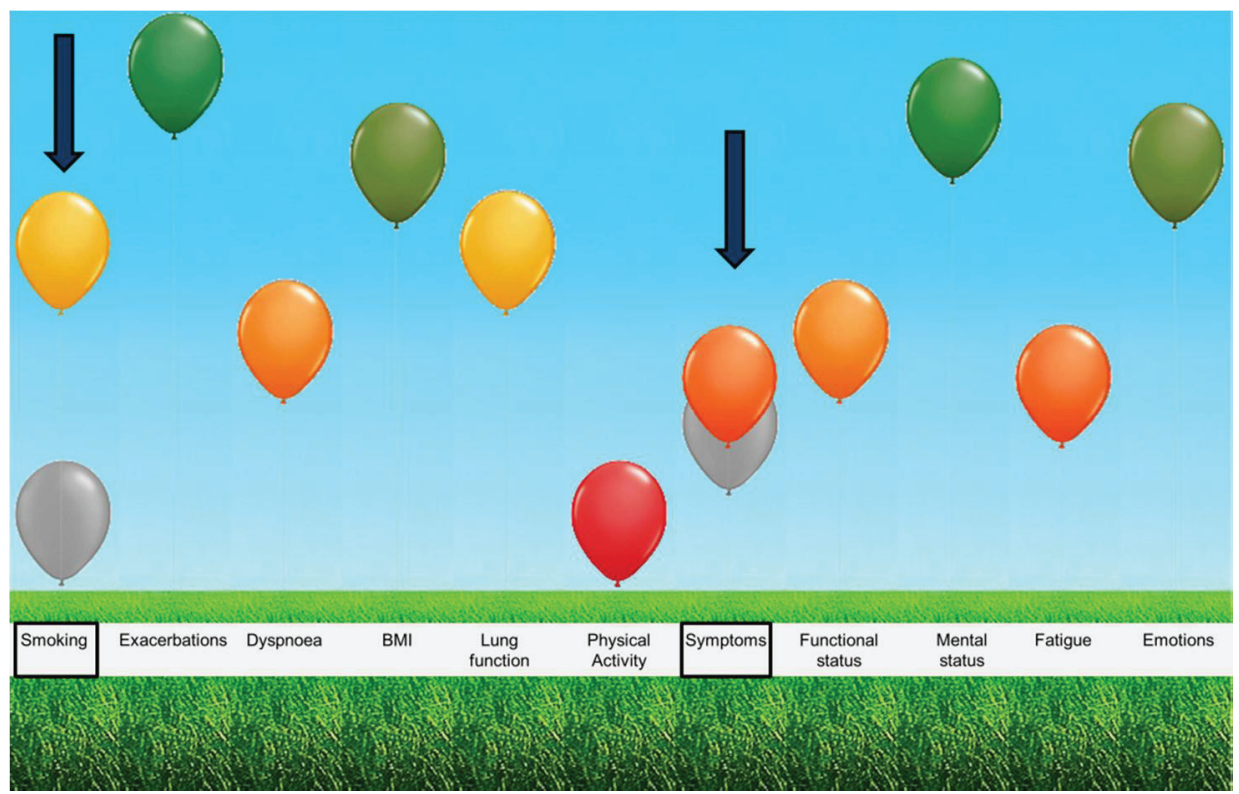

Figure 6.1 Overview of the integrated health status of a COPD patient, showing a change in smoking behaviour and symptoms since the previous visit, as indicated by the arrows. A change is visualised by adding the scores of previous assessment in the display with grey balloons.

We hypothesise that integration and visualisation of the different aspects of COPD helps healthcare providers and patients develop an awareness of the different components associated with the experienced burden. If patients experience more symptoms, for example, they can easily relate this to their smoking behaviour (see Figure 6.1), which then makes them more motivated to quit. ${ }^{18,19}$ The $A B C$ tool also uses a treatment algorithm with treatment advice, based on current COPD healthcare guidelines. The visual display could be used in shared decision-making between patients and healthcare providers, by integrating the coherence of the domains, e.g. symptoms and smoking status, supporting a personalised treatment plan with behavioural change. Since the majority of COPD treatment options relate to behavioural change management, it stresses the importance of patients' managing their own disease and treatment plan. ${ }^{5}$

Since the $A B C$ tool is a newly developed tool, it is important to evaluate its performance. The psychometric properties of the scale and the effectiveness of the tool on different outcome measures have already been investigated in a cluster randomised controlled trial (RCT). The $A B C$ scale was found to be a valid and reliable questionnaire. Moreover, results of the RCT showed that when the ABC tool is used, 
patients report a better disease-specific quality of life and a better perceived quality of care. These results are reported elsewhere. ${ }^{20,21}$ In addition, it is important to conduct an in-depth investigation of the experiences of patients and healthcare providers who have already used the tool in daily care, in order to discover whether users of the $A B C$ tool consider it a valuable contribution to the usual care.

Therefore, the aim of this study was to conduct a qualitative evaluation to assess healthcare providers' and patients' experiences with the $A B C$ tool, by examining (1) the opinion of the healthcare providers and patients about the different components of the $A B C$ tool; (2) the extent to which the $A B C$ tool is useful in daily COPD care; and (3) the factors that would facilitate and hamper possible future implementation.

\section{METHODS}

\section{Design}

A qualitative study was performed, and since our aim was to describe the reactions and experiences of $A B C$ tool users, the methods of conventional content analysis were used. $^{22}$ Individual interviews were performed to collect information. This study was approved by the Medical Ethics committee of Zuyderland Hospital, Heerlen, the Netherlands.

\section{Information collection}

The data were collected from interviews consisting of mainly open-ended questions. Topic lists were used in the individual interviews. These are included in Appendix 2 and 3. Topics that were relevant for answering the research questions were decided upon by different researchers involved in this project, who reached consensus by discussion.

The interviews with healthcare providers were conducted by $L$, under supervision of AHMS, at the practices of the healthcare providers. Patients were interviewed by AHMS, at home or in the hospitals, depending on their preference and practical or logistical reasons. AHMS had previous experience in interviewing patients for research purposes and $\mathrm{L}$ was extensively trained in interviewing during her medical education. Consistency between interviews was warranted by AHMS being present during all interviews. 


\section{Study population}

We approached 30 healthcare providers (general practitioners (GPS), pulmonologists, practice nurses (PNs), and pulmonary clinical nurse specialists (PCNS), who were previously randomly allocated to the intervention group of the RCT, by e-mail and subsequently by telephone to investigate their willingness to participate in an individual interview. In total 28 persons indicated that they were willing to participate in the interviews. One PN and one PCNS declined participation due to a busy work schedule.

We selected a total of 15 providers (2 GPs, one pulmonologist, 5 PN, 6 PCNSs, and one healthcare provider who works both as PN and PCNS) for a face-to-face interview to discuss how the $A B C$ tool was used in both primary and hospital care. Participants were mainly PNs and PCNSs, since they play a central role in the use of the ABC tool. Our selection criteria were healthcare providers from both primary and hospital care and from different places in the Netherlands to ensure a good geographical spread, in order to prevent potential cultural differences. After interview nine we observed data saturation.

We approached 160 patients who were randomised to the intervention group of the RCT to participate in an individual interview by adding a reply card to the final questionnaire of the RCT. ${ }^{23}$ This reply card included postage for mailing, the address of the university and check boxes to indicate whether the researchers were allowed to contact the patient by telephone or not. Over 60 patients (almost 40\%) replied that they were willing to be contacted for an interview. When planning the interviews we intentionally considered patients from both genders and from both primary care and hospital care. Patients were phoned by the researcher and if they decided to participate an appointment was made. Patient information and an informed consent form were sent to the patient by mail, who was asked to sign the consent form and give them to the researcher prior to the interview. After performing 15 interviews we observed data saturation. We interviewed another six patients, bringing the patient total to 21 , thereby achieving a balance between primary and hospital care.

\section{Analysis}

All interviews were audio-recorded and transcribed verbatim. Data were analysed according to the conventional content analysis, using specialised software called QSR Nvivo9. ${ }^{23}$ Data collection and analysis did not occur simultaneously. In order to 
familiarise ourselves with the data, we started by reading all transcripts in detail. We then highlighted phrases that captured the key concepts. Codes were derived from the data during the data analysis (inductive coding). ${ }^{22}$ These initial steps were performed independently by two different individuals: the healthcare provider interviews by $L$ and AHMS and the patient interviews by MT and AHMS. The researchers reached consensus on coding through discussion. Codes were then related, linked and divided into categories. ${ }^{22}$

\section{RESULTS}

We performed 15 individual interviews with healthcare providers. The interviews lasted between 23 and 55 minutes. Characteristics of the healthcare providers are shown in Table 6.1. We also performed 21 individual interviews with COPD patients who participated in the RCT, who were treated by eleven different healthcare providers from five hospitals and six primary care practices. The interviews lasted approximately 35 minutes. Characteristics of the patients are shown in Table 6.2.

Table 6.1 Characteristics of the healthcare providers

\begin{tabular}{|c|c|c|c|c|}
\hline $\begin{array}{l}\text { Interviewed healthcare } \\
\text { providers }\end{array}$ & $n$ & $\begin{array}{l}\text { Gender, } \\
(M / F)(n)\end{array}$ & $\begin{array}{l}\text { Age, range } \\
\text { (years) }\end{array}$ & $\begin{array}{l}\text { Experience in (COPD) } \\
\text { healthcare, range (years) }\end{array}$ \\
\hline General practitioners & 2 & $2 / 0$ & $52-61$ & $23-42$ \\
\hline Pulmonologists & 1 & $1 / 0$ & 52 & 25 \\
\hline Practice nurses & 5 & $0 / 5$ & $44-53$ & $12-30$ \\
\hline $\begin{array}{l}\text { Pulmonary clinical nurse } \\
\text { specialists }\end{array}$ & 6 & $1 / 6$ & $29-52$ & $8-32$ \\
\hline $\begin{array}{l}\text { Nurse practitioner and } \\
\text { nurse specialist }\end{array}$ & 1 & $0 / 1$ & 52 & 29 \\
\hline
\end{tabular}

\section{Content and components of the $A B C$ tool}

\section{ABC scale}

According to healthcare providers, the fact that the $A B C$ tool is based on the clinical COPD questionnaire (CCQ) is a significant strength. The CCQ is a commonly used questionnaire in the Netherlands and has been proven to be simple and quick, but valid, measuring the clinical status of the airways, functional limitations and psychosocial dysfunction. ${ }^{25-27}$ The healthcare providers mentioned that the four additional items, three questions measuring emotions and one question measuring fatigue, were useful and provided greater insight into the burden of COPD experienced by the patient. 
Table 6.2 Characteristics of the patients

\begin{tabular}{lllll}
\hline & Gender (M/F) & Age & Healthcare setting & $\begin{array}{l}\text { Number of times ABC } \\
\text { tool used* }\end{array}$ \\
\hline 1 & F & 67 & Hospital care & 2 \\
2 & M & 56 & Hospital care & 4 \\
3 & F & 72 & Hospital care & 4 \\
4 & F & 69 & Hospital care & 3 \\
5 & M & 64 & Hospital care & 4 \\
6 & M & 72 & Hospital care & 4 \\
7 & F & 70 & Primary care & 3 \\
8 & M & 79 & Primary care & 4 \\
9 & M & 65 & Hospital care & 3 \\
10 & F & 57 & Hospital care & 4 \\
11 & M & 70 & Hospital care & 4 \\
12 & F & 52 & Hospital care & 4 \\
13 & M & 67 & Hospital care & 4 \\
14 & M & 66 & Hospital care & 4 \\
15 & F & 69 & Hospital care & 3 \\
16 & F & 53 & Primary care & 4 \\
17 & F & 59 & Primary care & 4 \\
18 & M & 63 & Primary care & 4 \\
19 & M & 73 & Primary care & 4 \\
20 & F & 72 & Primary care & 4 \\
21 & F & 71 & Primary care & 4 \\
\hline
\end{tabular}

*Number of times the $A B C$ scale was completed during consultation according to the registration system of the cluster randomised controlled trial.

Patients also appreciated the questions assessing emotions as these influenced their perception of the disease burden. Assessing and visualising emotions helped them discuss this difficult topic. On the other hand, some did not understand why emotions were covered in the questionnaire, since they did not believe that emotions were directly related to COPD. However, the questions did not bother these patients, either, and they were willing to answer them.

"Emotions and feelings... They are very important. (....) They have a major impact. And of course your physical health and dyspnoea. But also those emotions. Fatigue and emotions are also related." - Patient 4

We asked healthcare providers and patients where the $A B C$ scale was administered, since it was designed to be self-administered. The majority completed the questionnaire in the waiting room, though several did so in the consultation room and others sometimes in the waiting room and sometimes in the consultation room. 
Regarding completion time, patients mentioned that filling out the questionnaire took them only a few minutes and that it required minimal effort to do so prior to each consultation. Though they did not report having trouble understanding the language in the questionnaire, some felt that seven response options might be too many, as it was difficult to distinguish between "a few times" and "several times", for example.

Furthermore, some patients mentioned that it is sometimes difficult to answer the questions due to the day-to-day variations of the disease, and because they suffer from other conditions as well, which makes it difficult to know whether the complaints are related to their COPD or other diseases, such as diabetes.

\section{Visual representation of integrated health status}

The healthcare providers considered the visual representation, both conceptually and as regards the illustration with coloured balloons, to be a key strength of the $A B C$ tool. They thought it was understandable for patients, and felt that it provided the patient greater insight into the various aspects of COPD and how they interrelate. Healthcare providers also welcomed the fact that the program provides an immediate overview after the results of all items are entered into the computer, which they considered helpful both for themselves and for the patients.

"Patients can watch it on the computer screen. They can understand
everything and it is also easy to grasp." - PN 2

"You immediately have an overview, so you do not have to explicitly ask all these questions, because you already have them in your overview." - PCNS 2

"And what I think is fantastic, is the balloon system. Actually, for me that is the most valuable part." - PCNS 1

All patients mentioned that it was clear that the positions of the balloons in the diagram were determined by their answers to the questions. They were generally positive about the visual representation. Their first impressions varied: most patients liked it and said it was fun and interesting, while others found it was a bit childish or strange. Most patients felt that the visual display clarified the integrated health status and that balloons were better-suited to visualising burden of COPD, than other options such as smileys, traffic-lights or graphs. The added value of the visual display 
over words was emphasised, since most patients were able to remember more of what the healthcare providers told them when the balloons were used as an aid. Furthermore, most patients found it stimulating and motivating to see the different balloons per domain. Not all patients necessarily responded positively: some patients had a neutral reaction and no real opinion or expectations. Some patients felt it was unnecessary to use a visual display and a few preferred graphs over an image with balloons.

I think that nine out of ten patients feel that this is better than when it is only discussed or when you have to read it. (...) This provides immediate insight. If I were this patient (interviewer brought a visual display of a test patient), then I would think: 'I have to do something with this. What can we do?'”- Patient 6

"Especially with the colours that they can see... this is good, and this is not so good. I have to work on this, I don't have to worry about that. Those are surely plusses. And it's a good tool for less-educated patients." Patient 2

\section{Grey balloons for monitoring}

The grey balloons, which showed a comparison with the scores of the previous consultation, were considered a useful addition by the healthcare providers, as they immediately showed the patients' clinical stability, improvement or deterioration. Patients tended to forget their previous health status once six months had passed between the two medical check-ups, so showing previous health status as well as current health status is considered to be a good reminder.

Some patients did not remember having seen the grey balloons. However, when the purpose of the grey balloons was explained by the interviewer, they did understand it and thought it was very clear. Most of them felt that including grey balloons to monitor progression and deterioration stimulated and motivated them to take action. They thought that having this information would encourage conversation with their healthcare provider about what caused the changes in their experienced burden and possible treatment options. 
Patient: "I thought it was important, because I also started working quite intensively on my physical fitness, and the balloons indeed show the results." Interviewer: "And how do you feel about the visualisation of these results?" Patient: "Well, it motivates you." - Patient 9

\section{Usability and users}

Several healthcare providers thought that the $A B C$ tool could play an important role in the transfer of patients between different sectors of care, for instance between primary and hospital care, and between pulmonologists and PCNSs. The tool could thus be used as standard for all healthcare providers involved in patient care and might improve continuity of the care.

It took some healthcare providers awhile to get acquainted with the tool. Nevertheless, after figuring out the program they eventually found it easy to access the tool and add a new patient and felt the composition was logical.

"Yes, it speaks for itself, it is very simple." - PN 1

Several healthcare providers and patients thought that mainly PNs and PCNSs would start using the program. They usually have more time per patient than pulmonologists and GPs, and have therefore more time to use the tool as the researchers intended, namely to increase patient involvement in the treatment of their disease and promote self-management.

"The tool would be mainly usable for the practice nurses, if I am truly honest, I think they are more consistent than we are. They also have more time. "GP1

The majority of the healthcare providers indicated that the $A B C$ tool was useful for the entire COPD patient population, and especially for new patients. Patients confirmed this finding, and added that the visual display might be especially helpful for older or less-educated patients or for patients with lower health literacy. The tool might not be suitable for patients who have difficulties filling out the $A B C$ scale, such as those who are not fully able to understand the Dutch language due to for example low literary or Dutch not being their native language.

"Well I would use it for every COPD patient." - PN 4 


\section{Purpose and added value of the $A B C$ tool}

Patients were asked if they understood the purpose of the $A B C$ tool, and why it was developed. Patients who understood the question indicated that it was developed to show how they are doing, to monitor improvement and deterioration, and in which domains there was room for improvement. Some patients indicated that the purpose was to highlight changes in their health and their condition and in domains that have room for improvement. Not all patients understood the question from the researcher about the purpose of the $A B C$ tool initially, but they did after it was explained.

"You want to visualise it and I think you want to visualise what has gone well and what needs working on." - Patient 19

\section{Complete overview and structure}

Most healthcare providers and patients felt that the $A B C$ tool was complete and representative for COPD. It was stated by both healthcare providers and patients that during consultations, the $A B C$ tool provides structure, and it looks at aspects which are all relevant to COPD. Several strengths of the tool were mentioned: since all relevant topics are visualised, nothing is left out; it aids in the discussion of difficult topics, such as psychosocial aspects and smoking cessation; it provides insight into the disease and the possible treatment options; and it makes patients aware of the things they can do something about themselves. Some patients did not share this opinion, but mentioned the added value of being able to monitor progression or deterioration.

"You can provide insight, and you can make sure that you do not forget the most important aspects (...) you create the opportunity to work according to a somewhat structured format, a step-by-step plan" - Pulmonologist 1

" (...) because it highlights the problems...it is easier to get to the heart of the matter." - PCNS 3

"Because of the balloons I have become more aware of things. More aware of things I can do something about, what else I can do myself to improve it, to stay in better shape." - Patient 10 
"I feel like everything: smoking, exacerbations, dyspnoea, everything will be discussed because of the balloons. And without the balloons, we randomly discuss things that I mention. And now you really discuss all balloons." Patient 12

\section{Personalised care and patient involvement}

Healthcare providers mentioned that it could be helpful for the less experienced healthcare providers and might encourage the more experienced providers to think outside their routine. The program provided action points for shared decision-making with the patient, which also led to more meaningful discussions in the consultation.

The tool fit in well with the concept of "motivational interviewing" as well as "individualised care planning", which are currently relevant topics for healthcare providers. It helped healthcare providers discuss behavioural change with patients. Furthermore, healthcare providers felt that it forced the patients to think about their personal goals and a treatment plan. Especially if consultations were frequent, healthcare providers tended to notice an increase in their patients' proactivity with regard to the treatment plan.

Some patients mentioned the importance of setting personal goals, especially if their health deteriorated. By contrast, some patients did not feel this was necessary, and had no expectations of the consultations with their healthcare providers in terms of treatment plans. They preferred to continue behaving as they had in the past without setting new goals. When questioned, most patients confirmed the importance of being involved in the decision-making process of their treatment plan. A few patients preferred that the treatment plan be determined by the healthcare provider.

Interviewer: "Have you ever discussed with your pulmonary nurse what you would like to achieve? Whether you have a goal?" Patient: "No, never. I will see what happens. We cannot discuss this because I cannot predict the future." - Patient 7

After each consultation, an overview of the balloons and the treatment plan could be printed. We asked patients if they had received the print out from their healthcare provider and if they did anything with this overview. A few patients mentioned that 
they had discussed it with their partner, but most patients reported that they did not do anything with the overview and had thrown it away.

\section{Suggestions for improvement and implementation}

\section{Lay-out and content}

Some improvements were suggested concerning the layout of the program, such as the addition of a "home-button". Some suggestions were also made regarding the content of the $A B C$ tool. It was recommended that personal goals from previous consultations would be shown in order to refer to and reflect on these goals with the patient. This could facilitate a conversation about how the patient is progressing towards achieving these goals. Additionally, they felt it would be necessary to qualify the disease burden as mild, moderate or severe, since the health insurance companies would require this.

\section{Treatment algorithm}

Some healthcare providers missed a few items in the treatment algorithm, such as inhalation instructions for patients, vital signs (pulse rate, blood pressure) and adaptation or coping. Furthermore, several of them believed that some of the treatment options were too general and not sufficiently concrete, especially those that advised referral of the patient to other healthcare providers. One of the healthcare providers stated that there was a risk that the tool would at one point provide insufficient opportunity to deviate from protocols if they believed doing so would benefit their patient. Some healthcare providers suggested that the treatment advice should be formulated such that it is easier for patients to understand and that obscure abbreviations such as "ICS" (inhalation corticosteroid) should be avoided.

"Yes, the treatment options are very general. They are not so specific that you think...okay...this is useful for patients." - PN 3

\section{Implementation of the tool in COPD care}

Almost all healthcare providers agreed that the $A B C$ tool must be implemented in the electronic medical record (EMR) systems of the GP practice or hospital. Since the ABC tool had not yet been integrated into the EMR systems by the time the RCT took place, using the tool was time-consuming, due to the extra preparation required and the fact that all data had to be transferred from the ABC tool into the EMR systems. 
"It takes longer, because you have to transfer data and information." - PN 1

Therefore this information should preferably be transferred automatically from one system to another. No specific preference was expressed as to whether the $A B C$ tool should be fully integrated into or be linked to the EMR systems. Even if the tool could not be integrated, several healthcare providers would still use it, but only for a select group of COPD patients, though some would not, as it would be too labour-intensive due to the extra preparations and entry of data in two systems.

"It should really be integrated into the electronic medical record systems." PN 3

"I can do this with the 10 patients from the RCT...but I cannot... I cannot work with two systems if I have a busy schedule." - PCNS 1

It was suggested that a concise manual be developed that provides practical instructions on how to use the program efficiently in a consultation, explaining for example what preparations should be made before seeing a patient and how to start a conversation with them. Additionally, it would be helpful to create a "dummy" patient or an instructional video to learn about the program before using it in a consultation with a real patient. The development of a workshop or training was also proposed. These would need to focus on how to start a conversation with a COPD patient and complete it efficiently, as well as how to optimally use the $A B C$ tool for shared decision-making and individualised care planning.

"If the $A B C$ tool is going to be implemented, I think it will be very important that a good manual is made available." - PCNS 3

"There should be a 'dummy' patient. They could fill out the ABC tool and you could see what happens." - PN 1

"If you had made an instructional video, I would have watched it." - PCNS 4

The interviews with patients were concluded with the question: "Would you prefer to use the $A B C$ tool with the balloons in the next consultation with your healthcare 
provider, or not?" The majority of the patients would prefer using the $A B C$ tool, because they thought that the consultation was much clearer when the $A B C$ tool was used and because it provides a good overview of their changes that have occurred since previous consultations. Only a few patients felt it was unnecessary, but they said they would not mind if the $A B C$ tool were used.

"Well... you can see that for yourself how it....or if there has indeed been a change. If something changed in my conversations, in my dyspnoea, in everything. So, I would choose to have the balloons." - Patient 21

\section{DISCUSSION}

The ABC-tool has been developed to guide patients and healthcare providers towards making a tailor-made self-management plan. The tool can facilitate a structured consultation and can provide insight into the patients' disease and different treatment options. The healthcare providers and patients who participated in the interviews were positive about this newly developed $A B C$ tool. Healthcare providers thought the $A B C$ tool's visual representation was effective and comprehensible for patients and provided them insight into their disease, a finding that was confirmed by patients. The tool not only provides structure for the consultations, but it is also compatible with the concepts of "motivational interviewing" (e.g., increasing patients' motivation to change behaviour, by for example focusing on a balloon that has room for improvement) and "individualised care planning" and it supports shared decisionmaking. The tool was considered to be user-friendly and was easy to use in the consultation. It is likely to be used mainly by PNs and PCNSs, since they have more time per patient.

In its current form, the daily use was hindered by the extra preparation required (for instance logging in to the program and adding new patients) and the need to record patient information in both the $A B C$ tool and the EMR system. Therefore it was suggested that the tool be integrated into the EMR systems healthcare providers already use. Implementation of the tool in EMR systems is feasible but challenging, since there are many EMR systems for hospitals and primary care practices in the Netherlands. Possible options for implementation could be integrating the $A B C$ tool in the different EMR systems or making a central application developed by one central party that maintains a linkage between the $A B C$ tool to the different EMR systems. 
A striking finding was the lack of recollection of the grey balloons by most patients. They were added to the program to show previous health status, in order to monitor disease progression. This finding might be partly attributed to recall bias and the fact that the duration of the study was only 18 months, which might have been too short a time to become familiar with the tool. It could also be explained by the fact that most patients remained stable, so no grey balloons were actually shown. Furthermore, various studies investigated the effects of colours on emotions and memory, and results indicate a relation. ${ }^{24-28}$ Therefore, further research could be conducted to investigate patients' preferences regarding the colours and the effects of the coloured balloons on the patients' emotions and memory in the context of the $A B C$ tool.

The use of a tool like the $A B C$ tool is in line with the latest insights regarding the support of patients with chronic conditions in self-management action planning. ${ }^{29,30}$ Nowadays, healthcare providers seem to be more familiar with these concepts, but still tend to focus on biomedical outcomes, ${ }^{15,31}$ also indicated in the current study by some healthcare providers who mentioned that certain topics, such as emotions, are difficult to discuss with patients. Moreover, patients seem to be unfamiliar with the term "care-planning" 32 and tend to arrive at consultations without any expectations and without being prepared, displaying a passive attitude, ${ }^{15}$ which was also found in our study. Patients were asked about their expectations of the regular check-ups and their personal goals, but some replied that they had no expectations at all, that they would just come to a consultation because their healthcare provider invited them and that they had no specific goals, since they knew that getting better was not possible. This indicates that patients should be encouraged and supported to change their approach and play a more active role in consultations. Patients need support in order to be able do this, and the $A B C$ tool is an easy facilitator in this respect. When deciding on a treatment plan, patients and healthcare providers should work together and form an alliance, $^{33}$ to promote better communication ${ }^{34}$ and greater medication adherence. 35,36

Not only will patients have to change their behaviour, but so will the healthcare providers. ${ }^{33}$ To prevent miscommunication and lowering patient expectations, it is essential that healthcare providers can identify patient needs. ${ }^{15}$ The $A B C$ tool can be used to facilitate self-management action planning, by first reporting experienced burden of COPD and deciding on a self-management domain by discussing the domains with an orange or red or balloon showing deterioration. ${ }^{33}$ 


\section{Strengths and limitations}

A strength of this study was the heterogeneity in the characteristics of the respondents. We conducted interviews with healthcare providers and patients from both primary and hospital care, and within the healthcare provider group, we interviewed physicians as well as practice nurses and nurse specialists. This covers the intended population of healthcare providers and patients who will be using the $A B C$ tool if it is implemented. The fact that some healthcare providers participating in the RCT were already more engaged in COPD care and, consequently, tended to be enthusiastic about the $A B C$ tool from the start is one possible limitation of the study. In contrast, these healthcare providers could have been more critical due to higher expectations about the developed tool. Furthermore, not every patient could remember that the $A B C$ tool was used in the consultation, despite the fact that the completion of the $A B C$ scale was registered at least twice for each patient, as shown in Table 6.2. Therefore, sometimes the answers might have been based on hypothetical situations, instead of being real memories. Additionally, although the researcher repeatedly explained that there were no right or wrong answers, patients may have given socially desirable answers. ${ }^{37}$

\section{Implications}

In order for the $A B C$ tool to be used efficiently in consultations, it must be integrated into the EMR systems. Additionally, some revisions to the tool might render it more user friendly, such as adding a 'home-button' and showing the personalised treatment plan of previous consultation. Furthermore, the treatment options have to be updated according to current guidelines, and adjusted as suggested during the interviews. Healthcare providers should be instructed on how to use the tool effectively during consultations, to promote self-management and guide patients towards goal-setting. For this purpose an instructional video and a workshop would be useful.

It is important that healthcare provider empower patients, so patients arrive at consultations prepared and aware of their current health status, switching from being a passive recipient to an active participant. ${ }^{38}$ Patients who take an active role in creating and applying an appropriate self-management plan impacts on the ability of coping with the disease, ${ }^{9}$ health status, ${ }^{10,11}$ use of care services and hospital admissions. ${ }^{10-12}$ Further research should focus on implementation and on how the ABC 
tool can be used to help patients create a personalised treatment plan and strengthen their self-management skills.

\section{Conclusions}

The $A B C$ tool appears to be a very useful instrument for consultations with COPD patients. Both patients and healthcare providers believe the tool offers added value and therefore recommend that the $A B C$ tool should be integrated into regular care and consequently into the EMR systems of healthcare providers. 


\section{REFERENCES}

1. Wilkinson A \& Whitehead L. Evolution of the concept of self-care and implications for nurses: a literature review. Int J Nurs Stud 2009;46:1143-1147.

2. Kaptein AA, Fischer MJ \& Scharloo M. Self-management in patients with COPD: theoretical context, content, outcomes, and integration into clinical care. Int J Chron Obstruct Pulmon Dis 2014;9:907-917.

3. Greenhalgh T. Patient and public involvement in chronic illness: beyond the expert patient. $B m j$ 2009;338:b49.

4. Wagner EH, Austin BT, Davis C, Hindmarsh M, Schaefer J \& Bonomi A. Improving chronic illness care: translating evidence into action. Health Aff (Millwood) 2001;20:64-78.

5. Bourbeau J, Nault D \& Dang-Tan T. Self-management and behaviour modification in COPD. Patient Educ Couns 2004;52:271-277.

6. Lorig KR \& Holman H. Self-management education: history, definition, outcomes, and mechanisms. Ann Behav Med 2003;26:1-7.

7. Bodenheimer T, Lorig K, Holman H \& Grumbach K. Patient self-management of chronic disease in primary care. Jama 2002;288:2469-2475.

8. Peek ME, Drum M \& Cooper LA. The Association of Patient Chronic Disease Burden and SelfManagement Requirements With Shared Decision Making in Primary Care Visits. Health Serv Res Manag Epidemiol 2014;1.

9. Jones RC, Hyland ME, Hanney K \& Erwin J. A qualitative study of compliance with medication and lifestyle modification in Chronic Obstructive Pulmonary Disease (COPD). Prim Care Respir J 2004;13:149-154.

10. Bourbeau J, Julien M, Maltais F, Rouleau M, Beaupre A, Begin R, Renzi P, Nault D, Borycki E, Schwartzman K, Singh R, Collet JP \& Chronic Obstructive Pulmonary Disease axis of the Respiratory Network Fonds de la Recherche en Sante du Q. Reduction of hospital utilization in patients with chronic obstructive pulmonary disease: a disease-specific self-management intervention. Arch Intern Med 2003;163:585-591.

11. Labrecque M, Rabhi K, Laurin C, Favreau H, Moullec G, Lavoie K \& Julien M. Can a selfmanagement education program for patients with chronic obstructive pulmonary disease improve quality of life? Can Respir J 2011;18:e77-81.

12. Effing T, Monninkhof EM, van der Valk PD, van der Palen J, van Herwaarden CL, Partidge MR, Walters EH \& Zielhuis GA. Self-management education for patients with chronic obstructive pulmonary disease. Cochrane Database Syst Rev 2007:CD002990.

13. Rollnick S, Miller WR, Butler CC \& Aloia MS. Motivational Interviewing in Health Care: Helping Patients Change Behavior. COPD 2008;5:203-203.

14. Elwyn G, Dehlendorf C, Epstein RM, Marrin K, White J \& Frosch DL. Shared decision making and motivational interviewing: achieving patient-centered care across the spectrum of health care problems. Ann Fam Med 2014;12:270-275.

15. Chew-Graham CA, Hunter C, Langer S, Stenhoff A, Drinkwater J, Guthrie EA \& Salmon P. How QOF is shaping primary care review consultations: a longitudinal qualitative study. BMC Fam Pract 2013;14:103.

16. Gibson PG, Powell H, Coughlan J, Wilson AJ, Hensley MJ, Abramson M, Bauman A \& Walters EH Limited (information only) patient education programs for adults with asthma. Cochrane Database Syst Rev 2002:CD001005.

17. Slok AHM, In 't Veen JCCM, Chavannes NH, van der Molen T, Rutten-van Mölken MPMH, Kerstjens HAM, Salome PL, Holverda S, Dekhuijzen PNR, Schuiten D, Asijee GM \& van Schayck OCP. Development of the Assessment of Burden of COPD tool: an integrated tool to measure the burden of COPD. npj Prim Care Respir Med 2014;24:14021.

18. Hilberink SR, Jacobs JE, Schlosser M, Grol RP \& de Vries H. Characteristics of patients with COPD in three motivational stages related to smoking cessation. Patient Educ Couns 2006;61:449-457.

19. Walters N \& Coleman T. Comparison of the smoking behaviour and attitudes of smokers who attribute respiratory symptoms to smoking with those who do not. Br J Gen Pract 2002;52:132134. 
20. Slok AHM, Bemelmans TCH, Kotz D, Van der Molen T, Kerstjens HAM, in 't Veen JCCM, Chavannes NH, Asijee GM, Rutten-van Mölken MPMH \& van Schayck CP. The Assessment of Burden of COPD (ABC) scale: a reliable and valid questionnaire. COPD 2016;13:431-438.

21. Slok AHM, Kotz D, van Breukelen G, Chavannes NH, Rutten-van Mölken MPMH, Kerstjens HAM, van der Molen T, Asijee GM, Dekhuijzen PNR, Holverda S, Salomé PL, Goossens LMA, Twellaar M, in 't Veen JCCM, van Schayck OCP. Effectiveness of the Assessment of Burden of COPD (ABC) tool on health-related quality of life in patients with COPD: a cluster randomised controlled trial in primary and hospital care. BMJ Open. 2016;6(7):e011519.

22. Hsieh HF \& Shannon SE. Three approaches to qualitative content analysis. Qual Health Res 2005;15:1277-1288.

23. NVivo qualitative data analysis Software; QSR International Pty Ltd. Version 9, 2010.

24. Elliot AJ \& Maier MA. Color psychology: effects of perceiving color on psychological functioning in humans. Annu Rev Psychol 2014;65:95-120.

25. Luck SJ \& Vogel EK. The capacity of visual working memory for features and conjunctions. Nature 1997;390:279-281.

26. Abbas N, Kumar D \& McLachlan N. The psychological and physiological effects of light and colour on space users. Conf Proc IEEE Eng Med Biol Soc 2005;2:1228-1231.

27. Jonauskaite D, Mohr C, Antonietti JP, Spiers PM, Althaus B, Anil S \& Dael N. Most and Least Preferred Colours Differ According to Object Context: New Insights from an Unrestricted Colour Range. PloS one 2016;11:e0152194.

28. Dael N, Perseguers MN, Marchand C, Antonietti JP \& Mohr C. Put on that colour, it fits your emotion: Colour appropriateness as a function of expressed emotion. Q J Exp Psychol (Hove) 2016;69:1619-1630.

29. Cramm JM \& Nieboer AP. Self-management abilities, physical health and depressive symptoms among patients with cardiovascular diseases, chronic obstructive pulmonary disease, and diabetes. Patient Educ Couns 2012;87:411-415.

30. Lorig K, Laurent DD, Plant K, Krishnan E \& Ritter PL. The components of action planning and their associations with behavior and health outcomes. Chronic IIIn 2014;10:50-59.

31. Osterlund Efraimsson E, Klang B, Larsson K, Ehrenberg A \& Fossum B. Communication and selfmanagement education at nurse-led COPD clinics in primary health care. Patient Educ Couns 2009;77:209-217.

32. Newbould J, Burt J, Bower P, Blakeman T, Kennedy A, Rogers A \& Roland M. Experiences of care planning in England: interviews with patients with long term conditions. BMC family practice 2012;13:71.

33. Benzo R, Vickers K, Ernst D, Tucker S, McEvoy C \& Lorig K. Development and feasibility of a selfmanagement intervention for chronic obstructive pulmonary disease delivered with motivational interviewing strategies. J Cardiopulm Rehabil Prev 2013;33:113-123.

34. Hurwitz EL, Morgenstern H, Kominski GF, Yu F \& Chiang LM. A randomized trial of chiropractic and medical care for patients with low back pain: eighteen-month follow-up outcomes from the UCLA low back pain study. Spine 2006;31:611-621; discussion 622.

35. Kerse N, Buetow S, Mainous AG, 3rd, Young G, Coster G \& Arroll B. Physician-patient relationship and medication compliance: a primary care investigation. Ann Fam Med 2004;2:455-461.

36. Pulliam C, Gatchel RJ \& Robinson RC. Challenges to early prevention and intervention: personal experiences with adherence. Clin J Pain 2003;19:114-120.

37. Paulhus DL. Two-component models of socially desirable responding. J Pers Soc Psychol 1984;46:598-609.

38. Fromer L. Implementing chronic care for COPD: planned visits, care coordination, and patient empowerment for improved outcomes. Int J Chron Obstruct Pulmon Dis 2011;6:605-614. 



\section{CHAPTER}

General Discussion 



\section{GENERAL DISCUSSION}

During the last decade, the view on chronic obstructive pulmonary diseases (COPD) is shifting away from focusing only on the measurement of airflow towards a more complex and personalised view of COPD..$^{1-3}$ In 2013, Agusti and MacNee published a paper about the necessity of a 'control panel' in the assessment and management of COPD. ${ }^{4}$ This control panel should be able to guide practitioners towards personalised medicine by providing an overview of the relevant domains of the disease and specific therapeutic requirements. ${ }^{4}$ They proposed three domains - severity, activity and impact - and suggested a visualisation similar to the cockpit of a plane, as shown in Figure 7.1.

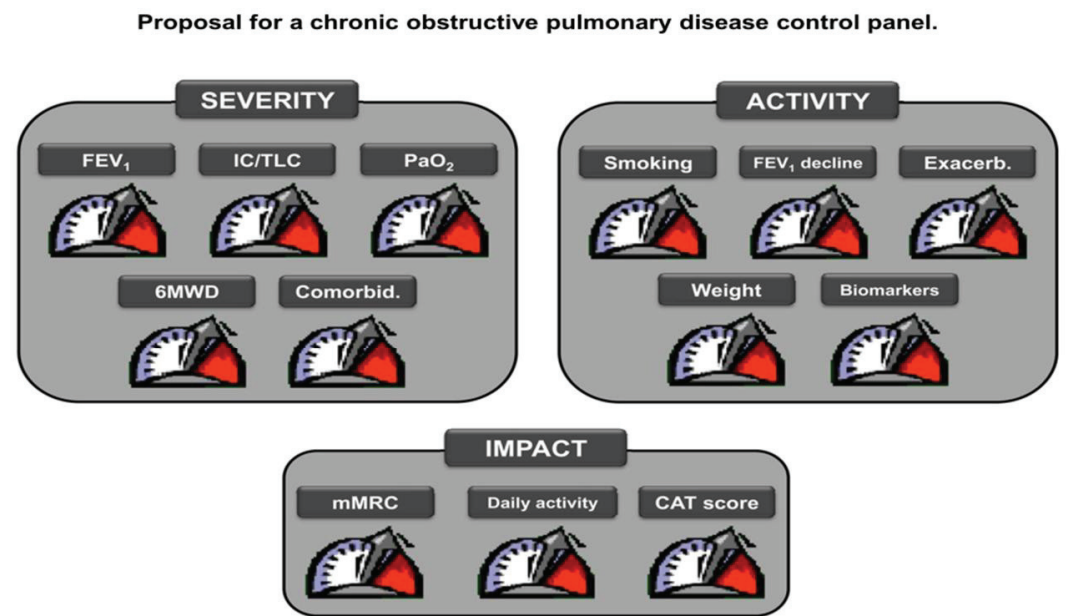

Alvar Agusti, and William MacNee Thorax 2013;68:687-690

Figure 7.1 "Reproduced from The COPD control panel: towards personalised medicine in COPD, Agusti A \& Macnee W, 68, 687-690, 2013, with permission from BMJ Publishing Group Ltd.". 6MWD: 6 min walk distance; CAT: Chronic Obstructive Pulmonary Disease Assessment Test; $\mathrm{FEV}_{1}$ : forced expiratory volume in $1 \mathrm{~s}$; IC/TLC: inspiratory to total lung capacity ratio; mMRC: modified Medical Research Council Dyspnoea Scale; $\mathrm{PaO}_{2}$ : arterial oxygen pressure. ${ }^{4}$

This paper, in which clinicians expressed their view on the management of COPD, is in line with the central positioning of the concept of experienced burden of disease in the Dutch Healthcare Standard. ${ }^{5}$ This shift towards more personalised medicine inspired us to develop a tool compliant with this view.

The rationale behind measuring and visualising the burden of COPD is to provide patients with insights into their own disease and help them take control over it. 
Especially in chronic diseases, patients should take the lead in disease management, metaphorically sitting in the driver's seat next to their healthcare providers.

The aim of this dissertation was therefore to develop and evaluate a tool that measures and visualises the burden of COPD. The tool should not only measure and visualise the experienced burden of COPD, as the core part of the integrated health status, but should also provide treatment advice accordingly, to guide patients and healthcare providers in making tailored treatment plans. We needed to investigate whether it was necessary to develop a new tool, or whether an existing tool could be used for this purpose. Therefore, this study started with defining burden of COPD and formulating the conditions that a tool should meet (e.g., a completion time of less than ten minutes, and visualisation of the outcomes). As described in Chapter 2 of this dissertation, the burden of COPD was defined as follows: "Burden of disease is the physical, emotional, psychological and/or social experiences of a patient with COPD. These experiences influence the patient's ability to cope with the consequences of COPD and its treatment". Additionally, a literature search was conducted to check the literature for existing tools measuring burden of COPD. If no tool was available, a tool had to be developed and then evaluated to test its effectiveness in daily care.

This chapter starts by presenting an overview of the main findings of this study. The implications of these findings for daily practice will then be described. Some methodological issues of the presented study will be discussed which should be considered when interpreting the results. The chapter ends with implications for research, and a general conclusion.

\section{MAIN FINDINGS}

\section{Development of the tool}

The literature review showed that there was no tool available that measures all the aspects of experienced burden of COPD and complies with the predefined conditions a burden of disease tools should meet, for example, visualising the outcomes and providing treatment advice. Therefore, the Assessment of Burden COPD (ABC) tool was developed. The most important part of the $A B C$ tool is the $A B C$ scale which measures experienced burden of COPD. This scale is based on the Clinical COPD Questionnaire (CCQ), which was developed to measure COPD specific health status. ${ }^{6}$ However, the CCQ did not fully comply with the aforementioned conditions and, therefore, was adapted by adding four questions that measured emotions and fatigue, 
resulting in the $A B C$ scale. Patients and their experienced disease burden should be the main focus of the management of COPD; however, objective parameters also should be taken into account. Objective parameters provide information about the physiological aspects of the disease, and can give an indication of potential risks or the necessity of pharmacological treatment. Therefore, lung function parameters and the number of exacerbations were added to the tool. Additionally, since almost all treatment options involve behavioural changes by patients in their lifestyles, items on lifestyle factors (e.g., smoking and physical activity) were added to the tool. Assessment of all these concepts provides an overview of the integrated health status of an individual COPD patient. To make this overview more visible for patients, a visual display was added to the tool (see Figure 7.2). By means of this display, patients receive a direct overview of the domains that have a good score and of the domains that need attention. For the visualisation, we chose to use balloons; every domain of the integrated health status is represented by a coloured balloon. The green balloons towards the top of the figure indicate a satisfactory score in the respective domain, whereas red balloons signify a low score, and orange balloons an intermediate score. Grey balloons were added to the figure, and represent the balloons of previous visits; this provides the opportunity to monitor over time. The five domains of experienced burden of COPD, as measured with the ABC scale, are represented by five balloons; symptoms, functional status, mental status, fatigue and emotions.

\section{Psychometric properties}

When a questionnaire (a patient-reported outcome) is the basis of the assessment and management of a disease, it is important that this questionnaire measures what it is expected to measure, that is, the questionnaire should be valid. Furthermore, the questionnaire should be reliable, which could be established by measuring test-retest reliability and internal consistency. In Chapter 4 , the results of these analyses were described. Since the $A B C$ scale largely consists of the $C C Q$, we expected to find results in line with the CCQ. The psychometric properties of the CCQ have already been studied, and it was found to be a valid questionnaire for research and clinical practice. $^{6-9}$

We used baseline data of the patients enrolled in the intervention group of the cluster randomised controlled trial (RCT). We were able to perform analyses with the data of 162 patients to test the internal consistency of the total scale and its subdomains, the divergent validity and known-groups validity. With data from 137 patients, we were 
able to analyse test-retest reliability, and 133 patients provided data for convergent validity. Results showed that the $A B C$ scale is a reliable and valid questionnaire, with excellent discriminative properties.

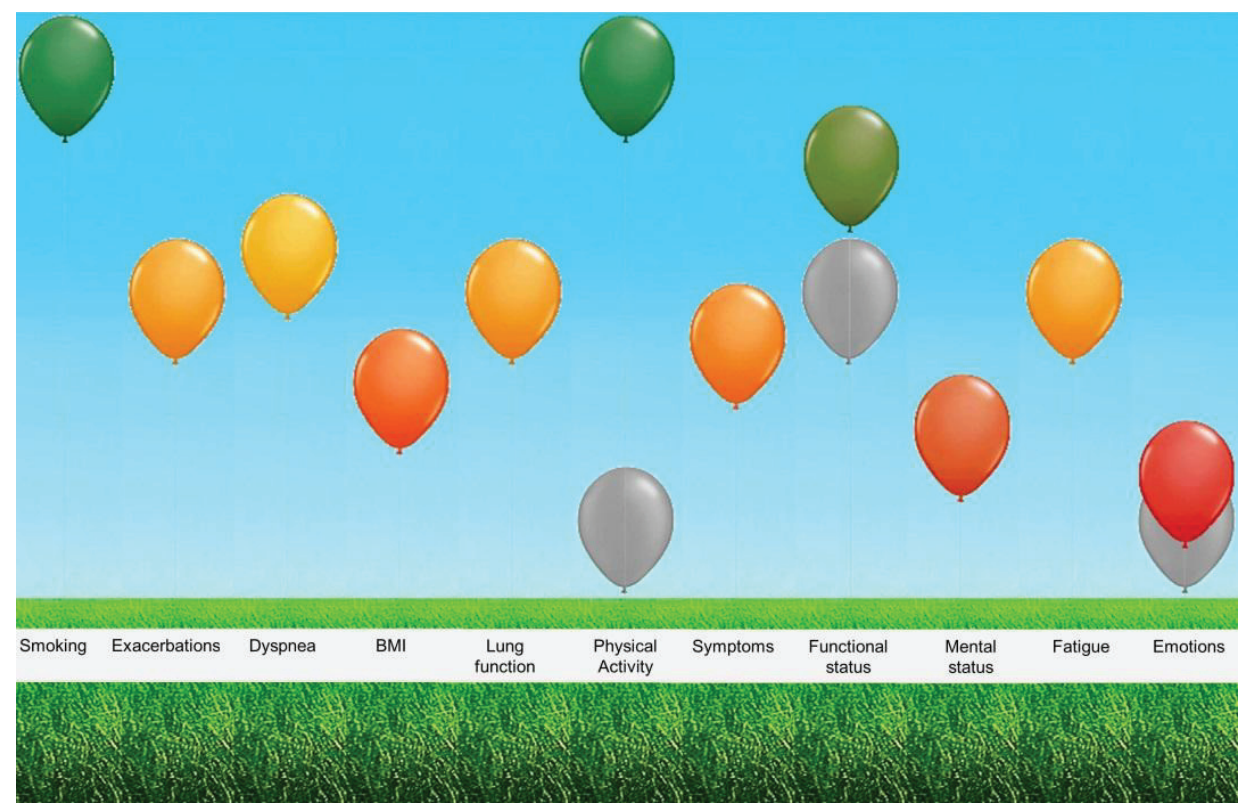

Figure 7.2 Visual overview of the integrated health status of a COPD patient: Follow-up visit; since the previous visit, the patient has increased physical activity, and functional status and emotions have improved.

\section{Effectiveness}

The effectiveness of the $A B C$ tool was tested in a cluster RCT, comparing an intervention group that was given the $A B C$ tool during consultations with a control group that was provided with care as usual. The intervention consisted of: (1) the ABC scale completed by patients, measuring their experienced burden of COPD; (2) additional parameters, such as lung function parameters and risk factors (e.g., smoking) reported by healthcare providers; (3) a visualisation of the integrated health status; (4) a treatment algorithm with possible treatment options to be discussed by patients and healthcare providers; and (5) making a personalised treatment plan. A total of 39 Dutch primary care practices and 17 hospitals recruited 357 patients who provided data to analyse. The primary outcome was the number of patients with a clinically relevant improvement as indicated by the Saint George's Respiratory Questionnaire (SGRQ), a disease-specific quality of life questionnaire, between baseline and 18 months follow-up in the intervention group, compared to those in the 
control group. Results showed that, at 18 months follow-up, $34 \%$ of the patients in the intervention group showed a clinically relevant improvement on the SGRQ compared to $22 \%$ of the patients in the control group - a statistically significant difference. A significant difference in the number of patients improved was also found after 12 months, but not after six months. When comparing the number of patients who had a clinically relevant deterioration, we found no significant (alpha level 1\%) differences between groups. Using a different disease-specific quality of life questionnaire, the COPD Assessment Test, ${ }^{10}$ we found no significant differences between groups. Additionally, the effect of the intervention on perceived quality of care was tested, as evaluated by the patient assessment of chronic illness care (PACIC). ${ }^{11}$ In the intervention group, patients evaluated their perceived quality of care as being significantly better than patients in the control group.

Regarding the COPD Assessment Test (CAT), another disease-specific quality of life questionnaire, we expected to find results comparable to the SGRQ. A systematic review of the CAT ${ }^{12}$ found that it is a reliable, valid, and responsive instrument. Research showed that the CAT and the SGRQ are strongly correlated ${ }^{12-14}$ and in previous studies the CAT and the SGRQ usually showed similar results. ${ }^{15-17}$ In the study reported in this dissertation, the $A B C$ tool was used in stable patients from both primary and hospital care. However, most studies evaluating the responsiveness of the CAT focused on patients with acute exacerbations and on patients receiving pulmonary rehabilitation interventions. ${ }^{18-21}$ This might indicate that the CAT is less sensitive to change in more stable situations than the SGRQ.

No analyses could be performed to evaluate the effect of the intervention on lung function parameters and exacerbations.

\section{Users' experiences}

Interviews with patients and healthcare providers revealed that the $A B C$ tool can be a useful instrument in consultations with COPD patients. The questionnaire is easy to complete, and the visual display provides a clear overview of the integrated health status. Remembering what was discussed during consultation is found to be a major problem in the field of doctor-patient communication, ${ }^{22-24}$ but patients mentioned that the visual overview made it possible to better recollect what was said. The $A B C$ tool facilitates discussion and can function as a starting point in making a treatment 
plan. Some suggestions and recommendations were made to improve the tool for daily use.

\section{IMPLICATIONS FOR DAILY PRACTICE}

Based on the results of the psychometric analyses and the RCT, and the positive experiences of patients and healthcare providers with the $A B C$ tool, it is suggested that the tool could be implemented in daily care.

\section{$A B C$ tool in guidelines}

As part of the implementation process, the tool should be integrated in the different guidelines healthcare providers can use when treating COPD patients in the Netherlands - a process that has already been started. One of the guidelines for the treatment of COPD is provided by the Dutch College of General Practitioners (in Dutch NHG; Nederlands Huisarts Genootschap) for Dutch primary healthcare providers. ${ }^{25}$ In these guidelines, experienced burden of COPD is also described as a core concept to determine the severity of the disease, next to objective lung function parameters. An update of the guidelines was released in 2015; in this version the development of the $A B C$ tool is already mentioned. Furthermore, the Lung Alliance Netherlands released a guideline in 2010 called the Dutch Healthcare Standard, ${ }^{5}$ to connect content and organisation of care, in which the concept of burden of COPD was introduced as the new parameter in the classification of disease severity. As stated earlier, this led to the development of the $A B C$ tool. In the new edition of January $2016,{ }^{26}$ the use of the $A B C$ tool is already advised to monitor the course of the disease, based on the positive results described in this dissertation.

\section{Users of the $A B C$ tool}

The $A B C$ tool can be used by practice nurses (i.e., nurses who work in primary care to support the GPs, especially in chronic disease management such as COPD, asthma and diabetes) and specialist nurses in secondary care to systematically assess different aspects of COPD according to protocols. ${ }^{27-29}$ Nurses can use the provided overview, the balloon display, to help patients formulate a treatment goal and a plan. Additionally, when nurses have completed all the items of the programme resulting in the visual display, it can be used by physicians as a preparation for patients' consultations. For physicians, the tool can contribute to structured agenda-setting, ${ }^{30}$ 
since all relevant aspects related to COPD are assessed and visualised or are included in the treatment advice.

\section{Disease management}

The $A B C$ tool can be used as part of disease management programmes. Often, Wagner's chronic care model (CCM) is used to operationalise disease management. ${ }^{31,32}$ The CCM describes six components, with two components referring to the context in which chronic care is provided (health systems and community), and four components related to the delivery of care (self-management support, delivery system design, decision support, and clinical information systems). ${ }^{33}$ Addressing these components should result in informed activated patients and prepared proactive practice teams, and eventually in improved outcomes. ${ }^{34}$ There are some studies evaluating disease management that have shown an improvement in quality of life. ${ }^{35,36}$ A systematic review by Adams et $\mathrm{al}^{37}$ demonstrated that COPD patients who received an intervention with two or more components of the CCM had less hospitalisations, emergency/unscheduled visits, and a shorter length of stay than patients in a control group.

The $A B C$ tool addresses different components of the CCM. For example, the tool can be used to facilitate self-management support, for example, providing patients with the opportunity to monitor their disease. Furthermore, the $A B C$ tool fits with the decision support component of the CCM, since it encompasses treatment options based on evidence based guidelines, which healthcare providers and patients can discuss together. Research shows that confidence and feedback from healthcare professionals, and patients' knowledge about the role of treatment, is associated with enhanced treatment adherence. ${ }^{38}$

The $A B C$ tool has also been developed to facilitate communication. Effective healthcare provider-patient communication is required for effective management of the disease, ${ }^{39}$ but is often evaluated as inadequate..$^{30,40-42}$ In several studies, an association was found between effective healthcare provider-patient communication and medication adherence, ${ }^{43,44}$ improved patient health outcomes, such as emotional health, symptoms resolution and functional status, ${ }^{45}$ and quality of care and confidence in dealing with breathing problems. ${ }^{46,47}$ 
The results described in this dissertation show that the $A B C$ tool could be of added value to regular COPD care in terms of increased disease-specific quality of life and perceived quality of care. The tool can be used to facilitate shared decision making (SDM) and patient-involvement during consultation, to enable personalised medicine and better self-management. This approach is consistent with the development of evidence based practice whereby healthcare professionals not only use evidence to make medical decisions (evidence based medicine), but also rely on their own clinical expertise and on the preferences, needs and choices of patients ${ }^{48}$.

\section{Shared decision making}

Healthcare providers can use the tool as a facilitator in SDM according to the threeway model of Elwyn and colleagues. ${ }^{49}$ The first step of SDM is to introduce a choice (choice talk); the $A B C$ tool facilitates this by visualising the different components of the integrated health status of COPD and how a patient is functioning in these domains. Domains with room for improvement are represented by red or orange balloons. One or two balloons can be chosen to work on, where patients feel they can achieve an improvement. The second step of SDM is describing options (option talk). In the $A B C$ tool, a treatment algorithm is incorporated that provides treatment options for each domain, according to the current guidelines. It is possible to click on a balloon and a pop-up screen will appear with treatment options. These treatment options, their pros and cons, and the resultant treatment burden can be discussed by the healthcare provider and the patient. The third step in SDM is helping patients to explore their preferences and make decisions (decision talk). When the different treatment options are discussed, the option(s) a patient prefers that could be beneficial for the patient can be selected and automatically placed in the treatment plan; for example, referral to a psychologist or for pulmonary rehabilitation, or a change in medication. Furthermore, the $A B C$ tool provides room to formulate and write down a specific personal goal expressed in the framing of this specific patient.

\section{Personalised care}

When using the $A B C$ tool, healthcare providers can help patients set a goal. Goal setting is seen as an important element of self-management. ${ }^{50,51}$ Self-management aims to help patients develop coping skills to develop or maintain an active lifestyle, to use medication correctly, and to early identify an increase of symptoms possibly leading to an exacerbation. ${ }^{52}$ Self-management is associated with quality of life, ${ }^{53}$ and 
in patients with chronic conditions self-management can result in better health and a decrease in care-consumption. ${ }^{54}$ Goal setting could be used, for example, to help patients make lifestyle changes. It involves a process of negotiating, setting, planning and evaluating. ${ }^{55,56}$ To go beyond standard medical practice, patients' self-efficacy and readiness to change their behaviour could be addressed when discussing a personal goal. $^{57}$

After setting a goal, patients and healthcare providers can discuss an action plan or treatment plan together, which includes planning on how to accomplish the predefined goals. ${ }^{50,56,58}$ The care that is provided should be tailored to the needs of each patient, ${ }^{59}$ and patients should take an active role to express those needs. ${ }^{60}$ The $A B C$ tool can be used as a facilitator in this shift from doctor-driven care towards patientcentred care. By measuring the experienced burden and visualising the integrated health status, patients can be confronted with the parameters associated with their COPD, and the possible treatment options and lifestyle changes needed or recommended to decrease their experienced burden or increase their health status. The tool provides room for writing down a personal goal and the relevant treatment plan.

\section{METHODOLOGICAL CONSIDERATIONS}

When interpreting the results of the study described in this dissertation, some methodological issues should be considered.

\section{Pragmatic design}

When evaluating an intervention, choices have to be made regarding the design of the study and its position on the continuum of explanatory and pragmatic trials. ${ }^{61}$ An explanatory trial is designed to evaluate if and how an intervention works under ideal circumstances (also called a treatment's efficacy), whereas a pragmatic trial evaluates an intervention in everyday clinical settings (effectiveness). Explanatory trials usually have an extensive list of inclusion and exclusion criteria regarding the selection of participants who will probably benefit most from the proof of concept testing; these trials make it possible to control for many possible biases. However, in these trials the generalisability is at stake, since the results usually are not applicable to every patient in regular care. This raises a demand for more trials on the continuum towards pragmatic designs. ${ }^{62}$ However, the downsides of pragmatic trials comprise the large 
sample sizes required and the long follow-up periods necessary to gather evidence. ${ }^{63,64}$ Furthermore, it is not always clear which part of the intervention is responsible for the difference found, since a whole package, with different components, is often evaluated. Or when no difference is found, it is not clear whether the intervention did not work or the implementation of the intervention was unsuccessful. ${ }^{63}$

A trial to evaluate the efficacy of the $A B C$ tool should have been conducted under highly controlled conditions. For example, healthcare providers should have had extensive training in the optimum use of the tool, learning how to use it in the SDM process and to guide patients towards formulating a personal goal. Furthermore, all factors that could have been of influence should have been measured, healthcare providers should have planned more time for each consultation to have enough room per patient to go through the programme, and the trial should have been comprehensively monitored. However, the results of such a study would not have been relevant for daily care situations. Furthermore, it would not have been feasible, due to time and financial constraints, amongst others. Besides these constraints, we were interested in patient-centred outcomes, and not so much in measurable symptoms or clinical/biological markers. The aim of our study was to investigate whether the intervention would work under usual conditions. It was therefore decided to evaluate the $A B C$ tool with a trial on the pragmatic side of the whole spectrum. ${ }^{65}$ We were especially interested in the possibilities of implementation of the tool, meaning that the results of the trial should be applicable in daily care, since the research question arose from daily care. ${ }^{65}$

\section{External validity}

A goal of pragmatic studies is to maximise the external validity, that is, the generalisability of the results to other settings in which the intervention is supposed to be used. However, there are some limitations concerning the generalisability of our results. This trial was conducted in the Netherlands where healthcare is relatively well organised; for example, patients have their own GP who functions as a gatekeeper for secondary care. Additionally, healthcare providers have access to clear guidelines and protocols. These results might therefore not be applicable in other countries with different healthcare systems. Furthermore, external validity might have been compromised by the participating healthcare providers in this trial. Several healthcare 
providers were, at the start, already very enthusiastic about the concept of the newly developed tool, and may have had a predisposed affinity with the topic; this might have resulted in a better implementation of the intervention. In contrast, these healthcare providers had high expectations of the tool, which might have made them more critical when evaluating it.

\section{Internal validity}

The internal validity of this study and its results might have been threatened by some possible biases. ${ }^{66,67}$ Due to the nature of the intervention (i.e., the $A B C$ tool had to become an integrated part of the consultation), blinding and allocation concealment was not possible. Healthcare providers knew to which group they were allocated, and patients obviously noticed this as well. Therefore, a selection bias might have occurred, since healthcare providers could have selectively enrolled patients into the study. Patients who seemed to be not appropriate for the intervention might have been rejected. ${ }^{66}$ At patient level, selective drop-out may have taken place for patients with a clear preference for the group to which they were not allocated.

Furthermore, a performance bias might have occurred if additional interventions were provided to one or both groups. Since the provided care was not monitored, it is not possible to check whether the intervention was properly executed, and whether the usual care was actually performed without additional interventions. ${ }^{66}$ Several studies have showed that trials with no appropriate blinding or allocation concealment often have more statistically significant results than trials that are better controlled. ${ }^{68-70}$ Since blinding of the participants was not possible, analyses of the outcomes were performed on a blinded dataset; that is, coding of treatment groups was unknown to the researchers. De-blinding was performed after drawing conclusions, by all researchers involved, regarding the outcomes.

\section{Missing data}

Not all outcomes could be evaluated due to missing data. Lung function parameters and exacerbation rates consequently were not measured or reported by the healthcare providers, which resulted in too many missing data to be able to perform the intended analyses. This was partly due to the pragmatic design of the study, in which measuring the objective parameters was the responsibility of the healthcare providers. Since we had no insight into the appointments between healthcare 
providers and patients we were not able to monitor or prompt the healthcare providers to use the $A B C$ tool and to report the necessary data. Unfortunately, since we do not have this information at this moment, we are not able to reflect on the effect of the $A B C$ tool on more objective parameters.

\section{Measurements}

\section{Primary outcome}

A matter of discussion in designing the study was the primary outcome measure. Ideally, we would have measured experienced burden of COPD, since the aim of the intervention was to lower the experienced burden. However, the use of a questionnaire as an outcome measure which plays a major part in the intervention was not desirable. Furthermore, there is a wide agreement that questionnaires that are used as outcomes measures should be valid. ${ }^{71}$ Before starting the RCT, the psychometric properties of the $A B C$ scale, measuring experienced burden of COPD, were not known. Preferably, a gold standard for measuring burden of COPD would be used in this type of research; however, since there is none available, the SGRQ was used, a questionnaire that has been used already many times in evaluating intervention studies. $^{72-75}$

\section{Patient-reported outcomes}

In the RCT, we could only analyse self-reported questionnaires, which are prone to biases caused by socially desirable answering ${ }^{76}$ and recall bias. ${ }^{77}$ However, because of the design of the study we were not able to measure and evaluate other outcomes, since this would have involved more patient-contacts with researchers or healthcare providers, which might have led to other biases.

Furthermore, in research with questionnaires there is always a chance of patients already changing their behaviour merely because they are participating in a study and they are being measured ${ }^{78}$ This phenomenon is referred to as the 'Hawthorne effect ${ }^{79}{ }^{79}$ However, this effect is more prone in uncontrolled trials. ${ }^{79}$

\section{Responsiveness}

Additionally, due to different completion times of the $A B C$ scale and the outcomes measures, it was impossible to test the responsiveness of the $A B C$ scale and to determine a minimal clinically important difference. We did not want to influence 
patients' experienced burden of COPD just by the act of measuring; therefore, we decided not to include the $A B C$ scale as an outcome measure in the pack of questionnaires patients had to complete. Consequently, we had no information on experienced burden of COPD in the control group, since in the control group the $A B C$ scale was not measured. Furthermore, the $A B C$ scale was completed as part of the normal practice of the healthcare providers during scheduled consultations. These consultations were planned by the healthcare providers and therefore unknown by the researchers, which made it impossible to synchronise the intervention moments with the measuring moments.

\section{Intervention compliance}

Because the researchers had no information regarding the scheduled appointments, it was not possible to properly monitor the intervention moments, or to prompt healthcare providers to invite a patient to come to the practice for another intervention. This resulted in the fact that not every patient received the intervention four times, as stated in the protocol of the study. Because we analysed data according to the principles of intention to treat, ${ }^{80}$ this might have resulted in an underestimation of the observed effect. ${ }^{81}$

\section{Randomisation level}

When designing the study, another point of discussion concerned whether randomisation should be at patient or healthcare provider level; that is, if cluster randomisation should be carried out. Randomisation at cluster level has some disadvantages. First, there is a chance of selection bias. Unconsciously, knowing to be an intervention group, could influence healthcare providers in the selection of participants. ${ }^{82}$ Furthermore, a disadvantage of randomisation at cluster level is the need for a much larger study population to maintain sufficient power. ${ }^{83}$

However, a major disadvantage of randomisation at individual level is the risk of contamination. This risk could exist at patient level because different patients from the same healthcare provider could meet, for example, in the waiting room; and also at healthcare provider level because there could be a learning effect and healthcare providers could use components of the $A B C$ tool during consultations with patients from the control group. ${ }^{82}$ 
Weighing these disadvantages, and evaluating as more severe the disadvantages of randomisation at patient level, it was decided to randomise on cluster-level, i.e., healthcare providers were randomly assigned to either the intervention or the control group.

\section{Role of the healthcare providers}

Healthcare providers were instructed by a written guide, with instructions on, for example, how to enter the data of a patient in the $A B C$ tool, and how to respond to questions resulting in the balloon-overview. They were not trained in how to optimally use the $A B C$ tool in daily practice, or to use the tool as a facilitator in SDM to guide patients towards making a personalised treatment plan. This might have resulted in a different application of the intervention than intended. Using a tool such as the $A B C$ tool requires a behavioural change, not only in patients but also in healthcare providers. We were convinced of the convenience and the self-evidence of the tool to implement the tool in daily routine. However, when healthcare providers were trained, the effect of the tool might have been even larger.

\section{IMPLICATIONS FOR FUTURE RESEARCH}

When using a questionnaire in clinical settings it is important that this questionnaire is able to measure change, that is, the questionnaire has to be responsive. It is also important to determine a cut-off point that indicates a clinically relevant improvement, or deterioration, within that individual. In the study presented in this dissertation, we were unable to determine a cut-off point that could be used as a minimal clinically important difference (MCID). For the CCQ total score this cut-off point was determined at $0.4 .^{84,85}$ It is expected that the cut-off point for the ABC scale is of the same magnitude, however further research is currently being performed to determine the MCID for the $A B C$ scale.

Further investigation could establish which determinants are related to changes in the disease-specific quality of life. It is important to investigate if behavioural changes occur, and if patients are more in control of their disease. Possible outcomes could be actual behaviour (e.g., smoking, physical activity), number of exacerbations, selfmanagement and SDM. 
Additionally, several smaller studies could be conducted to evaluate the different elements of the tool, such as the visual display of the $A B C$ tool, to investigate the contribution of each element of the tool to the change in quality of life.

Furthermore, it should be investigated how the $A B C$ tool could be optimally used in routine consultations to help patients set personal goals and support their selfmanagement, and also which elements of communication need further elaboration. ${ }^{45}$

Further research is currently being performed to translate the individual scores of the $A B C$ tool into an index. This is done by means of a discrete choice experiment, where COPD patients and persons from the general population can state preferences over hypothetical alternative scenarios. ${ }^{86}$ For example, judging which person is doing worse, the patient who coughs every day or the patient who worries all the time. An overall score from zero to 100 can be generated, based on the different weights attributed to each parameter of burden of COPD. Then cut off points can be calculated, which makes it possible to divide patients in groups of mild, moderate or severe burden of COPD.

Future research could focus on the possibilities of re-designing the $A B C$ tool into a generic burden of chronic illness tool, with generic elements and more diseasespecific modules. Almost $13 \%$ of the total Dutch population and $37 \%$ of patients of 55 years and older have two or more chronic diseases. ${ }^{87}$ By using a more integrated approach in the management of chronic diseases fragmented care could be prevented or resolved, since there is a major overlap in possible treatment options. Almost all of these treatments involve behavioural changes of the patients in relation to lifestyle. There might also be an overlap in factors that determine experienced burden of disease, such as emotional factors and fatigue. It should be investigated which of the factors that determine experienced burden of COPD show an overlap with factors determining experienced burden of other chronic conditions, such as asthma and diabetes. A more person-centred approach in the management of chronic conditions ${ }^{88}$ might result in a lower experienced disease burden and an increased health related quality of life in chronic patients, and might also have an effect on healthcare use and, therefore, healthcare costs. Funding already has been provided to develop an instrument that can also be used in other chronic conditions. 


\section{CONCLUSION}

The $A B C$ tool was designed to be used as an element in disease management, where healthcare providers can act as facilitators, and patients can take on an active role. ${ }^{89}$ Self-management is a key element of disease management; in order to increase selfmanagement skills, patients have to gain knowledge, skills and confidence to be able to deal with their experienced burden of COPD. ${ }^{89}$ The $A B C$ tool can be used as a facilitator in this process.

Our intervention study showed that a tool to measure and visualise the experienced burden of COPD was effective, compared to usual care. In the intervention group, significantly more patients had a minimal clinically relevant improvement in diseasespecific quality of life, as measured by the SGRQ. Additionally, patients using the $A B C$ tool evaluated their perceived quality of care as significantly better. Depth interviews with healthcare providers and patients revealed that the overall feeling about the tool is very positive, and most participants recommended to implement the tool to be used in daily COPD care. Based on the positive results and experiences described in this dissertation, a process has already been started to implement the $A B C$ tool in daily care in the Netherlands. 


\section{REFERENCES}

1. Agusti A, Sobradillo P \& Celli B. Addressing the complexity of chronic obstructive pulmonary disease: from phenotypes and biomarkers to scale-free networks, systems biology, and P4 medicine. Am J Respir Crit Care Med 2011;183:1129-1137.

2. Papaioannou Al, Loukides S, Gourgoulianis KI \& Kostikas K. Global assessment of the COPD patient: time to look beyond FEV1? Respir Med 2009;103:650-660.

3. Agusti A. The path to personalised medicine in COPD. Thorax 2014;69:857-864.

4. Agusti A \& Macnee W. The COPD control panel: towards personalised medicine in COPD. Thorax 2013;68:687-690.

5. Long Alliantie Nederland. Zorgstandaard COPD. Amersfoort:Long Alliantie Nederland; 2010.

6. Van der Molen T, Willemse B, Schokker S, Ten Hacken N, Postma D \& Juniper E. Development, validity and responsiveness of the Clinical COPD Questionnaire. Health Qual Life Outcomes 2003;1:13.

7. Stallberg B, Nokela M, Ehrs PO, Hjemdal P \& Jonsson EW. Validation of the clinical COPD Questionnaire (CCQ) in primary care. Health Qual Life Outcomes 2009;7.

8. Kocks JW, Kerstjens HA, Snijders SL, de Vos B, Biermann JJ, van Hengel P, Strijbos JH, Bosveld HE \& van der Molen T. Health status in routine clinical practice: validity of the clinical COPD questionnaire at the individual patient level. Health Qual Life Outcomes 2010;8:135.

9. Kon SS, Dilaver D, Mittal M, Nolan CM, Clark AL, Canavan JL, Jones SE, Polkey MI \& Man WD. The Clinical COPD Questionnaire: response to pulmonary rehabilitation and minimal clinically important difference. Thorax 2013;69:793-798.

10. Jones PW, Harding G, Berry P, Wiklund I, Chen WH \& Kline Leidy N. Development and first validation of the COPD Assessment Test. Eur Respir J 2009;34:648-654.

11. Glasgow RE, Wagner EH, Schaefer J, Mahoney LD, Reid RJ \& Greene SM. Development and validation of the Patient Assessment of Chronic Illness Care (PACIC). Med Care 2005;43:436-444.

12. Gupta N, Pinto LM, Morogan A \& Bourbeau J. The COPD assessment test: a systematic review. Eur Respir J 2014;44:873-884.

13. Tsiligianni IG, van der Molen T, Moraitaki D, Lopez I, Kocks JW, Karagiannis K, Siafakas N \& Tzanakis N. Assessing health status in COPD. A head-to-head comparison between the COPD assessment test (CAT) and the clinical COPD questionnaire (CCQ). BMC Pulm Med 2012;12:20.

14. Sarioglu N, Hismiogullari AA, Bilen C \& Erel F. Is the COPD assessment test (CAT) effective in demonstrating the systemic inflammation and other components in COPD? Rev Port Pneumol 2015;22:11-17.

15. Siler TM, Kerwin E, Singletary K, Brooks J \& Church A. Efficacy and Safety of Umeclidinium Added to Fluticasone Propionate/Salmeterol in Patients with COPD: Results of Two Randomized, Double-Blind Studies. Copd 2015;13:1-10.

16. Mendoza L, Horta P, Espinoza J, Aguilera M, Balmaceda N, Castro A, Ruiz M, Diaz O \& Hopkinson NS. Pedometers to enhance physical activity in COPD: a randomised controlled trial. Eur Respir $J$ 2015;45:347-354.

17. Ghobadi H, Lari SM, Pourfarzi F, Mahmoudpour A \& Ghanei M. The effects of atorvastatin on mustard-gas-exposed patients with chronic obstructive pulmonary disease: A randomized controlled trial. J Res Med Sci 2014;19:99-105.

18. Dodd JW, Hogg L, Nolan J, Jefford H, Grant A, Lord VM, Falzon C, Garrod R, Lee C, Polkey MI, Jones PW, Man WD \& Hopkinson NS. The COPD assessment test (CAT): response to pulmonary rehabilitation. A multicentre, prospective study. Thorax 2011;66:425-429.

19. Dodd JW, Marns PL, Clark AL, Ingram KA, Fowler RP, Canavan JL, Patel MS, Kon SS, Hopkinson NS, Polkey MI, Jones PW \& Man WD. The COPD Assessment Test (CAT): short- and medium-term response to pulmonary rehabilitation. Copd 2012;9:390-394.

20. Kon SS, Clark AL, Dilaver D, Canavan JL, Patel MS, Polkey MI \& Man WD. Response of the COPD Assessment Test to pulmonary rehabilitation in unselected chronic respiratory disease. Respirology 2013;18:974-977. 
21. Jones PW, Harding G, Wiklund I, Berry P, Tabberer M, Yu R \& Leidy NK. Tests of the responsiveness of the COPD assessment test following acute exacerbation and pulmonary rehabilitation. Chest 2012;142:134-140.

22. Kessels RP. Patients' memory for medical information. J R Soc Med 2003;96:219-222.

23. Ley P. Memory for medical information. BrJ Soc Clin Psychol 1979;18:245-255.

24. McGuire LC. Remembering what the doctor said: organization and adults' memory for medical information. Exp Aging Res 1996;22:403-428.

25. Smeele IJM, Van Weel C, Van Schayck CP, Van der Molen T, Thoonen B, Schermer T, Sachs APE, Muris JWM, Chavannes NH, Kolnaar BGM, Grol MH \& Geijer RMM. NHG Standaard- COPD [Dutch national guideline COPD in primary care]. 2007;50:362-379.

26. Long Alliantie Nederland. Zorgstandaard COPD. Amersfoort:Long Alliantie Nederland; 2016.

27. Duff LA, Kitson AL, Seers K \& Humphris D. Clinical guidelines: an introduction to their development and implementation. J Adv Nurs 1996;23:887-895.

28. Dowling S, Martin R, Skidmore P, Doyal L, Cameron A \& Lloyd S. Nurses taking on junior doctors' work: a confusion of accountability. BMJ 1996;312:1211-1214.

29. Paley G. A framework for clinical protocols. Nurs Stand 1995;9:33-35.

30. Marvel MK, Epstein RM, Flowers K \& Beckman HB. Soliciting the patient's agenda: have we improved? JAMA 1999;281:283-287.

31. Wagner EH, Bennett SM, Austin BT, Greene SM, Schaefer JK \& Vonkorff M. Finding common ground: patient-centeredness and evidence-based chronic illness care. J Altern Complement Med 2005;11 Suppl 1:S7-15.

32. Wagner EH, Austin BT, Davis C, Hindmarsh M, Schaefer J \& Bonomi A. Improving chronic illness care: translating evidence into action. Health Aff (Millwood) 2001;20:64-78.

33. de Bruin SR, Heijink R, Lemmens LC, Struijs JN \& Baan CA. Impact of disease management programs on healthcare expenditures for patients with diabetes, depression, heart failure or chronic obstructive pulmonary disease: a systematic review of the literature. Health policy 2011;101:105-121.

34. Bodenheimer T, Wagner EH \& Grumbach K. Improving primary care for patients with chronic illness: the chronic care model, Part 2. JAMA 2002;288:1909-1914.

35. Lemmens KM, Nieboer AP \& Huijsman R. A systematic review of integrated use of diseasemanagement interventions in asthma and COPD. Respir Med 2009;103:670-691.

36. Peytremann-Bridevaux I, Staeger P, Bridevaux PO, Ghali WA \& Burnand B. Effectiveness of chronic obstructive pulmonary disease-management programs: systematic review and metaanalysis. Am J Med Sci 2008;121:433-443 e434.

37. Adams SG, Smith PK, Allan PF, Anzueto A, Pugh JA \& Cornell JE. Systematic review of the chronic care model in chronic obstructive pulmonary disease prevention and management. Arch Intern Med 2007;167:551-561.

38. George J, Kong DC \& Stewart K. Adherence to disease management programs in patients with COPD. Int J Chron Obstruct Pulmon Dis 2007;2:253-262.

39. Nelson M \& Hamilton HE. Improving in-office discussion of chronic obstructive pulmonary disease: results and recommendations from an in-office linguistic study in chronic obstructive pulmonary disease. Am J Med Sci 2007;120:S28-32.

40. Levinson W, Gorawara-Bhat R \& Lamb J. A study of patient clues and physician responses in primary care and surgical settings. JAMA 2000;284:1021-1027.

41. Mjaaland TA, Finset A, Jensen BF \& Gulbrandsen P. Physicians' responses to patients' expressions of negative emotions in hospital consultations: a video-based observational study. Patient Educ Couns 2011;84:332-337.

42. Curtis JR, Engelberg RA, Wenrich MD \& Au DH. Communication about palliative care for patients with chronic obstructive pulmonary disease. J Palliat Care 2005;21:157-164.

43. Safran DG, Taira DA, Rogers WH, Kosinski M, Ware JE \& Tarlov AR. Linking primary care performance to outcomes of care. J Fam Pract 1998;47:213-220.

44. Stewart M, Brown JB, Donner A, McWhinney IR, Oates J, Weston WW \& Jordan J. The impact of patient-centered care on outcomes. J Fam Pract 2000;49:796-804.

45. Stewart MA. Effective physician-patient communication and health outcomes: a review. CMA $1995 ; 152: 1423-1433$. 
46. Slatore CG, Cecere LM, Reinke LF, Ganzini L, Udris EM, Moss BR, Bryson CL, Curtis JR \& Au DH. Patient-clinician communication: associations with important health outcomes among veterans with COPD. Chest 2010;138:628-634.

47. Arora NK. Interacting with cancer patients: the significance of physicians' communication behavior. Soc Sci Med 2003;57:791-806.

48. McKibbon KA. Evidence-based practice. Bull Med Libr Assoc;1998;86:396-401.

49. Elwyn G, Frosch D, Thomson R, Joseph-Williams N, Lloyd A, Kinnersley P, Cording E, Tomson D, Dodd C, Rollnick S, Edwards A \& Barry M. Shared decision making: a model for clinical practice. $J$ Gen Intern Med 2012;27:1361-1367.

50. Bodenheimer T \& Handley MA. Goal-setting for behavior change in primary care: an exploration and status report. Patient Educ Couns 2009;76:174-180.

51. Coleman MT \& Newton KS. Supporting self-management in patients with chronic illness. Am Fam Physician 2005;72:1503-1510.

52. Bucknall CE, Miller G, Lloyd SM, Cleland J, McCluskey S, Cotton M, Stevenson RD, Cotton P \& McConnachie A. Glasgow supported self-management trial (GSUST) for patients with moderate to severe COPD: randomised controlled trial. Bmj 2012;344:e1060.

53. Benzo RP, Abascal-Bolado B \& Dulohery MM. Self-management and quality of life in chronic obstructive pulmonary disease (COPD): The mediating effects of positive affect. Patient Educ Couns 2015;99:617-623.

54. Heijmans, M., Lemmens, L., Otten, W., Havers, J., Baan, C., Rijken, M. Zelfmanagement door mensen met chronische ziekten: kennissynthese van onderzoek en implementatie in Nederland. Utrecht, NIVEL, 2015.

55. Rosewilliam S, Roskell CA \& Pandyan AD. A systematic review and synthesis of the quantitative and qualitative evidence behind patient-centred goal setting in stroke rehabilitation. Clin Rehabil 2011;25:501-514.

56. Scobbie L, Dixon D \& Wyke S. Goal setting and action planning in the rehabilitation setting: development of a theoretically informed practice framework. Clin Rehabil 2011;25:468-482.

57. Dye CJ, Williams JE \& Evatt JH. Activating Patients for Sustained Chronic Disease SelfManagement: Thinking Beyond Clinical Outcomes. J Prim Care Community Health 2016;7:107112.

58. Thoolen B, de Ridder D, Bensing J, Gorter K \& Rutten G. Beyond Good Intentions: the development and evaluation of a proactive self-management course for patients recently diagnosed with type 2 diabetes. Health Educ Res 2008;23:53-61.

59. Vliet Vlieland TP. Managing chronic disease: evidence-based medicine or patient centred medicine? Health Care Anal 2002;10:289-298.

60. Hibbard JH, Mahoney ER, Stock R \& Tusler M. Do increases in patient activation result in improved self-management behaviors? Health Serv Res 2007;42:1443-1463.

61. Schwartz D \& Lellouch J. Explanatory and pragmatic attitudes in therapeutical trials. J Chronic Dis 1967;20:637-648.

62. Zwarenstein M, Oxman A \& Pragmatic Trials in Health Care S. Why are so few randomized trials useful, and what can we do about it? J Clin Epidemiol 2006;59:1125-1126.

63. Macpherson H. Pragmatic clinical trials. Complement Ther Med 2004;12:136-140.

64. March J, Kraemer HC, Trivedi M, Csernansky J, Davis J, Ketter TA \& Glick ID. What have we learned about trial design from NIMH-funded pragmatic trials? Neuropsychopharmacology 2010;35:2491-2501.

65. Patsopoulos NA. A pragmatic view on pragmatic trials. Dialogues Clin Neurosci 2011;13:217-224.

66. Higgins JP, Altman DG, Gotzsche PC, Juni P, Moher D, Oxman AD, Savovic J, Schulz KF, Weeks L, Sterne JA, Cochrane Bias Methods G \& Cochrane Statistical Methods G. The Cochrane Collaboration's tool for assessing risk of bias in randomised trials. BMJ 2011;343:d5928.

67. Juni P, Altman DG \& Egger M. Systematic reviews in health care: Assessing the quality of controlled clinical trials. BMJ 2001;323:42-46.

68. Wood L, Egger M, Gluud LL, Schulz KF, Juni P, Altman DG, Gluud C, Martin RM, Wood AJ \& Sterne JA. Empirical evidence of bias in treatment effect estimates in controlled trials with different interventions and outcomes: meta-epidemiological study. BMJ 2008;336:601-605. 
69. Odgaard-Jensen J, Vist GE, Timmer A, Kunz R, Akl EA, Schunemann H, Briel M, Nordmann AJ, Pregno $S$ \& Oxman AD. Randomisation to protect against selection bias in healthcare trials. Cochrane Database Syst Rev 2011:MR000012.

70. Pildal J, Hrobjartsson A, Jorgensen KJ, Hilden J, Altman DG \& Gotzsche PC. Impact of allocation concealment on conclusions drawn from meta-analyses of randomized trials. Int J Epidemiol 2007;36:847-857.

71. Hoffmann W, Latza U, Terschuren C \& Deutsche Arbeitsgemeinschaft fur Epidemiologie DGFMIBuEDGfSUPDRdIBG. [Guidelines and recommendations for ensuring Good Epidemiological Practice (GEP) -- revised version after evaluation]. Gesundheitswesen 2005;67:217-225.

72. Vincken W, van Noord JA, Greefhorst AP, Bantje TA, Kesten S, Korducki L, Cornelissen PJ \& Dutch/Belgian Tiotropium Study G. Improved health outcomes in patients with COPD during 1 yr's treatment with tiotropium. Eur Respir J 2002;19:209-216.

73. Harper R, Brazier JE, Waterhouse JC, Walters SJ, Jones NM \& Howard P. Comparison of outcome measures for patients with chronic obstructive pulmonary disease (COPD) in an outpatient setting. Thorax 1997;52:879-887.

74. Osman IM, Godden DJ, Friend JA, Legge JS \& Douglas JG. Quality of life and hospital re-admission in patients with chronic obstructive pulmonary disease. Thorax 1997;52:67-71.

75. Man WD, Polkey MI, Donaldson N, Gray BJ \& Moxham J. Community pulmonary rehabilitation after hospitalisation for acute exacerbations of chronic obstructive pulmonary disease: randomised controlled study. BMJ 2004;329:1209.

76. Paulhus DL. Two-component models of socially desirable responding. J Pers Soc Psychol 1984;46:598-609.

77. Coughlin SS. Recall bias in epidemiologic studies. J Clin Epidemiol 1990;43:87-91.

78. Sciurba F \& Rennard SI. Rationale for a redundant formulary. The Hawthorne effect and the art of medicine. Am J Respir Crit Care Med 2015;191:1224-1225.

79. Bouchet C, Guillemin F \& Briancon S. Nonspecific effects in longitudinal studies: impact on quality of life measures. J Clin Epidemiol 1996;49:15-20.

80. Hollis $S$ \& Campbell F. What is meant by intention to treat analysis? Survey of published randomised controlled trials. BMJ 1999;319:670-674.

81. Victora CG, Habicht JP \& Bryce J. Evidence-based public health: moving beyond randomized trials. Am J Public Health 2004;94:400-405.

82. Torgerson DJ. Contamination in trials: is cluster randomisation the answer? BMJ 2001;322:355357.

83. Bland JM \& Kerry SM. Statistics notes. Trials randomised in clusters. BMJ 1997;315:600.

84. Kocks JW, Tuinenga MG, Uil SM, van den Berg JW, Stahl E \& van der Molen T. Health status measurement in COPD: the minimal clinically important difference of the clinical COPD questionnaire. Respir Res 2006;7:62.

85. Kon SS, Dilaver D, Mittal M, Nolan CM, Clark AL, Canavan JL, Jones SE, Polkey MI \& Man WD. The Clinical COPD Questionnaire: response to pulmonary rehabilitation and minimal clinically important difference. Thorax 2014;69:793-798.

86. de Bekker-Grob EW, Ryan M \& Gerard K. Discrete choice experiments in health economics: a review of the literature. Health Econ 2012;21:145-172.

87. van Oostrom SH, Picavet HS, van Gelder BM, Lemmens LC, Hoeymans N, van Dijk CE, Verheij RA, Schellevis FG \& Baan CA. Multimorbidity and comorbidity in the Dutch population - data from general practices. BMC public health 2012;12:715.

88. Dwamena F, Holmes-Rovner M, Gaulden CM, Jorgenson S, Sadigh G, Sikorskii A, Lewin S, Smith RC, Coffey J \& Olomu A. Interventions for providers to promote a patient-centred approach in clinical consultations. Cochrane Database Syst Rev 2012;12:CD003267.

89. Bourbeau J, Sharafkhaneh A \& Adams SG. Disease Management Programs for COPD. COPD: A Guide to Diagnosis and Clinical Management. New York Dordrecht Heidelberg London:Springer 2011. 
SUMMARY 



\section{SUMMARY}

Chapter 1 starts with an introduction of this dissertation. Chronic Obstructive Pulmonary Disease (COPD) is a chronic condition that affects millions of people worldwide, and approximately 360,000 people in the Netherlands. It is a major cause of morbidity, the fourth leading cause of death in the world and the seventh leading cause of disability adjusted life years in 2030. In developed countries, the major risk factor for COPD is tobacco smoking, but there are also other environmental factors and genetic factors that can cause COPD. Possible symptoms of COPD are dyspnoea, cough, sputum production, wheezing and chest tightness, and in severe cases also fatigue, weight loss and anorexia. Sometimes, patients have an exacerbation, which is an acute event characterised by a worsening of the patients' respiratory symptoms that is beyond normal day to day variations, and leads to a change in medication. In the management of COPD there is a shift; away from merely focussing on biomedical factors and doctor-driven care, towards evaluating psychosocial factors and patient self-management. A holistic approach is desirable, where next to the evaluation of biomedical outcomes of the disease, there is also room for psychosocial aspects. Patient-reported outcomes, such as experienced burden of COPD, can be used in this approach as outcomes parameters.

In the Dutch Healthcare standard COPD the concept of experienced burden of COPD is positioned as a central theme and starting point in the assessment and management of COPD. Despite the fact that this concept is classified and accepted as extremely relevant, it has not yet been fully operationalised. Therefore, in 2010 the Lung Alliance Netherlands (in Dutch: Long Alliantie Nederland) assembled a nationwide expert group, to develop a tool that assesses integrated health status, with patients' experienced disease burden as core focus, to be used in daily care. Furthermore, the tool needs to facilitate in shared decision making and goal setting; healthcare providers should be able to use the tool in daily practice to help patients to get involved in making their own individualised care plan. This chapter describes four research aims: (1) To develop an instrument that measures burden of COPD; (2) To determine the validity and reliability of the questionnaire that measures burden of COPD; (3) To evaluate the effectiveness of the newly developed tool on diseasespecific quality of life, compared to usual COPD care, in COPD patients; and (4) To evaluate the experiences of COPD patients and healthcare professionals with the newly developed tool. 
Chapter 2 describes the development of an integrated tool to assess the burden of COPD in daily practice. Five consecutive steps were taken to develop this tool. 1) Defining the burden of COPD, 2) Checking whether the definition is compatible with the experiences of patients and healthcare providers, 3) Formulating requirements an instrument should meet, 4) Conducting a systematic review, 5) Developing an integrated tool.

A definition of the burden of COPD was formulated by a Dutch expert team. Interviews showed that patients and healthcare providers agreed on this definition. We found no existing instruments that fully measured burden of disease according to this definition. However, the Clinical COPD Questionnaire (CCQ) meets most requirements, and was therefore used and adapted. The adapted questionnaire is called the Assessment of Burden of COPD (ABC) scale. In addition, the ABC-tool was developed, a computer program with an algorithm that visualises the outcomes and provides treatment advice. The $A B C$-scale and tool were developed to assess and visualise the burden of COPD. The next step is to test the validity and effectiveness of both the $A B C$-scale and tool in daily practice.

Chapter 3 describes the study protocol to evaluate the $A B C$ tool. A cluster randomised controlled trial will be conducted in COPD patients in both primary and secondary care throughout the Netherlands. An intervention group, receiving care based on the $A B C$ tool, will be compared with a control group receiving usual care. The primary outcome will be the change in score on a disease-specific-quality-of-life questionnaire, the Saint George Respiratory Questionnaire. Secondary outcomes will be a different questionnaire (the COPD Assessment Test), lung function and number of exacerbations. During the 18 months follow-up, seven measurements will be conducted, including a baseline and final measurement. Patients will receive questionnaires to be completed at home. Additional data, such as number of exacerbations, will be recorded by the patients' healthcare providers. A total of 360 patients will be recruited by 40 general practitioners and 20 pulmonologists. Additionally, a process evaluation will be performed among patients and healthcare providers.

Chapter 4 describes the evaluation of the psychometric properties of the ABC scale. The newly developed scale is a 14-item self-administered questionnaire which measures the physical, psychological, emotional and/or social burden as experienced 
by patients with COPD. The $A B C$ scale is part of the $A B C$ tool that visualises the outcomes of the questionnaire. This multi-centre survey study was conducted in the practices of 19 general practitioners and 9 pulmonologists throughout the Netherlands. Next to the ABC scale, patients with COPD completed the Saint George Respiratory Questionnaire (SGRQ). Reliability analyses were performed with data from 162 cases. Cronbach's alpha was 0.91 for the total scale. Test-retest reliability, measured at a two week interval ( $n=137)$, had an intra-class correlation coefficient of 0.92. Analyses for convergent validity were performed with data from 133 cases. Discriminant and known-groups validity was analysed with data from 162 cases. The $A B C$ scale total score had a strong correlation with the total score of the SGRQ $(r=0.72, p<0.001)$ but a weak correlation with the forced expired volume in 1 second predicted $(r=-0.28, p<0.001)$. Subgroups with more severe disease, defined by GOLDstage, frequency of exacerbations, activity level and depression scored statistically significantly $(p<0.05)$ worse on almost all domains of the $A B C$ scale than the less severe subgroups. The $A B C$ scale seems a valid and reliable tool with good discriminative properties.

Chapter 5 describes the results of a pragmatic cluster-randomised controlled trial that was conducted in the Netherlands in 39 Dutch primary care practices and 17 hospitals, with 357 COPD (post-bronchodilator $\mathrm{FEV}_{1} / \mathrm{FVC}$ ratio<0.7) patients. Patient could participate if they were $\geq 40$ years of age and could understand and read the Dutch language. Healthcare providers were randomly assigned to the intervention or control group. The intervention group applied the $A B C$ tool, which consists of a short validated questionnaire assessing the experienced burden of COPD, objective COPD parameter (e.g., lung function), and a treatment algorithm including a visual display and treatment advice. The control group provided usual care. Researchers were blinded to group allocation during analyses. Primary outcome was the number of patients with a clinically relevant improvement in SGRQ-score between baseline and 18-month follow-up. Secondary outcomes were the COPD Assessment Test (CAT) and the Patient Assessment of Chronic Illness Care (PACIC; a measurement of perceived quality of care). At 18 months follow-up 34\% of the 146 patients from 27 healthcare providers in the intervention group showed a clinically relevant improvement in the SGRQ, compared with $22 \%$ of the 148 patients from 29 healthcare providers in the control group (OR 1.85, 95\% Cl 1.08 to 3.16). No difference was found on the CAT (-0.26 points (scores ranging from 0 to 40 ); $95 \% \mathrm{Cl}-1.52$ to 0.99 ). The $\mathrm{PAClC}$ showed a 
higher improvement in the intervention group (0.32 points (scores ranging from 1 to 5): $95 \% \mathrm{Cl}, 0.14$ to 0.50$)$. This study showed that use of the $A B C$ tool may increase quality of life and perceived quality of care.

In Chapter 6 a qualitative study is described in which we performed in-depth interviews with 15 healthcare providers and 21 patients who had worked with the $A B C$ tool in daily care during the intervention study. In general, participants responded positively to the tool. Healthcare providers felt the visual representation provided was effective and comprehensible for patients and provided them insight into their disease, a finding which patients confirmed. If patients were allowed to choose between a consultation with or without the $A B C$ tool, the majority would prefer using the tool: it provides them with an overview and insight, which makes it easier to discuss all relevant topics related to COPD. The tool can provide structure in consultations, and is compatible with the concepts of "motivational interviewing" and "individualised care planning". Suggestions for improvement related layout and content. So far, the tool has only been available as a separate program in addition to the electronic medical record system. It was therefore suggested that the tool be integrated into the systems to enhance its usability and the success of its implementation.

Chapter 7 presents the general discussion of this dissertation. Results of the study are described and implications for daily practice are listed. It is discussed how the $A B C$ tool should be implemented in healthcare guidelines, how it will probably be used mainly by practice nurses and nurse specialists, and how it can be part of a disease management program, where it can facilitate in shared-decision making and goal setting. Methodological issues regarding the design of the study, the internal and external validity and measurement instruments are then discussed. Furthermore, implications for further research are described. The responsiveness of the tool and an minimal clinically important difference should be determined. The determinants responsible for the change in quality of life should be investigated, and it should be investigated whether it is possible to make a burden of disease tool that is also suitable for other chronic conditions. 
SAMENVATTING 

In dit proefschrift wordt de ontwikkeling en evaluatie van de Ziektelastmeter COPD beschreven. In de Engelse artikelen wordt de Ziektelastmeter COPD beschreven als de Assessment of Burden of COPD ( $A B C)$ scale, die de ervaren ziektelast bij patiënten meet, en de $A B C$ tool, het complete instrument dat naast ziektelast ook de fysiologische stoornis meet en waar een behandelalgoritme de uitkomsten visualiseert en behandeladviezen genereert. In deze Nederlandse samenvatting zullen ook de termen $A B C$ scale en $A B C$ tool worden gebruikt.

Hoofdstuk 1 beschrijft de achtergrond en doelstellingen van dit proefschrift. Chronic Obstructive Pulmonary Disease (COPD) is een chronische luchtwegaandoening waar wereldwijd miljoenen mensen last van hebben. In Nederland ligt het aantal COPD patiënten rond 360.000. Verwacht wordt dat het in 2030 wereldwijd op de $4^{\mathrm{e}}$ plek staat van doodsoorzaken en de $7^{\mathrm{e}}$ plek voor verloren levensjaren door leven met een beperking. In Westerse landen is de grootste risicofactor voor COPD het roken van tabak, maar er zijn ook omgevingsfactoren en genetische factoren die COPD kunnen veroorzaken.

Mogelijke symptomen van COPD zijn benauwdheid, hoesten, slijm ophoesten, piepende ademhaling, een beklemmend gevoel op de borst en in ernstige gevallen ook vermoeidheid, gewichtsverlies en anorexia. Soms krijgen patiënten een exacerbatie, ook wel longaanval genoemd. Dit is een plotselinge verergering van de respiratoire symptomen van patiënten die verder gaat dan de normale van dag tot dag schommelingen en die leiden tot een verandering in medicatie.

In de behandeling van COPD is een verandering gaande; weg van alleen maar focussen op biomedische factoren en arts-gestuurde zorg, richting het evalueren van psychosociale factoren en het bevorderen van zelfmanagement van patiënten. Een meer holistische benadering is wenselijk, waar naast de evaluatie van biomedische uitkomsten van de ziekte ook ruimte is voor psychosociale aspecten en de beleving van de ziekte. Voor deze benadering kunnen patient-reported outcomes (PROs), zoals ervaren ziektelast, als uitkomstparameters worden gebruikt.

In de Nederlandse Zorgstandaard COPD die uitkwam in 2010, is het concept 'ziektelast' genoemd als uitgangspunt voor het meten van de ernst van COPD en de behandeling. Echter, dit concept was nog niet geoperationaliseerd. Daarom heeft de Long Alliantie Nederland een werkgroep samengesteld om een instrument te ontwikkelen dat ziektelast meet bij de patiënt met COPD, als onderdeel van de integrale gezondheidstoestand. Verder moet het instrument in staat zijn om de 
gezamenlijke besluitvorming en het stellen van doelen te faciliteren. Zorgverleners moeten het instrument in de dagelijkse zorg kunnen gebruiken om patiënten te helpen bij het maken van een geïndividualiseerd behandelplan. In hoofdstuk 1 worden de vier doelen van het onderzoek beschreven: (1) ontwikkelen van een instrument dat ziektelast van COPD meet; (2) vaststellen van betrouwbaarheid en validiteit van de vragenlijst die ziektelast meet; (3) evalueren van de effectiviteit van het nieuwe instrument op ziekte-specifieke kwaliteit van leven, vergeleken met gewone zorg, in COPD patiënten; en (4) evalueren van de ervaringen van COPD patiënten en zorgverleners die met het instrument hebben gewerkt.

Hoofdstuk 2 beschrijft de ontwikkeling van een instrument voor de dagelijkse zorg om ervaren ziektelast te meten. Het instrument is in vijf stappen ontwikkeld: (1) formuleren van een definitie van ervaren ziektelast van COPD, (2) controleren of deze definitie overeenkomt met de ervaringen van patiënten en zorgverleners, (3) formuleren van randvoorwaarden waaraan een instrument zou moeten voldoen, (4) uitvoeren van een systematische literatuur review, (5) en ontwikkelen van een instrument.

Een definitie van ervaren ziektelast van COPD was geformuleerd door de werkgroep van de Long Alliantie Nederland. Uit interviews met patiënten en zorgverleners kwam naar voren dat deze definitie congruent was met hun ervaringen. In de literatuur zijn geen bestaande instrumenten gevonden die de door ons gedefinieerde volledige ziektelast meten. Echter, de Clinical COPD Questionnaire (CCQ) kwam het meest overeen met de randvoorwaarden en werd daarom gebruikt als basis voor de $A B C$ scale, aangevuld met een viertal vragen die emoties en vermoeidheid meten. Daarnaast is de $A B C$ tool ontwikkeld, een computer programma waarbij de ervaren ziektelast aangevuld wordt met het meten van de fysiologische stoornis en met een algoritme dat de uitkomsten visualiseert en behandeladviezen genereert. De volgende stap was het evalueren van de validiteit en de effectiviteit van de $A B C$ scale en de tool in de dagelijkse zorg.

Hoofdstuk 3 beschrijft het studieprotocol om de $A B C$ tool te evalueren. Een cluster gerandomiseerd onderzoek uitgevoerd bij COPD patiënten in zowel de Eerste als Tweede Lijn in heel Nederland. Een interventiegroep, die zorg krijgt aangeboden met de $A B C$ tool, wordt vergeleken met een controlegroep, die zorg ontvangt zoals gebruikelijk. De primaire uitkomstmaat is een verschil in score op een ziekte specifieke 
kwaliteit van leven vragenlijst, de Saint George Respiratory Questionnaire (SGRQ). Secundaire uitkomstmaten zijn de COPD Assessment Test (CAT), een andere ziektespecifieke kwaliteit van leven vragenlijst, longfunctie parameters en het aantal longaanvallen. Gedurende 18 maanden zijn er zeven meetmomenten, inclusief een baseline meting en een laatste meting. Patiënten ontvangen thuis vragenlijsten die ze kunnen invullen en terugsturen.

Aanvullende data zoals aantal exacerbaties worden geregistreerd door de zorgverleners. In totaal zullen 40 huisartsen en 20 longartsen 360 patiënten includeren. Daarnaast zal er een proces evaluatie worden uitgevoerd bij patiënten en zorgverleners.

Hoofdstuk 4 beschrijft de evaluatie van de psychometrische eigenschappen van de $A B C$ scale, die onderdeel is van de $A B C$ tool, en ervaren ziektelast meet. De nieuw ontwikkelde schaal telt 14 items, kan door patiënten zelf ingevuld worden en meet de fysieke, psychologische, emotionele dan wel sociale ervaring van de patiënt met COPD. Dit multicenter onderzoek is uitgevoerd bij 19 huisartsenpraktijken en 9 ziekenhuizen in Nederland. Naast de ABC scale hebben patiënten ook de SGRQ ingevuld.

Betrouwbaarheidsanalyses zijn gedaan met data van 162 patiënten. De Cronbach's alpha was 0,91 voor de totaalscore. Test-hertest betrouwbaarheid, gemeten met een interval van 2 weken ( $n=137)$, had een intraclass correlatie coëfficiënt van 0,92 . Analyses voor convergente validiteit zijn uitgevoerd met data van 133 patiënten. Divergente en known-groups validiteit is uitgevoerd met data van 162 patiënten. De totaalscore van de $A B C$ scale had een sterke correlatie met de totaalscore van de SGRQ ( $r=0,72, p<0,001)$, maar een zwakke score met de longfunctie, meer specifiek de één seconde waarde als percentage van voorspeld $\left(\mathrm{FEV}_{1 \%}\right)(r=-0,28, p<0,001)$. Subgroepen met ernstigere COPD, zoals gedefinieerd door de ernst van de longfunctiestoornis (GOLD stadia 1-4), aantal exacerbaties, activiteitenniveau en depressie, scoorden statistisch significant slechter op bijna alle domeinen van de $A B C$ scale, vergeleken met de groepen met minder ernstige COPD. Samenvattend lijkt de $A B C$ scale een valide en betrouwbaar instrument met goede discriminatoire eigenschappen.

Hoofdstuk 5 beschrijft de resultaten van een pragmatisch cluster gerandomiseerd onderzoek dat is uitgevoerd in Nederland bij 39 huisartspraktijken en 17 ziekenhuizen, 
met 357 COPD (post-bronchodilatoir $\mathrm{FEV}_{1} / \mathrm{FVC}$ ratio<0.7) patiënten. Patiënten mochten meedoen met het onderzoek als ze 40 jaar of ouder waren en als ze Nederlands konden begrijpen en lezen. Zorgverleners waren op basis van toeval toegewezen aan de interventiegroep of de controle groep. Hulpverleners in de interventiegroep gebruikten de $A B C$ tool tijdens het consult. De controle groep leverde zorg zoals gebruikelijk. Tijdens de analyses waren de onderzoekers geblindeerd en wisten niet hoe de groepen waren gecodeerd. De primaire uitkomstmaat was het aantal patiënten met een klinisch relevante verbetering in SGRQ-score tussen baseline en 18 maanden follow-up. Secundaire uitkomstmaten waren de CAT en de Patient Assessment of Chronic Illness Care (PACIC; een maat voor ervaren kwaliteit van zorg). Na 18 maanden had 34\% ( $N=49)$ van de 146 patiënten geïncludeerd door de 27 zorgverleners in de interventiegroep een klinisch relevant verbetering op de SGRQ, vergeleken met $22 \%(\mathrm{~N}=33)$ van de 148 patiënten die waren geïncludeerd door de 29 zorgverleners uit de controle groep (Odds Ratio (OR) 1,85, 95\% Betrouwbaarheidsinterval (BI) 1,08 - 3,16). Er werd geen verschil gevonden tussen beide groepen op de CAT (-0,26 punten (scores van 0 tot 40 ); $95 \% \mathrm{BI}-1,52-$ $0,99)$. De interventiegroep liet een grotere verbetering zien op de PACIC $(0,32$ punten (scores van 1 tot 5): 95\% BI, 0,14-0,50). Dit onderzoek heeft laten zien dat het gebruik van de $A B C$ tool de kwaliteit van leven en de ervaren kwaliteit van zorg bij patiënten met COPD kan verbeteren.

In hoofdstuk 6 wordt een onderzoek beschreven waarbij we diepte-interviews hebben gehouden met 15 zorgverleners en 21 patiënten die mee hadden gedaan met het onderzoek en de $A B C$ tool hadden gebruikt tijdens de consulten. Over het algemeen waren deelnemers zeer positief over het instrument. Zorgverleners vinden dat de $A B C$ tool een sterke visuele weergave heeft, die begrijpelijk is voor patiënten en die inzicht geeft in de ziekte. Dit werd ook genoemd door de patiënten. Als patiënten de optie kregen om te mogen kiezen tussen een volgend consult met $A B C$ tool of zonder $A B C$ tool, dan geeft de meerderheid voorkeur voor een consult met $A B C$ tool: het geeft overzicht en inzicht, wat het makkelijker maakt om alle relevante onderwerpen die met COPD te maken te bespreken. Het instrument kan structuur bieden tijdens het consult en het past in de concepten van 'motiverende gespreksvoering' en 'individuele zorgplannen'. Een aantal suggesties zijn gegeven voor verbeteringen. Tot nu toe is de $A B C$ tool een apart programma dat naast de registratiesystemen van de zorgverleners geopend en gebruikt moet worden. Daarom 
werd genoemd door zorgverleners dat het programma geïntegreerd moet worden in de bestaande informatiesystemen om de bruikbaarheid en de implementatie te bevorderen.

Hoofdstuk 7 beschrijft nogmaals kort de resultaten van de studies en de implicaties voor de dagelijkse zorg. Er wordt bediscussieerd dat de $A B C$ tool geïmplementeerd moet worden in de richtlijnen voor de zorg, wie de gebruikers van het instrument waarschijnlijk zullen zijn, hoe het instrument onderdeel kan zijn van disease management programma's, hoe het kan faciliteren in gezamenlijke besluitvorming en het stellen van doelen. In de methodologische reflectie wordt gekeken naar het design van de studie, de interne en externe validiteit van de resultaten en de meetinstrumenten. Ook worden er implicaties voor vervolgonderzoek beschreven. Tijdens dit onderzoek was het nog niet mogelijk om de responsiviteit van de $A B C$ tool te meten en een minimaal klinisch relevant verschil vast te stellen. Verder onderzoek zal moeten worden uitgevoerd. Ook moet verder onderzoek worden gedaan naar de determinanten die verantwoordelijk zijn voor de verandering in kwaliteit van leven en moet worden onderzocht of het mogelijk is om een generiek instrument zoals de $A B C$ tool te maken voor meerdere chronische aandoeningen. 



\section{VALORISATIE}



Naast de wetenschappelijke waarde van de bevindingen die beschreven zijn in dit proefschrift, hebben de bevindingen ook een maatschappelijke waarde. Dit valorisatie hoofdstuk zal ingaan op de vertaling van de verworven kennis in dit onderzoek naar de praktijk. Vanuit vijf verschillende perspectieven zal gekeken worden naar de resultaten. (1) de relevantie van de bevindingen voor de praktijk; (2) het product dat voortkomt uit dit onderzoek; (3) de doelgroepen voor wie de resultaten belangrijk zijn; (4) hoe innovatief de resultaten zijn; en (5) de planning en implementatie.

\section{RELEVANTIE}

In de Zorgstandaard COPD die in 2010 uitkwam werd het begrip 'ziektelast' centraal gesteld. ${ }^{1}$ De ernst van de ziekte zou niet meer alleen gebaseerd moeten worden op basis van longfunctie, maar ook op basis van de ervaren ziektelast. Dit begrip was echter nog niet verder geoperationaliseerd, en daarom heeft de Long Alliantie Nederland een werkgroep ingesteld om aan dit begrip handen en voeten te geven. Deze samenwerking heeft geresulteerd in de ontwikkeling van de Ziektelastmeter COPD (in het Engels: Assessment of Burden of COPD ( $A B C)$ tool), die bestaat uit een vragenlijst die ervaren ziektelast van patiënten meet, objectieve parameters zoals longfunctie, risico factoren zoals rookgedrag, een visuele weergave van de uitkomsten en een algoritme met behandeladviezen die gebaseerd zijn op de huidige richtlijnen van de COPD zorg. De Ziektelastmeter COPD is ontwikkeld om communicatie tussen zorgverlener en patiënt te faciliteren en de patiënt te begeleiden in het aannemen van een actievere rol tijdens het consult en in het ontwikkelen van zelfmanagement vaardigheden. Onderdeel van deze actievere rol is het meebeslissen over behandeling. In oktober 2015 schreef de Minister van Volksgezondheid, Welzijn en Sport, mevrouw Edith Schippers, een brief aan de Tweede Kamer waarin zij stelde: 'Samen beslissen is de standaard. De tijd dat mensen klakkeloos het advies van hun dokter opvolgden, ligt achter ons. Mensen willen betrouwbare, begrijpelijke informatie over hun aandoening en ze willen die informatie makkelijk kunnen vinden. Zij willen weten welk ziekenhuis goede resultaten haalt. Zij willen weten welke arts de meeste ervaring heeft en welke opties er zijn als het gaat om de behandeling, in hun persoonlijke situatie'.2

In een rapport voor de Nederlandse organisatie voor gezondheidsonderzoek en zorginnovatie (ZonMw) over de zorg voor chronisch zieken, uitgevoerd door Nivel, het RIVM, CBO impact en TNO, staat dat er meer interventies op maat moeten worden 
aangeboden om het potentieel van zelfmanagement volledig te benutten. Het ondersteunen van zelfmanagement leidt bij mensen met een chronische ziekte tot een betere gezondheid en een kleine daling van zorgconsumptie. Zorgverleners hebben volgens het rapport een belangrijke rol daarin, en deze ondersteuning kan nog verder worden verbeterd. ${ }^{3}$ De Ziektelastmeter COPD past heel goed binnen deze nieuwe ontwikkelingen en kan faciliteren in deze processen.

\section{PRODUCTEN}

Omdat de Ziektelastmeter COPD meer is dan alleen een vragenlijst, maar het ook de integrale gezondheidstoestand visueel weergeeft en behandeladviezen geeft is het instrument als computer programma ontworpen. Om het programma te kunnen gebruiken moet de software hiervan geprogrammeerd worden in de informatiesystemen die hoor zorgverleners worden gebruikt (huisartsen informatiesystemen, HIS; ziekenhuis informatiesystemen, ZIS; ketenzorg informatiesystemen, KIS). De Ziektelastmeter COPD is nu ontwikkeld voor gebruik tijdens consulten in de praktijk. Verdere ontwikkelingen zouden zich ook kunnen richten op de mogelijkheden van het ontwikkelen van een patiënten versie, zodat patiënten ook thuis zelf kunnen inloggen en bijvoorbeeld de vragenlijst al thuis invullen via een patiënten portaal. Op deze manier kunnen patiënten meer betrokken worden in de zorg, om hen te helpen voorbereiden voor een consult en hen te helpen om hun eigen ziektelast onder controle te houden. Het bedrijf Curavista, dat E-health toepassingen voor PC, tablet en smartphone maakt, heeft hier al een eerste stap in gezet en heeft de vragenlijst en de ballonnen ingebouwd in de webapplicatie MijnCOPDonline.nl. Patiënten kunnen hierop inloggen, de vragenlijst invullen die ziektelast meet en met de visuele weergave hun eigen ziektelast monitoren.

Verder kan er gedacht worden aan de ontwikkeling van een smartphone app, die zorgverleners en patiënten kunnen gebruiken om het gebruiksgemak te vereenvoudigen en zodat patiënten altijd en overal hun ziektelast kunnen monitoren. Boehringer Ingelheim heeft al eerder de Mijn Luchtpunt app ontwikkeld en is hier nu ook de Ziektelastmeter COPD aan het inbouwen. 


\section{DOELGROEPEN}

Er zijn verschillende groepen voor wie de uitkomsten van dit onderzoek van belang zijn.

\section{Patiënten}

Wanneer de Ziektelastmeter COPD geïmplementeerd wordt in de dagelijkse praktijk kunnen zorgverleners en COPD patiënten het gebruiken tijdens reguliere consulten. Het belangrijkste onderdeel van de Ziektelastmeter COPD is de vragenlijst die de ervaren ziektelast meet - een lijst met 14 vragen. Doordat het startpunt van gesprek de ervaren ziektelast is, die als onderdeel van de integrale gezondheidstoestand visueel wordt weergegeven, kunnen patiënten aangeven wat voor hen belangrijk is, waar ze een probleem ervaren en waar ze aan willen gaan werken. Per consult kunnen er één of twee domeinen besproken worden waarvan de ballonnen rood of oranje zijn, wat betekent dat de patiënt niet zo goed scoort op dat specifieke domein, of waar de ballon is gedaald ten opzichte van vorig consult, wat betekent dat de patiënt is verslechterd op dat specifieke domein. Patiënten kunnen samen met de zorgverleners de behandelopties afwegen om zo tot een persoonlijk op maat gemaakt behandelplan te komen. Een belangrijk onderdeel van dit behandelplan is een persoonlijk streefdoel. De Ziektelastmeter COPD biedt ruimte voor patiënten om, samen met de zorgverlener, een doel te stellen en in eigen woorden dit te formuleren en te noteren in het programma. Het doel moet specifiek zijn, meetbaar, acceptabel, realistisch en binnen een afgesproken tijd haalbaar. ${ }^{4,5}$

\section{Zorgverleners}

Zorgverleners kunnen de Ziektelastmeter COPD inzetten tijdens het consult met hun COPD patiënten. Het instrument kan helpen om een overzicht te maken van de verschillende aspecten van de ziekte. Verder kan het ook helpen om moeilijkere onderwerpen, zoals psychologische aspecten of rookgedrag, ter sprake te brengen. Het instrument kan gebruikt worden om op protocollaire wijze de integrale gezondheidstoestand van de patiënt in kaart te brengen. Daarnaast kan het helpen met agendasetting. De Ziektelastmeter kan gebruikt worden door zowel huisartsen en longartsen als door met hen samenwerkende praktijkondersteuners en longverpleegkundigen. Echter, praktijkondersteuners en longverpleegkundigen hebben gemiddeld meer tijd per consult waardoor zij meer tijd hebben om het instrument in te zetten tijdens een regulier consult. Daardoor is het waarschijnlijk dat 
het instrument voornamelijk door praktijkondersteuners en longverpleegkundigen gebruikt zal worden. De Ziektelastmeter COPD kan ook faciliteren in de transitie tussen zorgverleners binnen de $1^{\mathrm{e}}$ of $2^{\mathrm{e}}$ lijn, maar ook in de transitie tussen de $1^{\mathrm{e}}$ en $2^{\mathrm{e}}$ lijn.

\section{Zorgverzekeraars}

Zorgverzekeraars kunnen een rol spelen in de implementatie van de Ziektelastmeter COPD door deze mee te nemen in de onderhandelingen betreffende zorginkoop. Het gebruik van de Ziektelastmeter COPD moet vergoed worden als onderdeel van reguliere COPD zorg of er kan een financiële incentive gekoppeld worden aan het gebruik van het instrument.

\section{Wetenschap}

De relevantie van de ontwikkelde Ziektelastmeter COPD werd onderstreept toen tijdens de internationale Scientific Research Meeting van de International Primary Care Respiratory Group (IPCRG) in mei 2015 een abstract over de Ziektelastmeter COPD twee maal werd onderscheiden met een Award voor Best Abstract. De resultaten van dit onderzoek bieden houvast voor verder onderzoek naar de Ziektelastmeter. Dit onderzoek toonde aan dat de ziekte-specifieke kwaliteit van leven significant meer verbeterde in de interventie groep dan in de controle groep. Echter, wat nog niet onderzocht is in deze studie zijn de processen die ten grondslag liggen aan deze verandering. Verder onderzoek kan worden gedaan naar onder andere gedragsverandering, maar ook naar het effect van het gebruik van de Ziektelastmeter COPD op zelfmanagement vaardigheden en gezamenlijke besluitvorming. Daarnaast willen we onderzoeken of het mogelijk is om een generieke ziektelastmeter te ontwikkelen die modulair kan worden opgebouwd, zodat deze ook voor andere chronische aandoeningen gebruikt kan worden zoals astma en diabetes.

\section{INNOVATIE}

Nog niet eerder is er in Nederland, maar ook niet elders in de wereld, een instrument zoals de Ziektelastmeter COPD geëvalueerd in een gerandomiseerd onderzoek. Het instrument gaat verder dan alleen het meten van ervaren ziektelast. Het geeft ook de ervaren ziektelast visueel weer. Voor deze visuele weergave is gekozen voor ballonnen. Elk domein relevant voor COPD, zoals roken en de vijf domeinen van ziektelast, worden weergegeven met een gekleurde ballon. In het programma is een 
algoritme ingebouwd, zodat wanneer op een ballon wordt geklikt behandeladviezen verschijnen. Zo kunnen patiënten per domein de behandelopties zien en bespreken met hun zorgverlener. Ook kan het instrument gebruikt worden om het ziekteverloop te monitoren. Tijdens elk consult kan de Ziektelastmeter COPD gebruikt worden en naast de scores van het huidige consult worden dan ook de scores van het vorige consult weergegeven met behulp van grijze ballonnen. Wanneer de grijze ballon boven de gekleurde ballon hangt, betekent dit dat de patiënt verslechterd is op dat betreffende domein. Wanneer de grijze ballon onder de gekleurde ballon hangt is de patiënt verbeterd. Het doel van deze manier is patiënten inzicht geven in hun ziektelast en dat ze daarmee een koppeling kunnen maken tussen gedrag (bijvoorbeeld roken) en de ervaren ziektelast, en tussen behandeling en de ervaren ziektelast. We hopen met het inzichtelijk maken van de last en de behandelopties, dat bij de patiënt het kwartje valt en de patiënt de leiding neemt in zijn/haar eigen behandeling.

\section{IMPLEMENTATIE}

De Long Alliantie Nederland heeft een plan gemaakt om de Ziektelastmeter COPD landelijk te gaan implementeren. Hiervoor is veel draagkracht, want onder andere het Longfonds, het Nederlands Huisarts Genootschap (NHG) en de COPD en Astma Huisartsen Advies Groep (CAHAG) zijn hierbij betrokken. Activiteiten binnen dit plan zijn het verankeren van de Ziektelastmeter COPD in richtlijnen voor de zorg, PR en communicatie, scholing, ICT, en zorginkoop.

Voor het verankeren van de Ziektelastmeter in richtlijnen zijn de eerste stappen al gezet. Omdat in 2015, toen de nieuw versie van de NHG-standaard uitkwam, het onderzoek naar de Ziektelastmeter COPD nog niet was afgerond kon in deze versie de Ziektelastmeter COPD niet meer worden opgenomen. Echter, hierin wordt al wel genoemd dat de Ziektelastmeter COPD in ontwikkeling is. ${ }^{6}$

In de nieuwe Zorgstandaard COPD die door de Long Alliantie Nederland is uitgegeven begin 2016, wordt de Ziektelastmeter COPD wel al genoemd als instrument dat gebruikt kan worden in de monitoring van COPD patiënten. ${ }^{7}$ 
Voor het onderdeel PR en communicatie is het van belang dat de resultaten worden verspreid onder o.a. zorgverleners, patiënten en zorgverzekeraars door middel van artikelen en lezingen.

Zorgverleners zijn verplicht om hun kennis en vaardigheden up to date te houden en nascholing te volgen. Ook voor de Ziektelastmeter COPD wordt een scholing ontworpen in samenwerking met de Nederlandse Vereniging van Artsen voor Longziekten en Tuberculose (NVALT) en de CAHAG. Er zijn reeds meerdere keren workshops voor praktijkondersteuners en longverpleegkundigen georganiseerd over de wijze waarop de Ziektelastmeter COPD in de praktijk ingezet kan worden als tool.

Naast het scholen van de zorgverleners is het ook van belang om patiënten te scholen, hoe zij de Ziektelastmeter COPD kunnen gebruiken en een persoonlijk streefdoel kunnen maken. Hiervoor kunnen we onder andere gebruik maken van visuele hulpmiddelen, zoals filmpjes waarin uitgelegd wordt wat de Ziektelastmeter COPD is en hoe de patiënt deze kan gebruiken om het gesprek aan te gaan met de zorgverlener. Belangrijk is om hierin samen te werken met het Longfonds.

Voor de implementatie van de Ziektelastmeter COPD in de HIS/KIS/ZISsen is er een ICT werkgroep samengesteld. Alle ICT-specificaties van de Ziektelastmeter COPD zijn gebundeld in één document zodat alle HIS/KIS/ZIS leveranciers het instrument precies kunnen bouwen zoals deze is ontworpen door de expert groep. Het hoogste doel is dat de Ziektelastmeter COPD voor iedereen die deze wil gebruiken beschikbaar is.

Tot slot is het ook belangrijk om met zorgverzekeraars om de tafel te gaan zitten om zaken te bespreken rondom de zorginkoop voor COPD zorg.

\section{REFERENTIES}

1. LongAlliantieNederland. Zorgstandaard COPD [Care Standard COPD]. (Long Alliantie Nederland, Amersfoort, 2010).

2. Ministerie van Volksgezondheid, Welzijn en Sport. Schippers: samen beslissen is de standaard. 29 oktober 2015.

https://www.rijksoverheid.nl/documenten/kamerstukken/2015/10/29/kamerbrief-over-samenbeslissen.

3. Heijmans M, Lemmens L, Otten W, Havers J, Baan C \& Rijken M. Zelfmanagement door mensen met chronische ziekten: kennissynthese van onderzoek en implementatie in Nederland. Utrecht:NIVEL; 2015.

4. Leach E, Cornwell P, Fleming J \& Haines T. Patient centered goal-setting in a subacute rehabilitation setting. Disabil Rehabil 2010;32:159-172. 
5. Siegert RJ, McPherson KM \& Taylor WJ. Toward a cognitive-affective model of goal-setting in rehabilitation: is self-regulation theory a key step? Disabil Rehabil 2004;26:1175-1183.

6. NHG-Werkgroep Astma bij volwassenen en COPD. NHG-Standaard COPD (Derde herziening). Huisarts Wet 2015;58:198-211.

7. Long Alliantie Nederland. Zorgstandaard COPD. Amersfoort:Long Alliantie Nederland; 2016. 




\section{APPENDIX 1}

\section{Examples of treatment advice that are included in the $A B C$ tool}

\section{Symptoms}

Symptoms (subscore > 1)

The total score on the CCQ is...

The score of the questions about symptoms is...

Treatment advice for healthcare provider (select if necessary):

Provide patient with information about COPD.

Check adherence / inhalation-techniques. If necessary, provide

explanation/demonstration.

Check if inhalation therapy (medication + type of inhaler) is correct for this patient.

Amend, if necessary.

If necessary start short-acting bronchodilators or add a second

(long-acting) bronchodilator.

\section{Symptoms (subscore>2):}

The total score on the CCQ is..

The score of the questions about symptoms is...

Treatment advice for healthcare provider (select if necessary):

Provide patient with information about COPD.

Referral to secondary care, in accordance with the healthcare standard.

Re-entering primary care:

Continue policy secondary care

\section{Functional state}

\section{Functional state (subscore>1):}

The total score on the CCQ is...

The score of the questions about physical functioning is...

Treatment advices for healthcare provider (select if necessary):

Provide patient with information about COPD.

Provide patient with advice about physical activity/exercise.

\section{Functional state (subscore $>2$ ):}

The total score on the CCQ is...

The score of the questions about physical functioning is...

Treatment advice for healthcare provider (select if necessary):

Provide patient with information about COPD.

Referral to secondary care, in accordance with the healthcare standard.

Re-entering primary care:

Continue following secondary care policy. 


\section{Mental state \\ Mental state (subscore>1):}

The total score on the CCQ is...

The score of the questions about the mental state is..

Treatment advice for healthcare provider (select if necessary):

Provide patient with information about COPD.

Discuss mental problems.

\section{Mental state (subscore $>2$ ):}

The total score on the CCQ is...

The score of the questions about the mental state is...

Treatment advice for healthcare provider (select if necessary):

Provide patient with information about COPD.

Referral to secondary care, in accordance with the healthcare standard.

Re-entering primary care:

Continue policy secondary care.

\section{Fatigue: poor $>2$}

You indicate that you suffer from fatigue.

Treatment advice for healthcare provider (select if necessary):

Treat non-pulmonary causes of fatigue.

Consider referral to secondary care if pulmonary cause is the only possible indication.

Consider referral to psychologist/psychosocial care/support groups.

\section{Emotions: poor $>2$}

You indicate that you have emotional problems.

Treatment advice for healthcare provider (select if necessary):

Treat non-pulmonary causes of emotional problems.

Consider referral to secondary care if pulmonary cause is the only possible indication.

Consider referral to psychologist/psychosocial care.

Consider referral to support groups / Luchtpunt.

\section{Lung function: $<50 \%$}

Your FEV $\mathrm{F}_{1}$ score is $<50 \%$.

Treatment advice for healthcare provider (select if necessary):

Did the patient have a flu shot? If not, emphasise the importance.

Referral to secondary care, in accordance with the healthcare standard.

Re-entering primary care:

Check and implement treatment advice provided in secondary care.

Has FEV ${ }_{1}$ decreased in comparison to previous measurements? In case of rapid deterioration (>100ml per year), refer to pulmonologist, in accordance with the healthcare standard. 


\section{Weight loss: $>10 \%$}

Since previous visit, you have lost...

Check whether weight loss is related to COPD, or whether there is another explanation.

Treatment advice for healthcare provider (select if necessary):

Dietary advice in primary care.

Additionally, referral to secondary care for further analyses of the weight loss, in accordance with the healthcare standard.

Re-entering primary care:

Check and implement treatment advice provided in secondary care.

Consider referral to dietician.

\section{Exacerbations: 2 or more}

In the past year, you have had two exacerbations. It is important to evaluate the determinants of these temporary worsening's.

Treatment advice for healthcare provider (select if necessary):

Check adherence / inhalation-techniques. If necessary, provide explanation/demonstration.

Check if inhalation therapy (medication + type of inhaler) is correct for this patient. Amend, if necessary.

Did the patient have a flu shot? If not, emphasise the importance.

Assessment of other possible causes of recurrent exacerbations.

Add ICS, if not yet in use.

Make follow-up appointment with practice nurse for exacerbation treatment plan. Already ICS:

Refer to secondary care, in accordance with the healthcare standard.

Follow up advice:

Check up after 4-6 weeks

\section{Smoking: Yes}

You smoke. It is very important for COPD-patients to quit smoking.

Are you motivated to quit smoking? Yes / No

Treatment advice for healthcare provider (select if necessary):

When patient is motivated to quit smoking:

Provide smoking cessation advice.

Make follow-up appointment with practice nurse for smoking cessation

counselling, in accordance with the healthcare standard.

Refer to smoking cessation clinic.

When patient is not yet motivated to quit smoking:

Provide smoking cessation advice.

Consider referral to websites and provide information about smoking cessation.

Consider motivational sessions to guide the patient towards a quit attempt. 


\section{APPENDIX 2}

\section{Interview guide for individual interviews with healthcare providers (originally in Dutch)}

1. What is your opinion on the user-friendliness of the program?

2. What is your opinion on the lay-out?

a. Do you think that the visual concept of the balloons is clear for patients?

3. Currently patients fill out the $A B C$ scale in the waiting room, how does this work?

a. What is your opinion on this?

b. If this does not function well, do you have any suggestions for improvements?

4. On what basis did you include your patients in the trial?

a. What reasons did you have for not including patients?

5. What do you consider as strengths of the program?

6. What do you consider as limitations of the program?

7. Could the program be used in its current form? If no:

a. What are points of improvement with regard to user-friendliness?

b. What are points of improvement with regard to the content of the algorithm?

8. Does the program cover all the relevant aspects in the treatment of COPD or are there factors that are overlooked?

9. How does the consultation proceed with patients while using the program?

a. Does the program add certain features to your usual level of care with regard to COPD patients?

b. Do you approach things differently than you normally do?

i. If yes, could you give us an example?

ii. Does this in your opinion add value to the treatment of COPD?

c. Does the program make you discuss other things with patients than normal?

i. If yes, could you give us an example?

ii. Do you acquire different information than normal? Do you consider this relevant and of added value?

10. Do you think that patients have a different way of coping with COPD because of the program?

a. Does it encourage patients to actively contribute to the treatment plan and to subsequently stick to it?

i. Are patients able to formulate a personal objective?

b. Does the treatment plan match the patients' needs better?

11. Would you recommend the program to colleagues?

12. Suppose the program would ultimately not be implemented into the information systems, would you still use it?

a. If yes, could you briefly explain why?

b. If no, could you briefly explain why not? 
13. Which factors could hinder the implementation of the program in your practice or department?

14. If we were to organise a workshop about the $A B C$ tool and computer program in the future, what should we focus on? 


\section{APPENDIX 3}

Interview guide for individual interviews with patients (originally in Dutch)

1. Can you remember your last consultation with your healthcare provider? What happened during this consultation?

"Researcher shows the visual display with balloons"

2. Can you remember these balloons?

3. Can you tell me something about these balloons?

4. Which topics did you discuss compared to normal?

5. What do you think is the purpose of these balloons?

6. How do you feel about active participation during consultation?

7. Which personal goal did you formulate during last consultation?

8. What do you do at home with what you have heard during consultation? Is this changed compared to usual?

9. What do you consider as strengths of the program?

10. What do you consider as limitations of the program?

Additional questions if necessary:

1. How did you experience the provided healthcare in the past 1.5 year?

2. Was there a difference in comparison with before using the balloons?

3. How do you feel about completing a questionnaire?

4. How do you feel about the questions?

5. How long did it take to complete the questionnaire?

6. Did you have enough time to complete the questionnaire?

7. Where would you like to complete the questionnaire (at home, waiting room/consultation room)?

8. How do you feel about the balloons?

9. Do you think the balloon-picture gives a complete overview of your COPD or health?

10. Do you think the picture is clear?

11. How do you feel about formulating a personal goal?

12. How do you feel about using the balloons during every consultation?

13. How do you feel about monitoring your progression or deterioration?

14. Did you have an overview of your treatment plan at the end of the consultation?

15. Do you discuss things now with your healthcare provider that you did not discuss before (the $A B C$ tool was used)?

16. Would you recommend the tool to other COPD patients?

17. Would you like to use the tool with the balloons during next consultation? 
DANKWOORD 

Dit proefschrift had ik nooit kunnen schrijven als ik niet zoveel mensen om mij heen zou hebben. Allereerst had ik een sterk promotieteam dat mij begeleid heeft bij het uitvoeren van het onderzoek en het schrijven van dit proefschrift. Onno, heel veel dank voor alle kansen die jij mij hebt geboden. Met een enorm enthousiasme zijn we voor en door dit project gegaan. Veel dank dat je mijn 'glas-is-halfvol-tegenhanger' bent. Telkens creëer je nieuwe kansen. Je bent motiverend en geeft eerlijke en opbouwende feedback. Ondanks dat je altijd ontzettend druk bent had je toch bijna altijd tijd om even te overleggen.

Daniel, je hebt me gered toen ik wat verloren alleen op Deb aan het rondzwerven was. Ik ben je dankbaar dat je mijn begeleider wilde worden en me zo door allerlei moeilijke momenten heen hebt geholpen en onze werkgroep enorm hebt versterkt met je expertise. Zelfs vanuit Duitsland was je er en ik kon altijd skypen als dat nodig was. Jouw grondige en kritische blik stelden me altijd op scherp om zo het beste eruit te halen en het werk naar een hoger niveau te tillen.

Hans, wat fijn om iemand als jij in het promotie team te hebben. Jouw klinische blik was erg belangrijk in de ontwikkeling van de Ziektelastmeter. Ik heb een dag met je mee mogen lopen om te kijken hoe het nu eigenlijk gaat in de praktijk. Jouw patiënten mogen zich gelukkig prijzen met een dokter als jij. Bedankt dat je altijd grondig naar mijn stukken hebt gekeken.

Niels, inspirerend hoe jij tijd vindt om in zoveel verschillende organisaties een rol te vervullen. Jouw ervaring als huisarts en onderzoeker was erg belangrijk in de ontwikkeling van de Ziektelastmeter COPD. Bedankt voor je feedback. Als ik je mailde kon ik altijd rekenen op een snelle reactie.

Ik had het geluk dat ik naast mijn promotieteam nog een hele werkgroep om mij heen had met wie ik samen dit project heb mogen uitvoeren. Een zeer intrinsiek gemotiveerde groep die de COPD zorg in Nederland wil verbeteren en de patiënten centraal stellen. Heel veel dank voor alle werkgroep-vergaderingen, waar ik altijd weer vandaan ging met een hele to-do lijst, maar ook met het gevoel dat we bezig waren met een fantastisch project. Guus, Denise, Maureen, Huib, Richard, Bas, Thys, Philippe, heel veel dank, want ook zonder jullie zou dit boekje er nu niet in deze vorm liggen!

Ook wil ik graag Emiel Rolink en zijn collega's en de leden van de Long Alliantie Nederland bedanken. Dankzij jullie waren er de (financiële) middelen om dit project uit te voeren. En nu trekken jullie de kar om de Ziektelastmeter COPD te 
implementeren in de dagelijkse zorg. Wat een mooi product hebben we samen kunnen maken.

Collega's van MEMIC, veel dank dat jullie hebben meegeholpen om dit onderzoek en de ontwikkeling van de Ziektelastmeter COPD zo'n succes te maken. Stephan, Daniël, Alfons, Jacqueline en Annemie. Veel dank voor jullie harde werk, jullie adviezen en de prettige samenwerking.

Maar zonder alle deelnemers van het onderzoek hadden we natuurlijk nooit de Ziektelastmeter COPD kunnen maken en evalueren. Huisartsenpraktijken en ziekenhuizen die mee hebben gewerkt aan het onderzoek, heel veel dank voor al jullie inzet en jullie enthousiasme. Ook wil ik alle patiënten met COPD die ik heb mogen interviewen en die al die vragenlijsten voor mij hebben ingevuld bedanken. Wat een werk, iedere keer die lange lijsten. Maar toch hielden jullie vol. Dankzij jullie hebben we nu beter inzicht in de effecten van de Ziektelastmeter. Zonder jullie kunnen we geen onderzoek doen. Veel dank!

Maarten Fischer, veel dank voor je hulp bij de interviews met de COPD patiënten. Focusgroepen leiden is een kunst die jij als geen ander beheerst.

Ook de leescommissie, bestaande uit Job Metsemakers, Jean Muris, Geertjan Wesseling en Jiska Snoeck-Stroband wil ik bedanken voor het zorgvuldig lezen en beoordelen van mijn proefschrift. Bedankt voor jullie interesse en tijd om dit te doen.

Gelukkig hoef ik tijdens mijn promotie niet helemaal alleen vooraan te staan. Naast mij staan twee lieve paranimfen. Anneke en Esther, wat fijn dat jullie meer zijn dan kamergenootjes. Fijn om elke dag op kantoor te komen op onze gezellige kamer, die nu gaat veranderen van promovendus naar post-doc kamer. Onder het genot van zelfgemaakte kopjes cappuccino en bergen chocola hebben we veel gelachen maar ook hele goede gesprekken gehad, zowel werk-gerelateerd als persoonlijk. Bedankt voor al die fijne momenten. Ik hoop dat we nog heel lang kamergenootjes en vriendinnen mogen blijven. En de traditie om een high-tea te koppelen aan een promotie houden we erin, goed?! 
Bij HAG werken natuurlijk nog veel meer jonge onderzoekers. Altijd gezellig om een praatje te maken en/of een kopje koffie te drinken, vlaai te eten in het keukentje, te lunchen, een wandelingetje te maken, of carnaval te vieren. Sofie, Ilona, en Dianne, ook jullie bedankt voor de gezellige lunch-momentjes en werkonderbrekingen. De gezellige sfeer op het werk, gecreëerd door alle fijne collega's, maakt dat ik het nooit vervelend vind om naar het werk te komen. Eefje, er lijkt een duidelijk verband tussen jouw aanwezigheid op kantoor en onze fitness-oefeningen. Kun je voor altijd bij ons blijven werken?

Ellen, Hilde, Paddy, Judith, Karin, Karin, Susanne, Silvia, Anneke, Hanny, Frits. Wat zouden we zonder jullie moeten. Bijna allemaal hebben jullie een bijdrage geleverd aan mijn project, maar sowieso hebben jullie allemaal een bijdrage geleverd aan het plezier op het werk. Bedankt dat het iedere dag weer gezellig was en dat jullie altijd bereid waren te helpen waar nodig. Ine, zonder jou geen HAG. Bedankt voor al je support en lieve woorden. Je hebt altijd tijd om even te luisteren, te helpen waar nodig, of gezellig te kletsen. Fijn dat je zo goed voor ons allemaal zorgt!

Mascha, held! Je bent op mijn project komen werken, omdat ik geopereerd moest worden. En ik ben ontzettend blij dat je daarna niet meer bent weggegaan. Jij hebt me met al je kennis, rust en vaardigheid geholpen om dit onderzoek uit te voeren. Voor alle praktische zaken zoals etiketten printen en plakken, vragenlijsten versturen en vragenlijsten invoeren draai jij je hand niet om. Maar samen hebben we ons ook door de data geworsteld om er een mooie schone dataset van te maken. Je hebt helpen analyseren en schrijven. Zonder jou zou ik nu nog lang niet klaar zijn! En je hebt ook met al je creativiteit mijn boekje zo'n mooie kaft gegeven. Heel veel dank!!

Sandrien, Daisy en Bo, jullie hebben voor mij heel wat afspraken geregeld en zelfs een reis naar San Francisco boeken was geen probleem. Heel veel dank voor al jullie precieze en doortastende werk.

Jos, veel dank voor alle ondersteuning rondom de ICT. Als mijn laptop weer eens kuren had, of als ik dácht dat mijn laptop kuren had, dan was jij er om het op te lossen.

Ook de overige collega's van HAG die ik nu nog niet heb genoemd wil ik bedanken. De sfeer op de afdeling is altijd goed en het is altijd mogelijk om even binnen te lopen voor een praatje of advies. 
Erie, veel dank voor al je hulp bij het regelen van de financiën. Als er weer plannen gemaakt moeten worden over contract verlengingen en begrotingen kan ik altijd op je rekenen.

Nadat ik een cursus ingewikkelde statistiek (Multi-level analyses of longitudinal data) had gevolgd zag ik het eigenlijk niet meer zitten. Ik ging van de cursus weg met meer vragen en onduidelijkheden dan ik gekomen was. Maar... daar was Gerard van Breukelen! Zonder jou zou ik er niet uitgekomen zijn. Bedankt dat je me geholpen hebt met de analyses en het schrijven. Het was altijd flink zweten bij jou op de kamer. Fijn dat je, als ik je weer glazig aan zat te kijken, het gewoon nog een keer begon uit te leggen.

Thomas, Leslie, Kylie en Kaoutar. Leuk dat jullie als onderdeel van jullie studie geneeskunde jullie wetenschapsstage bij het Ziektelastmeter-project wilden doen. Heel leuk om met jullie samen te werken aan dit ballonnetjes project. Bedankt voor al het werk dat jullie hebben gedaan. Ik wens jullie heel veel succes met jullie carrière, en hoop dat deze stage jullie geprikkeld heeft om naast jullie carrière als arts ook werkzaamheden als onderzoeker te exploreren.

Ik heb een heleboel lieve vrienden om mij heen die mij heel veel waard zijn.

Marja. We hadden dit jaar ons 25 jarig jubileum. Wat een zegen om al zo lang jou mijn beste vriendin te mogen noemen. Wil je samen met mij over 40 jaar als twee oude dametjes theeleuten aan de keukentafel?

Jarinka, Hedwig, Petra, Susan, Rachelle, alle Navigators en Opwelling-ladies, bedankt dat jullie mijn vrienden zijn en voor steun en afleiding hebben gezorgd.

Cornel, als vrouw van Onno heb jij op de achtergrond een hele belangrijke rol gespeeld in mijn promotie traject. Maar ook op de voorgrond. Bedankt dat je voor me klaarstond toen niet alles even gemakkelijk ging. Je hebt me doen inzien dat niet alles 'moet', maar dat er vooral heel veel 'mag'. lets wat ik mezelf nog steeds dagelijks 'moet' vertellen.

Papa en Mama, ik ben jullie ontzettend dankbaar, dat ondanks dat het zo ontzettend spannend was dat ik als 17 jarige in Maastricht wilde gaan studeren, dat jullie mij toch hebben gesteund. Door jullie emotionele en financiële steun was het voor mij mogelijk om mijn studie af te maken en een mooi leven in Maastricht op te bouwen. 
Het is niet altijd even makkelijk om zo ver weg te zitten. Maar het is relatief. Binnen twee uur kunnen we bij elkaar zijn. Dank voor alles wat jullie mij hebben geleerd. Ik ben trots op jullie als mijn ouders! En het kwam toch ook best vaak goed uit dat jullie in het midden van het land wonen. Menig nacht heb ik bij jullie gelogeerd als stopover naar bijvoorbeeld Groningen of Friesland. Heerlijk om altijd weer thuis te kunnen komen en welkom te zijn.

Maarten en HJ. Mijn broertjes. Of nou ja... tjes...Bedankt dat jullie mijn grote broers zijn en ik jullie kleine zusje mag zijn.

Opa en oma. Met jullie autootje ben ik het hele land door gecrost om interviews te gaan doen met patiënten en zorgverleners. Dankzij jullie heb ik zo heel veel tijd en moeite bespaard. Oma stond zelfs al klaar met de pinpas, want 'je hoeft die benzine toch niet allemaal zelf te betalen?!'. Bedankt voor jullie vrijgevigheid.

En sinds mei heb ik er ook een hele lieve schoonfamilie bij. Bedankt voor jullie steun aan Luc en mij.

Lieve Luc, waar moet ik beginnen... We hebben elkaar ontmoet op het werk, dus je kunt eigenlijk wel zeggen dat wij zonder HAG niet samen zouden zijn. Ik ben je dankbaar. Dankbaar voor je rust, je geduld, al je hulp als ik weer eens gestrest over de gang aan het sjeesen was. Je hebt me leren relativeren en waarderen. Je bent zo ontzettend slim en goed in je werk. Fijn dat je al je kennis (o.a. over statistiek) met mij wilt delen. Ik ben misschien niet zo'n geduldige leerling, maar jij bleef altijd kalm. En ondanks alles wilde je ook nog met me trouwen! Dank je wel lieve Luc. Je maakt mij een mooier mens. Ik hou van jou!! 

CURRICULUM VITAE 

Annerika (Anne Hendrika Marie) Slok was born in Veenendaal on October 13, 1986. She completed secondary school at the Ichthus College in Veenendaal. In 2004 she started her study Health Sciences in Maastricht, with a specialisation in Health Promotion and Education. In 2009 she

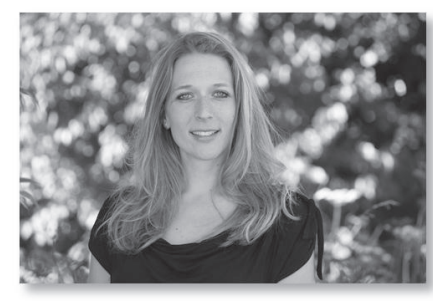
obtained her master's degree. In January 2010 she started working at the department of Health promotion of Maastricht University as a research assistant. She was mainly involved in the development of an internet-based intervention for tailored smoking cessation counselling. In December 2010 she started working at the department of Family medicine of Maastricht University, and worked together with an expert group to develop a burden of disease instrument for COPD. In June 2011 her PhD trajectory started which resulted in this dissertation and in the Assessment of Burden of COPD tool. Annerika is now working at Maastricht University as a post-doc researcher to redesign the Assessment of Burden of COPD tool into a tool that can be used for other chronic conditions as well, such as asthma and diabetes.

Annerika is happily married to Luc Gidding. 


\section{LIST OF PUBLICATIONS AND PRESENTATIONS Publications}

Slok AHM, in 't Veen JCCM, Chavannes NH, van der Molen T, Rutten-van Mölken MPMH, Kerstjens HAM, Salomé PL, Holverda S, Dekhuijzen PNR, , Schuiten D, Asijee GM, van Schayck OCP. Development of the Assessment of Burden of COPD tool: an integrated tool to measure the burden of COPD. npj Primary Care Respiratory Medicine. 2014;24: 14021 (Published online 10 July 2014).

Slok AHM, in 't Veen JCCM, Chavannes NH, van der Molen T, Rutten-van Mölken MPMH, Kerstjens HAM, Asijee, GM, Salomé PL, Holverda S, Dekhuijzen PNR, Schuiten $D$, van Breukelen G, Kotz D, van Schayck OCP. Effectiveness of the Assessment of Burden of Chronic Obstructive Pulmonary Disease ( $A B C$ ) tool: study protocol of a cluster randomised trial in primary and secondary care. BMC Pulmonary Medicine. 2014;14:131.

Slok AHM, Bemelmans TCH, Kotz D, van der Molen T, Kerstjens HAM, In 't Veen JCCM, Chavannes NH, Asijee GM, Rutten-van Mölken MPMH, Schayck, OCP. The Assessment of Burden of COPD ( $A B C)$ scale: a reliable and valid questionnaire. COPD: Journal Of Chronic Obstructive Pulmonary Disease. 2016; 13 (4): 431-438.

Slok AHM, Kotz D, van Breukelen G, Chavannes NH, Rutten-van Mölken MPMH, Kerstjens HAM, van der Molen T, Asijee GM, Dekhuijzen PNR, Holverda S, Salomé PL, Goossens LMA, Twellaar M, in 't Veen JCCM, van Schayck OCP. Effectiveness of the Assessment of Burden of COPD $(A B C)$ tool on health-related quality of life in patients with COPD: a cluster randomised controlled trial in primary and hospital care. BMJ Open. 2016;6(7):e011519.

Slok AHM, Twellaar M, Jutbo L, Kotz D, Chavannes NH, Holverda S, Salomé PL, Dekhuijzen PNR, Rutten-van Mölken MPMH, Schuiten D, in 't Veen JCCM, van Schayck OCP. To use or not to use: experiences of healthcare professionals and patients with the Assessment of Burden of $\operatorname{COPD}(A B C)$ tool. Accepted for publication in npj Primary Care Respiratory Medicine. 


\section{Other articles}

Slok AHM. Alle ballonnen in de lucht houden. Inspiratie, Vakblad voor longverpleegkundigen, juli 2016.

Slok AHM, van Schayck, OCP. De bal(lon) ligt nu bij de patiënt. CAHAG bulletin, 022016.

Slok, AHM. Hoe houden we alle ballonnen in de lucht? CAHAG bulletin, 01-2015.

Slok AHM, van Schayck, OCP. De ontwikkeling van de Ziektelastmeter COPD. CAHAG bulletin, 01-2012.

van Schayck CP, A Slok, JCCM in 't Veen. Wat betekent het begrip "Ziektelast COPD" in de dagelijkse praktijk: nu en in de toekomst? Huisartsgeneeskunde 2012, nr.9.

Veen JCCM in 't, Slok A, van Schayck CP. Wat betekent het begrip 'ziektelast COPD' in de dagelijkse praktijk: nu en in de toekomst? Newsletter Longziekten.2012; nr.7.

\section{Published abstracts}

Annerika Slok, Hans in 't Veen, Niels Chavannes, Daniel Kotz, Onno van Schayck. Implementing the assessment of burden of COPD $(A B C)$-tool in primary and secondary care: qualitative assessment amongst healthcare providers. npj Primary Care Respiratory Medicine (2015) 25, 15039; published online 21 May 2015.

Annerika Slok, Hans in 't Veen, Niels Chavannes, Daniel Kotz, Onno van Schayck. An integrated tool to measure the burden of COPD, the Assessment of Burden of COPD $(A B C)$-tool: Development and validity. npj Primary Care Respiratory Medicine (2015) 25, 15038; published online 21 May 2015.

\section{Presentations}

Poster presentation: An integrated tool to measure the burden of $C O P D$, the Assessment of Burden of COPD (ABC)-scale: Development and validity. Congress European Respiratory Society, Munchen, 7-9-2014. 
Poster presentation: An integrated tool to measure the burden of COPD, the Assessment of Burden of COPD (ABC)-scale: Development and validity. CAHAG conferentie, Utrecht, 15-1-2015.

Oral presentation as invited speaker: De $A B C$ tool: sturen op ziektelast. COPD Ketenzorg congres, Utrecht, 12-2-2015.

Oral presentation: An integrated tool to measure the burden of COPD, the Assessment of Burden of COPD (ABC)-scale: Development and validity. Research Meeting IPCRG, Singapore, 29-5-2015.

Oral presentation: Implementing the $A B C$ - tool in primary and secondary care; Qualitative assessment amongst healthcare providers. Research Meeting IPCRG, Singapore, 29-5-2015.

Oral presentation: How to create an integrated tool to assess and visualise the experienced burden of both COPD and asthma. Research Meeting IPCRG, Singapore, 30-5-2015.

Oral presentation The Assessment of Burden of COPD (ABC)-tool: Development and evaluation. Congress American Thoracic Society, San Francisco, 17-05-2016.

Oral presentation The Assessment of Burden of COPD (ABC)-tool: Development and evaluation. Congress European Respiratory Society, London, 05-09-2016.

\section{Workshops / education}

Workshop: Ziektelast...Hoe meet en bespreek ik dit? Longsymposium V\&VN Ede, 1812-2014.

Workshop: Ziektelast...Hoe meet en bespreek ik dit? Symposium "Astma\&COPD, V\&VN, Groningen, 3-11-2015.

Nascholing: Ziektelast... Hoe meet en bespreek ik dit? CAHAG POH cursussen 22 maart 2016. 
Nascholing: Ziektelast... Hoe meet en bespreek ik dit? CAHAG POH cursussen 14 april 2016.

Nascholing: Ziektelastmeter COPD, Ontwikkeling en evaluatie. Deskundigheidsbevordering huisartsen Westelijke Mijnstreek. 30 juni 2016.

\section{Award}

Best Abstract Award for the abstract: An integrated tool to measure the burden of COPD, the Assessment of Burden of COPD (ABC)-scale: Development and validity. Research Meeting IPCRG, Singapore, 30-5-2015.

\section{Societal impact}

Krantenartikel: Een uniek ballonnenveld dat inzicht biedt op ziektelast COPD, Bijlage Financieel Dagblad Chronische Ziekten, 30-12-2014.

Krantenartikel: Ziektelastmeter verbetert leven COPD-patiënt, NRC, 23-07-2016. 
